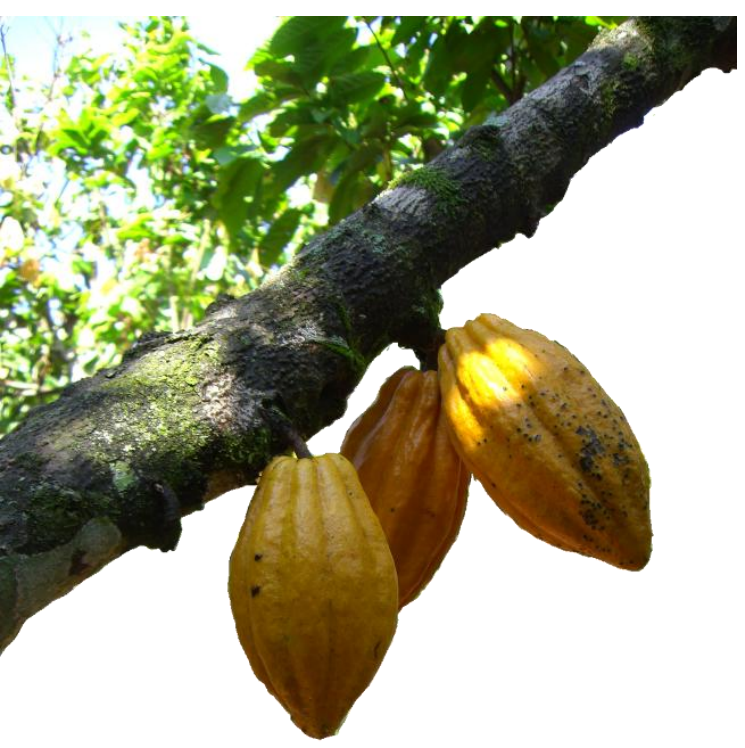

\title{
Diversity and distribution patterns of foliar fungal endophytes in Theobroma cacao in Central Sulawesi and interactions between endophytes and host plant
}

\author{
Dissertation \\ zur Erlangung des Doktorgrades \\ der Fakultät für Agrarwissenschaften \\ der Georg-August-Universität Göttingen
}

vorgelegt von

Carsten Schmidt

geboren in Leipzig 


\section{Table of Contents}

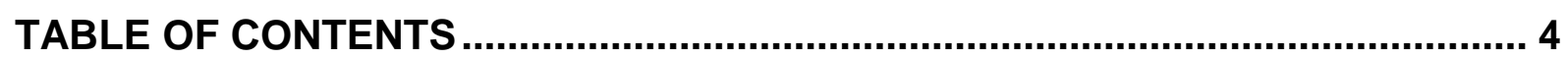

SUMMARY ................................................................................................... 7

GENERAL INTRODUCTION........................................................................... 9

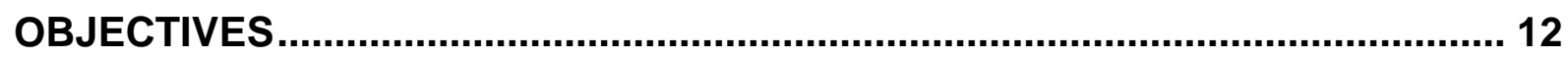

CHAPTER 1: THE LOST ENDOPHYTES: ENDOPHYTIC FUNGAL DIVERSITY OF A NEOTROPICAL TREE (THEOBROMA CACAO) IN CENTRAL SULAWESI,

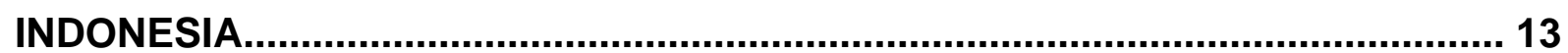

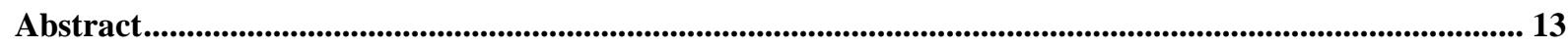

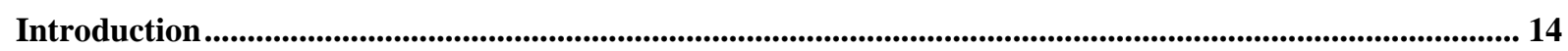

Material and Methods...................................................................................................................................................... 15

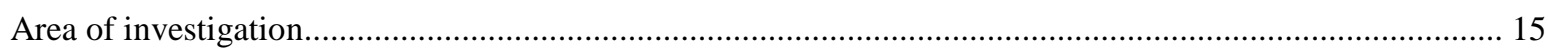

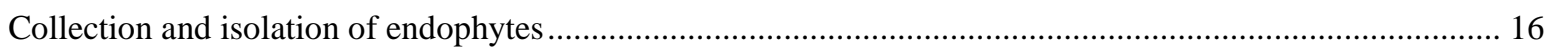

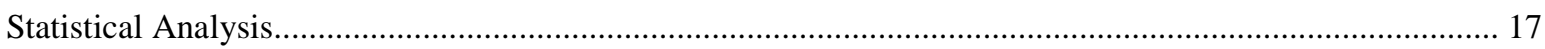

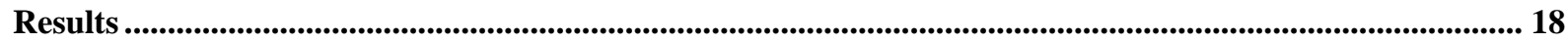

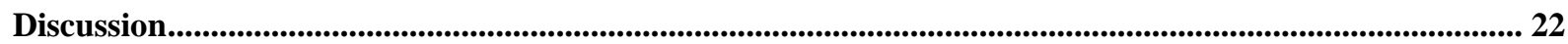

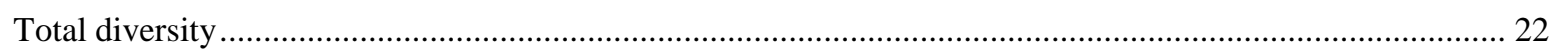

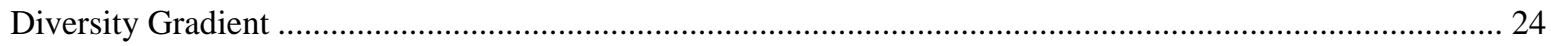

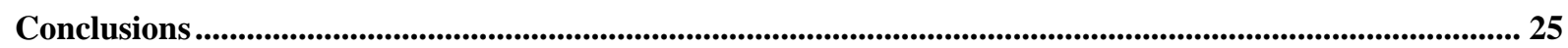

Acknowledgements..................................................................................................................................................... 26

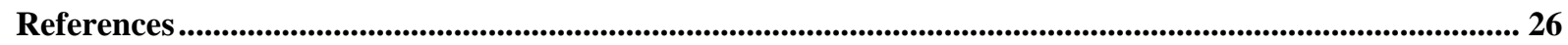

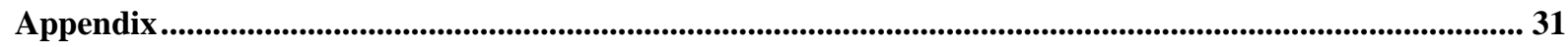

CHAPTER 2: ENDOPHYTES STRESSED OUT: EFFECT OF A SIMULATED ENSO-DROUGHT ON FUNGAL ENDOPHYTE COMMUNITIES IN CACAO TREES 
Introduction

Results 36

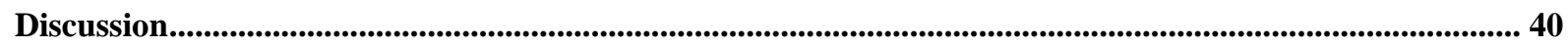

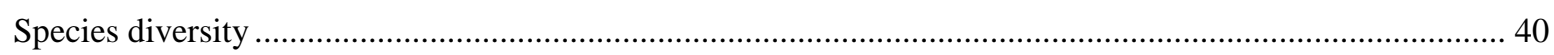

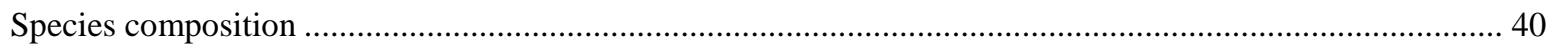

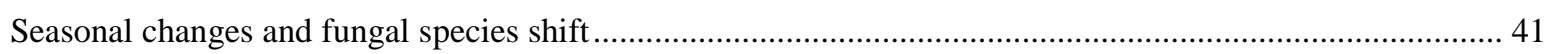

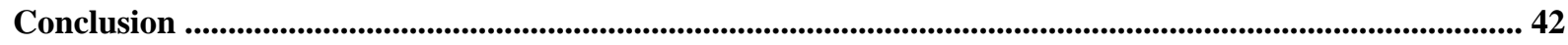

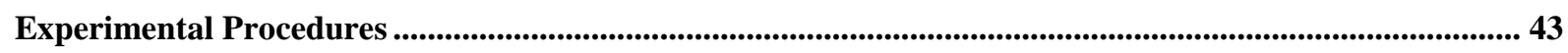

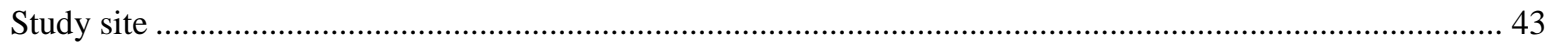

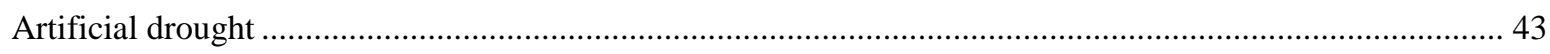

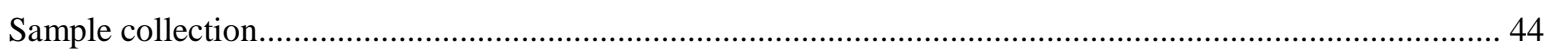

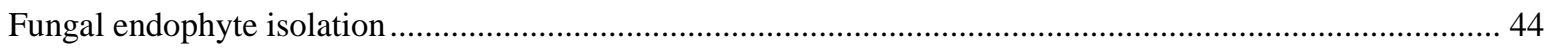

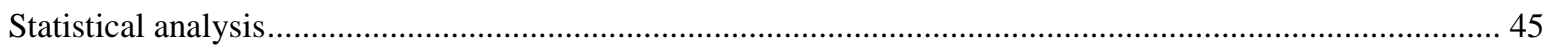

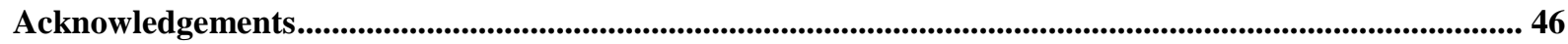

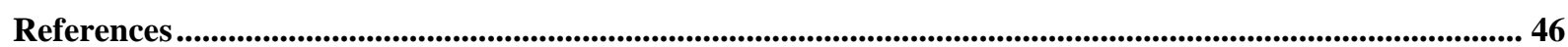

CHAPTER 3: DISTRIBUTION AND DIVERSITY OF FUSARIUM SPP. IN CACAO

PLANTATIONS OF CENTRAL SULAWESI - INDONESIA ..................................52

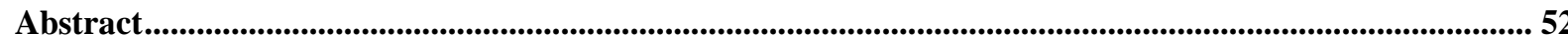

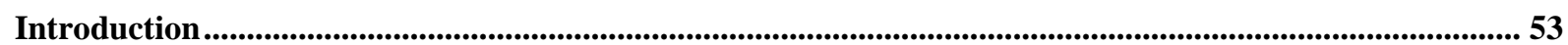

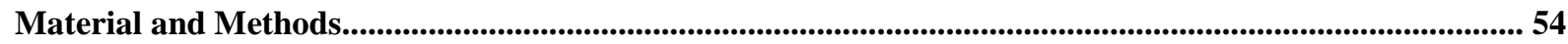

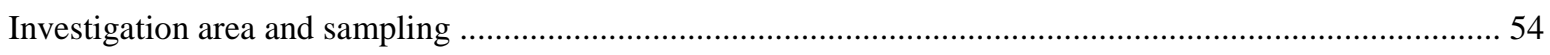

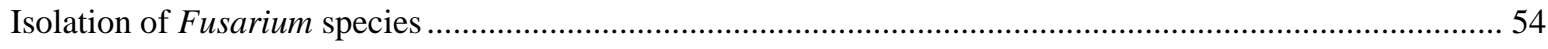

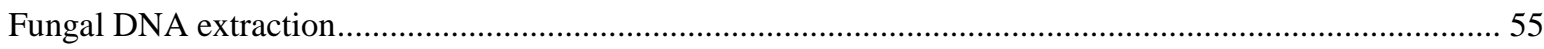

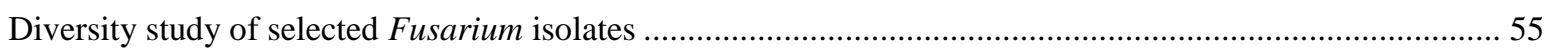

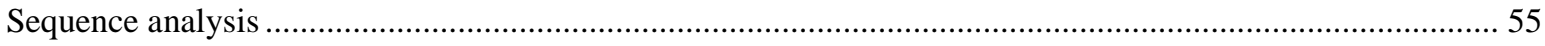

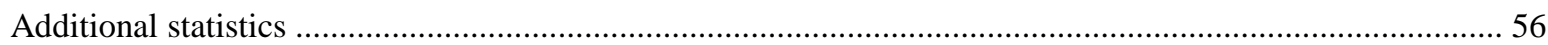

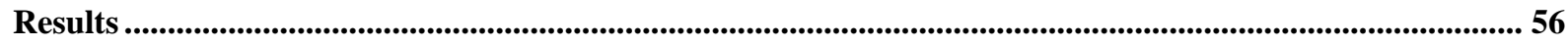

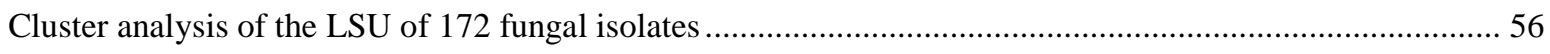

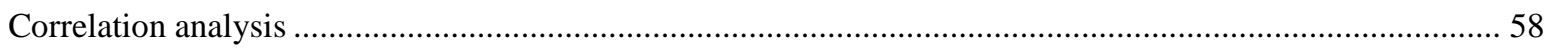

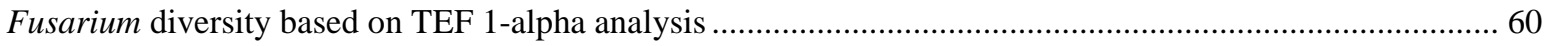

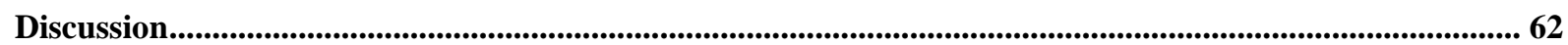

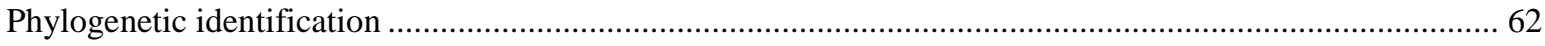




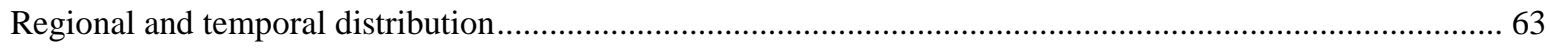

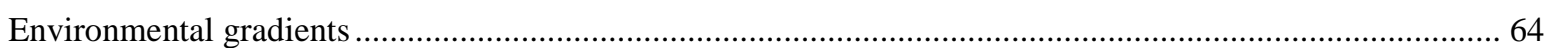

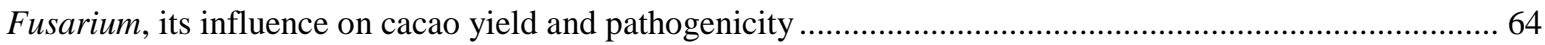

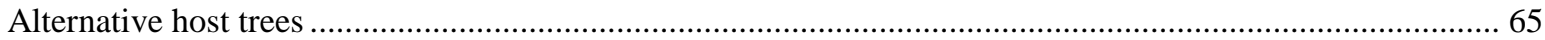

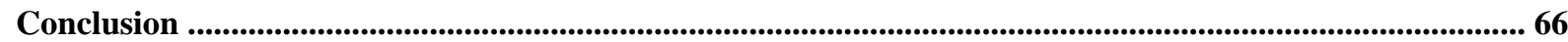

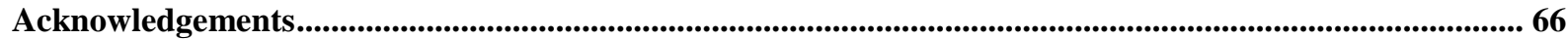

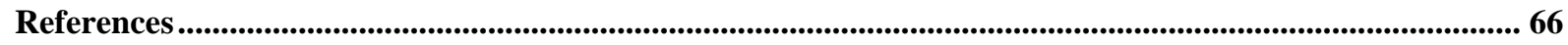

GENERAL DISCUSSION............................................................................... 72

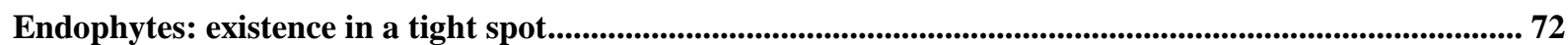

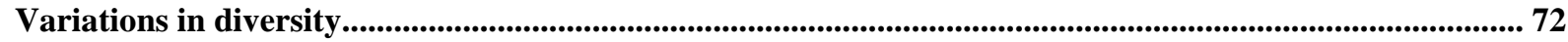

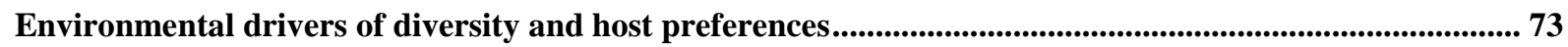

Climate Change

REFERENCES CITED IN GENERAL INTRODUCTION AND DISCUSSION .......... 76

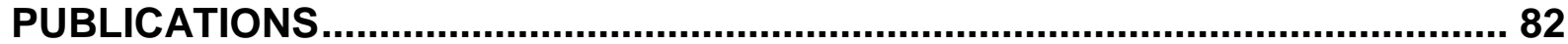

ACKNOWLEDGEMENTS …............................................................................ 83

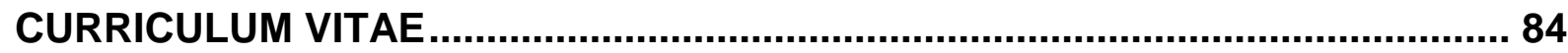

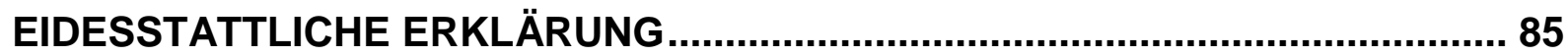




\section{Summary}

Tropical plants are colonized by a highly diverse community of fungal endophytes. Factors contributing to fungal endophyte diversity pattern and underlying mechanisms are, however, largely unknown. Interactions between host plants and their endophytes are regarded to be highly complex and dynamic. The life cycles of endophytic fungi, their distribution, and diversity are driven by host plant conditions and environmental factors. Some fungal endophytes may be latent pathogens, mutualists or anti-pathogens, depending on their host plants or not yet identified signals inducing switches in their life cycles.

The introduction of cultivated plants to new geographic regions provides an opportunity to compare the fungal endophyte diversity between continents. Cacao (Theobroma cacao L.) has been introduced to Sulawesi less than 25 years ago and is therefore reflecting local endophyte communities on a quite recently co-adapted level.

This study aimed at evaluating the changes in fungal endophyte communities in cacao leaves, based on interactions with the host plant and environmental parameters. It provides information about endophyte diversity of the area and therefore about potential outbreaks of latent pathogens in cacao or intercrops, due to environmental conditions.

We investigated the diversity and environmental parameters of the fungal leaf endophyte community of 23 cacao plantations and compared the diversity with existing data from Latin America, the area of origin of cacao.

We found that:

The endophyte diversity of fungi of cacao leaves in Sulawesi is reduced as compared to Latin America.

The composition of the endophyte community within the region is determined mainly by the diversity of shade trees planted in between cacao plants and therefore by the attenuation of radiation provided by the additional canopy.

There is clear evidence for spatial structure of the endophyte diversity, with the similarity of fungal endophyte composition continuously declining between plots with distance. 
We analysed the change of fungal endophyte diversity and composition with regard to changing host plant conditions by exposing an artificial drought period in a cacao plantation in Central Sulawesi, Indonesia.

We found that:

After 13 month of throughfall displacement cacao trees exhibited a significant decrease in fungal endophyte diversity.

Given the impact of drought, the endophyte composition within cacao trees became more similar.

The dominance of the species abundance changed, with Fusarium spp. becoming the most abundant taxa.

The fungal endophyte community in cacao leaves was sensitive to seasonality.

Furthermore, we analysed the diversity and phylogeny of the various pathogenic Fusarium taxa obtained from cacao leaves using molecular methods.

We found

four species known to science ( $F$. decemcellulare, G. fujikuroi, F. lateritium, F.mangiferae), having pathogenic potential for cacao or nearby crops (rice, sweet potato, mango)

two unknown Fusarium spp.

that all species obtained (except 2) have been also reported from Vanilla, commonly planted in cocoa plantations in Sulawesi.

Fusarium diversity was following a temperature gradient 


\section{General Introduction}

Fungal life on earth is highly varied. The estimation of fungal diversity was revised when Petrini reported in 1986, that every observed plant exhibited fungal organisms living within plant tissues. Only 74-120 thousand fungal species are known in contrast to at least 1.5 million expected species (Hawksworth 1991, Hawskworth 2001). The undiscovered fungi were assumed to be associated with plants, lichens or insects (Hawksworth \& Rosman 1997). In 1995 Willson defined plant associated fungi that occur with complete or partial developmental stages in living tissues, without harming their host plant, such as necrosis or pathogenicity as fungal endophytes. The fungal leaf endophytes were proven to be hyperdivers in tropical trees (Arnold et al. 2000). In leaves of several species a dense patchwork community of abutting fungi was found (Lodge et al. 1996, Gamboa \& Bayman 2001, Herre et al. 2007). Additional, host preferences (Arnold et al. 2001) led to the suggestion that a thrust worthy estimation of fungal global species number is relying mainly on the ratio fungal to plant species and plant diversity (Hyde 2001). Conversely, fungal endophytes are able to affect the diversity, structure and dynamics of plant communities (Saikkonen et al. 1998, Clay \& Holah 1999). Several studies investigated the various host plant-fungal endophyte interactions and found the endophytes to be mutualists, antipathogens, and latent pathogens affecting host plants (Photita et al. 2004.Müller \& Kraus 2005, Schulz \& Boyle 2005, Kogel et al 2006, Arnold \& Engelbrecht 2007, Arnold 2007). An increased knowledge about dynamics in fungal communities and about the interactions with the host plant, could reveal potential biological agents that could stem important pests and diseases in agriculture (e.g. Tong-Kwee et al. 1989, Krauss \& Soberanis 2001, Posada \& Vega 2005, Rubini et al. 2005, Tondje et al. 2007, Mejia et al 2008, Bailey et al 2008 Zabalgogeazcoa 2008, Vega et al. 2008, Vega et al. 2009a, Ownley et al. 2010). Yet there is only little known about the coherence of endophyte community within a plant, which might complicate the application of fungal bio control agents.

There would be nearly

For example the worlds cash crop number one cacao (Theobroma cacao L.), an ancient neotropical crop, is grown today in more than 50 countries around the tropics (Lass 2004, Schroth \& Harvey 2007). Nevertheless cacao production is threatened by numerous diseases: 1) The "black pod" disease is caused by Phytophthora palmivora and Phytophthora megakarya. These Oomycetes attacks all parts of the cacao tree, is causing most crucial losses word wide (Appiah et al. 2004a, Appiah et al. 2004b, Guest 2007, Clough et al. unpublished). 2) The vascular streak dieback caused by the highly specialized basidiomycete Oncobasidium theobromae led to severe losses in the cacao production in South East Asia, 
by wiping entire cacao plantations (Guest \& Keane 2007, Ploetz 2007). 3) One of the main cacao diseases in the neotropics is the "witches broom" disease caused by the basidiomycete Moniliophthora perniciosa. The infection with the fungus leads to necrosis of plant tissues, after hypertrophy and hyperplasia (Griffith 2004, Aime \& Phillips-Mora 2005). 4) Another threat to cacao production in South America is the "frosty pod" disease by the agent Moniliophthora roreri, which infects and destroys cacao pods (Griffith 2004). 5) Insect pests such as mirids (e.g. Sahlbergella spp., Helopeltis spp., Monalonain spp., Distantiella theobroma) or the cocoa pod borer (Conopomorpha cramerella) are causing further serious yield losses by damaging ripe cacao pods (Ploetz 2007, IOOC Database). Beside the direct damage, the insects act as vectors for fungal diseases and enhance fungal infestation rates by additional infections via lacerations of plants epidermis (Williams 1953, Bisseleua 2007). 6) If pathogens with minor potential are introduced in the same cacao plants, pathogens might interact and enhance their pathogenicity. If for example Fusarium decemcellulare, the agent responsible for cushion galls and Lasiodiploidia theobromae co-occur in cacao plants, they will additional inflict stem cancer or lead to diebacks (William 1953, Bisseleua 2007, Adu-Acheampong 2009).

The knowledge about the endophyte communities of cacao plantations in Africa and Asia is very limited (but see Crozier et al. 2006). While professional cacao production was established in Africa during the late $19^{\text {th }}$ century (Edwin \& Masters 2005, Laird et al. 2007, Sonwa et al. 2007), the main cacao production in Asia started with the cacao boom 25 years ago (Clough et al. 2009). The introduction of cultivated plants to new geographic regions provides an opportunity to compare the fungal endophyte diversity between continents. The endophyte community of a host plant is known to change, when introduced in a new region with a different climate (Hoffman \& Arnold 2008). Additionally it was shown, that endophyte composition changes along precipitation gradients (Suryanarayanan et al. 2002) and that even in desert areas, adapted plant species with rich endophyte communities can be found (e.g. El-Zayat 2008, Porras-Alfaro 2008). Though the impact of gradually- as well as suddenly occurring changes in microclimate are yet unknown.

The global climate change influences the intensity and frequency of the El Niño-Southern Oscillation (ENSO) phenomenon in the tropics (IPCC 2001, Walter et al. 2002, Thomas et al.2004, Parmesan 2006). South East Asia suffered in recent ENSO phenomena severe droughts periods (Quinn et al 1978, Kerr 1998, Timmermann et al. 1999). If latest climateprediction-models prove to be true, Indonesia will be threatened in future more frequent by severe drought events (Sheffield \& Wood 2008). The impact of long term drought on the physiology of evergreen tropical tree species used to stable climatic conditions is widely unclear. The cacao production of Central Sulawesi decreased by $38 \%$ associated with the 
recent ENSO related drought events (Keil et al. 2008), suggesting that cacao trees are susceptible to drought stress. The changes in plant physiology of an affected tree may also affect the fungal endophytes within the climatic sensitive leaves. All changes in endophyte community, might affect the interactions between endophyte community and host plants. On one hand interaction between endophytes and host plant might get out of balance and latent pathogens might break out causing diseases (Schulz et al. 1999). On the other hand there are some endophytes are known to induce some drought resistance by stimulating drought stress related genes (Sherameti et al 2008), or regulating photosynthesis rates (Bacon 1993, Arnold \& Engelbrecht 2007). The reactions of foliar fungal endophytes community to drought stressed cacao as host plants and consequential changes in host plants physiology are largely unknown. Investigations of the endophytic fungal community and their physiology in cacao plant are necessary for diseases predictions, bio control agent monitoring, and as basic knowledge for a successfull and sustainable establishment of bio control agents.

The aim of this investigation was to increase the knowledge about the diversity and distribution patterns of fungal endophytes in cacao agricultural management. Additionally the impact of drastic climatic change on the foliar fungal endophyte composition of one cacao plantation was investigated, with respect to fungi-host plant interactions. 


\section{Objectives}

The aim of this work was to investigate the foliar fungal endophyte composition of cacao (Theobroma cacao) in Central Sulawesi, Indonesia. The focus laid on diversity, distribution patterns, interactions with the host plant in agricultural management and impact of Climate Change.

The diversity of leaf-inhabiting fungal endophytes of 23 cacao plantations was investigated and compared to existing data from South America, the area of origin of cacao. The fungal endophyte composition was investigated for environmental parameters.

Changes of fungal endophyte diversity and composition with regard to changing host plant conditions by exposing an artificial drought period in a cacao plantation were analysed to understand host plant - endophyte interactions under extreme conditions.

Diversity and phylogeny of the various pathogenic genus Fusarium obtained from cacao plantations in Central Sulawesi has been investigated, using the LSU of the ribosomal DNA and EF-1a. 


\title{
Chapter 1:
}

\section{The Lost Endophytes: Endophytic Fungal Diversity of a Neotropical Tree (Theobroma cacao) in Central Sulawesi, Indonesia}

\author{
Carsten Schmidt ${ }^{1}$, Yann Clough $^{2}$, Stefan Vidal ${ }^{1}$ \\ ${ }^{1}$ Georg-August University Goettingen, Department of Crop Sciences, Agricultural \\ Entomology, Grisebachstrasse 6, 37077 Goettingen, Germany \\ ${ }^{2}$ Georg-August University Goettingen, Department of Crop Sciences, Agroecology, \\ Grisebachstrasse 6, 37077 Goettingen, Germany
}

\begin{abstract}
Patterns of fungal endophyte diversity in trees and underlying mechanisms are largely unknown. Introductions of cultivated plants to new regions provide an opportunity to compare endophyte diversity between continents. This study investigated diversity and environmental drivers of leaf endophyte community of Theobroma cacao L. in 23 plantations in Central Sulawesi, Indonesia. With 149 morphospecies and 32 distinguished taxa the diversity is reduced compared to South America, where cacao originates. The differences in endophyte community suggest that host preferences of local endophytes cause this pattern. The composition of the endophyte community within the region was determined mainly by the diversity of shade trees planted in between cacao plants and, to some extent, by the attenuation of radiation by additional canopy. In addition, there was clear evidence for spatial structure, with the similarity of fungal endophyte composition between plots continuously declining with distance.
\end{abstract}

Keywords: cocoa/ diversity/ endophytes/ similarity/ species richness/

Subject Category: Microbial ecology and functional diversity of natural habitats 


\section{Introduction}

Tropical plants are colonised by a highly diverse community of fungal endophytes, as has been shown for several tree species (Brown et al. 1998, Arnold et al. 2000, Arnold et al. 2001, Hyde 2001, Suryanarayanan et al. 2002, U'ren et al. 2007). The ecological roles of fungal endophytes are diverse and variable (Saikkonen et al. 1998): Fungal endophytes may occur as pathogens or mutualists, inducing systemic resistances or providing their hosts with antipathogenic compounds depending on the host plant or releasing unknown signals to switch life cycles (Müller \& Kraus 2005, Schulz \& Boyle 2005, Kogel et al. 2006, Arnold 2007, Zabalgogeazcoa 2008). Given the ecological importance of endophytes, disentangling the drivers of endophyte community diversity and composition is of major importance (Saikkonen et al. 1998, Arnold 2007).

The agricultural history of cacao reaches back to the Mayas, which contributed to the widespread use of cacao in South America (Hurst et al. 2002, Motamayor et al. 2002). Recently, molecular investigations using microsatellites identified the upper Amazonian region in Brazil to be the geographic origin of cacao (Sereno et al. 2006, Zhang et al. 2009). In the early 19th century cacao (namely the Amelonado cultivar) was introduced for the first time to Africa (Edwin \& Masters 2005). In 1886 the Trinitario variety was introduced to this region and became the dominant cultivar because of its productivity as well as its resistance against plant diseases (Laird et al. 2007, Sonwa et al. 2007). Today cacao is grown in more than 50 countries around the tropics, including several African and Asian countries (Lass 2004, Schroth \& Harvey 2007). Compared to the long cacao growing history in South America and Africa, Asian cacao production is very young.

Several surveys confirmed a high diversity of fungal endophytes associated with cacao (Theobroma cacao L.) and related plant species in South America (Arnold et al. 2003, Evans et al. 2003, Rubini et al 2005, Thomas et al. 2008). However, studies on the endophytes of cacao outside the neotropics are rare (Crozier et al. 2006).

So far there have been no comparative studies on the characteristics of fungal endophyte diversity in cacao grown in Asia compared to South America. In this study we therefore investigated the diversity of fungal endophytes in leaves of cacao trees from Central Sulawesi in Indonesia, where cacao was introduced less than 25 years ago. We deliberately used the same methodological approach for the assessment of endophyte diversity in Central Sulawesi as in published studies from Panama (Arnold et al. 2001, Arnold et al 2003), aiming at comparing the intercontinental endophyte diversity with the same methodological approach. We are aware of drawbacks inherent to this approach; a more timely approach would have been assessing the diversity of endophytes by molecular 
methods. However, with regard to our hypotheses proposed below comparisons would have been impossible when using these more recent methods as compared to the isolation methods used in these previous studies (Arnold et al. 2000, Arnold et al. 2003).

Plants introduced outside of their native ranges typically host a reduced plant pathogen diversity (Parker \& Gilbert 2004), which needs decades to re-establish (Mitchell et al. 2010). Based on this well established evidence for plant pathogens we hypothesized that several fungal endophyte species should have been lost by the introduction of cacao in Sulawesi, and, due to the short history of cacao growth in this region, should be either permanently missing from the species pool or should not yet have re-established in this plant species. Therefore we expected the diversity of endophytic fungi in Sulawesi to be less species rich compared to Panama. Furthermore we hypothesized that the cacao plants in Sulawesi are mostly colonized by unspecific local endophytes, recruited on the base of environmental factors.

\section{Material and Methods}

\section{Area of investigation}

The plantations were selected along the Kulawi valley, located at the western border of the Lore Lindu National Park in Central Sulawesi (Fig. 1). The humidity in the investigation area is between $77 \%$ and $85 \%$ while minimum temperature ranges between 12 and $17^{\circ} \mathrm{C}$ and maximum temperatures between 26 and $35^{\circ} \mathrm{C}$. Rainfall is very variable and may range between 84 and 2110mm per month (The Nature Conservancy, 2004 During data collection in March 2007, the mean temperature in the Kulawi valley ranged from $22-25 \mathrm{C}^{\circ}$ depending on the plantation elevation (Tab. 1). The precipitation in March reached $242-250 \mathrm{~mm}$ and the last dry month before was in October 2006 when the rainfall was below $46 \mathrm{~mm}$. The wind was blowing mainly northwards (down the valley) with mean wind speed of $1.13 \mathrm{~m} / \mathrm{s}$. (Kreilein, pers. communication). The 23 investigated plantations were chosen within $40 \mathrm{~km}$ along environmental gradients of shading, shade tree composition and distance to natural rainforest. In each plantation one $40 \times 40 \mathrm{~m}$ investigation plot was established. The distances between plots were greater than $850 \mathrm{~m}$, while the distances between plots and natural rainforest ranged between $10 \mathrm{~m}$ and $2500 \mathrm{~m}$. Cacao trees in the investigation plots originated from nurseries and are grown under overstory canopy of natural forest, or planted shade trees. These shade trees originated from cuttings. Most common planted shade tree species are Gliricidia sepium (Jacq.) Walp. and Erythrina subumbrans Merr.. Furthermore fruit trees were planted to increase the shade, like candlenut (Aleurites moluccana (L.) Willd.), rambutan (Nephelium lappaceum L.), avocado (Persea americana Mill.), langsat, (Lansium domesticum Correa) and durian (Durio zibethinus Merr.). Species that are both planted and naturally occurring are sugar palm (Arenga pinnata (Wurmb) Merr.) and sago palm 
(Metroxylon sagu Rottb.). In plantations formerly covered with rainforest Ficus $s p$., Pterospermum celebicum Miq. and Bischofia javanica Blume commonly remain in the cacao plantations as shade trees. In addition to the shade trees, other crops, such as coffee (Coffea sp.), or chili (Capsicum annuum L.) are grown within the cacao plots. All together 150 tree species were recorded in the cacao plantations, with a maximum diversity of 20 species in one plot (Clough et al. 2009). The density of tall shade trees $(h>15 m)$ ranged from two to 42 individuals per plot. (Tab. 1). Because of the different number of shade trees, the investigated plantations differed in solar exposition. The openness as an index for radiation was measured using a digital camera system with a calibrated fish-eye lens converter (WINSCANOPY Basic Mini) in a self-leveling mount with remote control at noon on days with clear sky (Propastin \& Erasmi 2010). Data were recorded in the centre as well as in all four corners of each plot and subsequently averaged across the plot using the software CanEye. The canopy openness was measured over the cacao canopy in a height of $5.80 \mathrm{~m}$ as well as under the cacao canopy in $1.30 \mathrm{~m}$ height. Values ranged from from 21.79 to $76.65 \%$ in $5.80 \mathrm{~m}$ and 8.05 to $20.20 \%$ in $1.30 \mathrm{~m}$ height. Under the cacao in the herbaceous layer a grid $(5 \times 5 \mathrm{~m})$ was installed and weed diversity was recorded twice a year. The diversity of weeds ranged from two to 19 species (Cicuzza et al. 2010). According to the farmers, no fungicides had ever been applied to the cacao trees in the experimental plots.

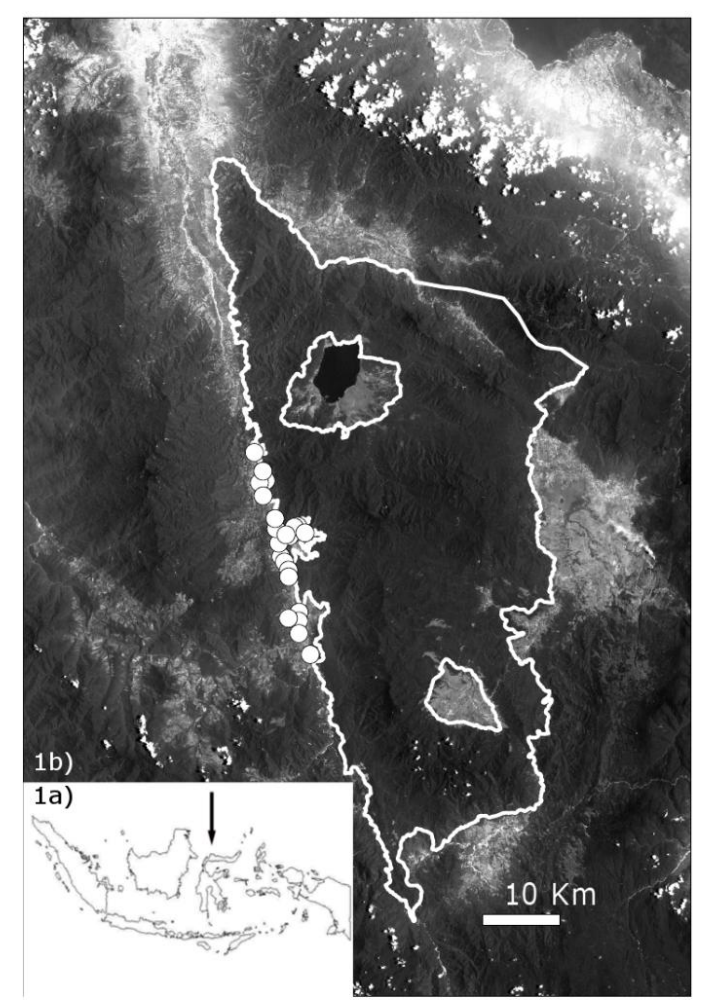

Collection and isolation of endophytes
Figure 1 a) Study area in Sulawesi (Indonesia) marked with an arrow; b) Lore Lindu National Park (border marked with white line) and sampled cocoa plantations (white dots).

The sampling of foliar endophytes on cacao trees was carried out from March 10th to 15th, 2007. 544 mature and healthy cacao leaves were collected. From each tree (Theobroma 
cacao L.) four leaves from separate branches of two different canopy layers were sampled. Because foliar endophyte diversity is known to increase with exposition of the leaves to the environment (Arnold \& Herre 2003), only mature leaves were harvested. Immediately after sampling, the leaves were individually enclosed in sterile polyethene bags and transported to the laboratory of the University of Tadulako (Central Sulawesi), where they were stored at $8^{\circ} \mathrm{C}$ and processed within the following two days. For surface sterilization the whole leaves were bleached in $3 \% \mathrm{NaOCl}$ for 3 minutes, afterwards washed in $70 \%$ ethanol for 3 minutes and then rinsed in distilled water for 3 minutes. To obtain a representative diversity of endophytes per leaf, five leaf discs were cut out from each leaf, using a flame sterilized circle-cutter $\left(\right.$ area $\left.=78.5 \mathrm{~mm}^{2}\right)$. While one leaf disc was cut of midvein on the leaf tip, four further discs were cut aside the midvein of the leaf. Distance between leaf discs was not less than $3 \mathrm{~cm}$. To control for a successful surface sterilization process the leaf surfaces were pressed on Malt Extract Agar (MEA. (Roth, Karlsruhe, Germany) and, after incubation for seven days, Petri dishes were examined for fungal infections. The five leaf discs of one leaf were placed on antibiotic (streptomycin 600ppm) 2.5\% MEA in a 9cm Petri Dish sealed with Parafilm and incubated at $25^{\circ} \mathrm{C}$. All fungi that grew out from each leaf disc were isolated, purified and grouped to morphospecies (hereafter called morphospecies) based on cultural characteristics, using the following parameters: colony surface textures, hyphal pigments, colours of exudates, and growth rates (Brown et al. 1998, Arnold et al. 2000, Suryanarayanan \& Vijaykrishna 2001). We excluded isolates of Aspergillus, Penicillium and Mucor species following the suggestion of Hyde \& Soytong (2008), as we expected them to be contaminants, invading through lacerations of parafilm during isolate shipment to Germany. For descriptive identifications purified fungi were placed on a thin layer of nutrient less MEA and stored in a UV-Chamber at $20^{\circ} \mathrm{C}$ with a light regiment of $12 \mathrm{~h}$ light: $12 \mathrm{~h}$ darkness. MEA was used because it is regarded to encourage higher sporulation in many genera of fungi (Brown et al. 1998). Following one month of UV radiation, fungal isolates were characterized based on their spores (hereafter called fungal taxa). Because several of the fungal endophytes remained sterile even under UV- and nutrient stress conditions, we classified those cultures who failed to sporulate using characteristics of the mycelium. Only morphospecies data were used for the statistical analyses. Nodulisporium species are considered anamorphs of some Xylaria species and form different morphospecies. As this study has been designed to closely mimic the sampling and data analyses methods of a former study in Panama (Arnold et al. 2000), pleomorphs were not considered.

\section{Statistical Analysis}

We analyzed leaf-level presence/absence data of the fungal endophyte morphospecies. Because four leaves were collected from each tree, each tree could reach a maximum frequency of four, while each site could reach a maximum frequency of 16 . Based on the 
results of Herre et al. (2007), who report an endophyte species density of one fungal endophyte each $2 \mathrm{~mm}^{2}$ leaf fragment on Theobroma cacao L., we regard it valid to treat foliar fungal endophyte samples separated by more than $2 \mathrm{~mm}$ as abundances. Dominances (D) were calculated and categorized in dominance classes (Engelmann 1978). Furthermore alpha diversity indices (Fishers- $\alpha$ and Shannon index) as well as gamma diversity were calculated to assess the species richness of the area. This allows comparative studies of endophyte communities regardless of hosts and country. In proportion to the mean leaf area $\left(34.3 m^{2} \pm 14.2\right)$ (Köhler et al. 2009) of one cacao tree in the investigation area, the 20 per tree sampled leaf discs $\left(1.5{ }^{*} 10^{3} \mathrm{~m}^{2}\right)$ were randomly selective to the inhabiting endophyte community. Therefore we also calculated the Simpson Index (SI) which takes into account that species are randomly sampled from a population (Simpson 1949).

The similarity in endophyte composition between plots was calculated to test for spatial structure and environmental drivers. Jaccard- (JI) and Soerensen (Sol) indices, which are based on presence/absence data were calculated, as they have previously been used in fungal endophyte ecology (Arnold et al. 2000). Abundance-based Morisita-Horn (MH. and Bray-Curtis dissimilarity (BC) indices were also computed (Arnold et al. 2001, Arnold et al. 2003, Vega et al. 2009). A matrix of between-plantation distance classes (0 to $28.000 \mathrm{~m}$, $1000 \mathrm{~m}$ steps) was generated. A linear regression was used to relate distance with similarity in endophyte composition. For the regression and significance tests the program Statistica (version 2.0) was used. Diversity and shared species analysis was calculated using Estimate $\mathrm{S}$ (version 8.2) with 1000 randomizations (Colwell 2008).

\section{Results}

Though all 544 leaves (2720 leaf discs) contained fungi (data not shown), fungi considered to be endophytes could not be isolated from all leaves (Tab. 1). Altogether 2885 fungal isolates were cultured, from which 32 fungal taxa were distinguished based on spore and morphological characters (Tab. 2). Based on the morphospecies concept, 149 morphospecies were obtained representing a Fishers- $\alpha$ of $41.34 \pm 2.78$ as well as an exponential Shannon Index of $78.35 \pm 2.38$ over all plantations in the Kulawi valley. Species richness ranged from seven to 64 distinguished morphospecies per plot, with a mean value of $44.47 \pm 13.31$ (Tab. 1). Environmental factors showed no significant influence on species richness. The likelihood of two randomly sampled endophytes in this valley belonging to the same morphospecies was $52.66 \pm 3.17 \%$ (SI. (Simpson 1949). 


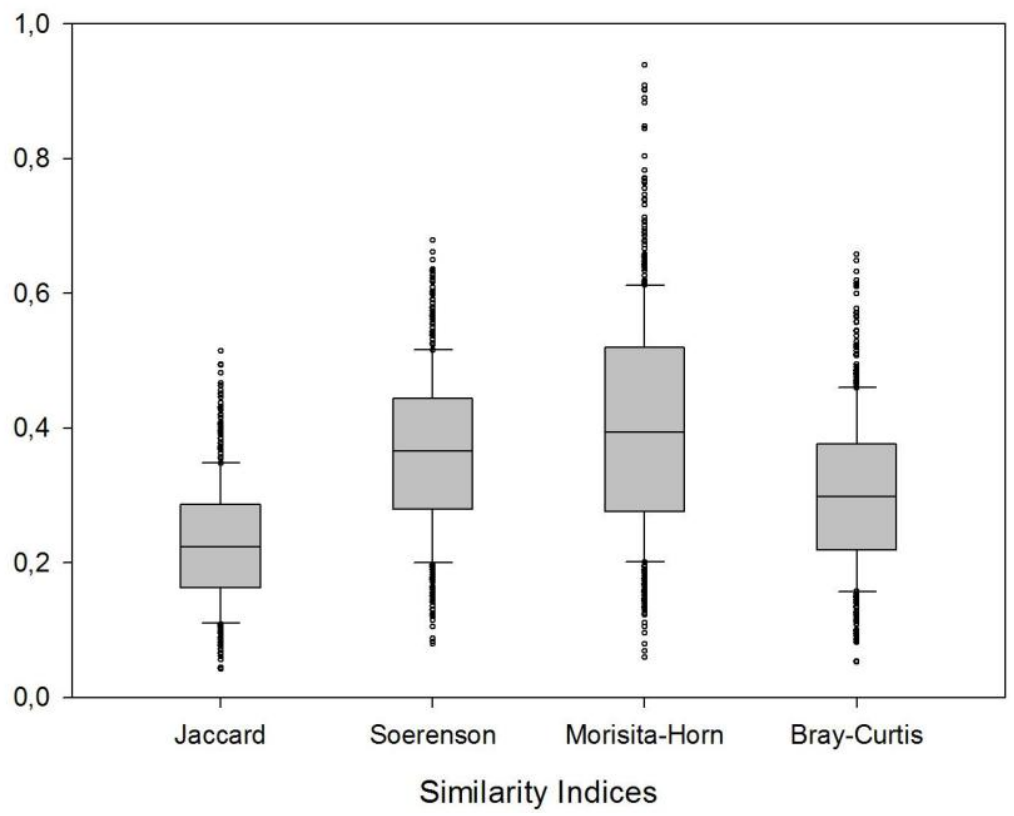

Figure 2 Indices of beta diversity of fungal foliar endophyte composition based on morphospecies for all cocoa plantations in Kulawi valley, Central Sulawesi.

\section{Accumulation Curve}

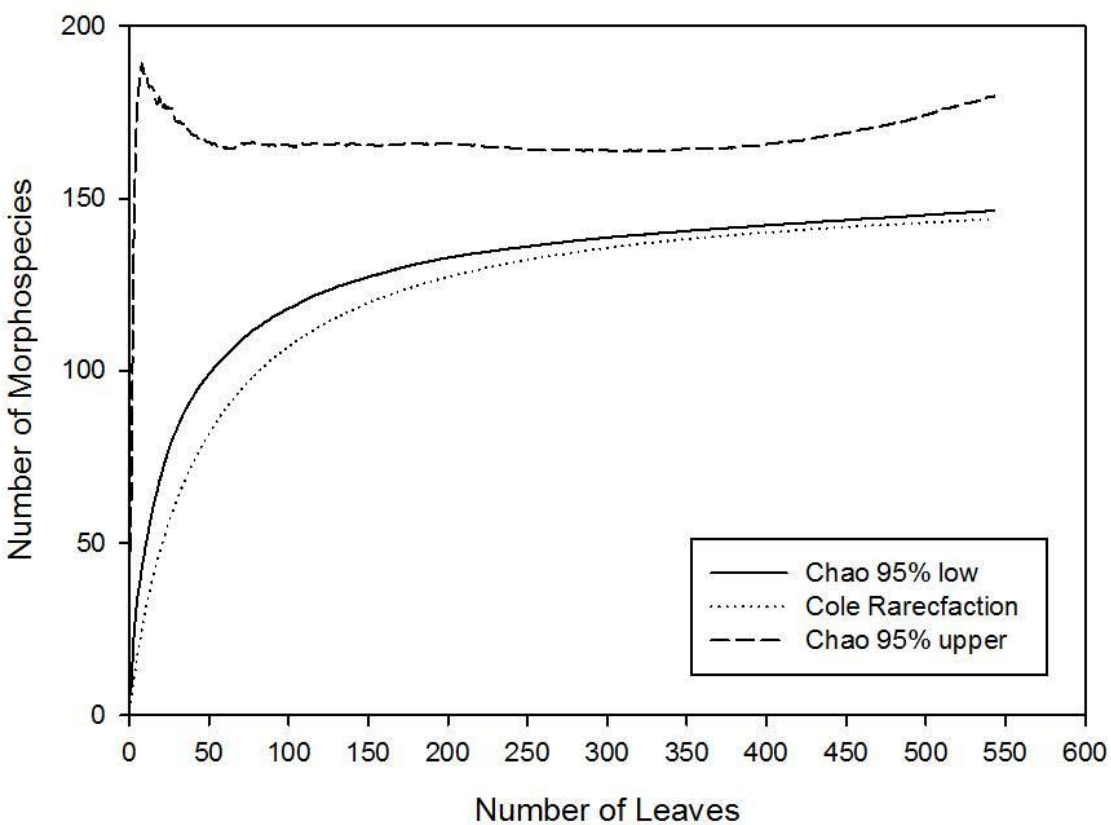

Figure 3 Rarefaction curve for expected and estimated number of foliar fungal endophytes per cocoa leaf in central Sulawesi. 
The rarefaction curve showed an initially strong rate of increase of accumulated morphospecies, which declined slightly after 45 sampled leaves. After 200 collected leaves the majority of the fungal endophytes diversity was obtained (Fig. 3). With regard to spore characterisations, the endophyte composition was dominated by the genera Nodulisporium with 303 samples $(D=10.5 \%$ ) besides subdominant occurring genera of Fusarium with 280 samples $(D=9.7 \%)$ and Xylariaceae with 214 samples $(D=7.4 \%)$ (Tab. 2). Medium similarity of the endophyte morpho-species composition in all investigated plantations of the Kulawi valley was $0.23 \pm 0.09(\mathrm{JI}+$ standard deviation SD. $0.37 \pm 0.12(\mathrm{SI}+\mathrm{SD}) 0.40 \quad 0.16$ (MH+SD) $0.30 \pm 0.12(\mathrm{BC}+\mathrm{SD})$ (Fig. 2).

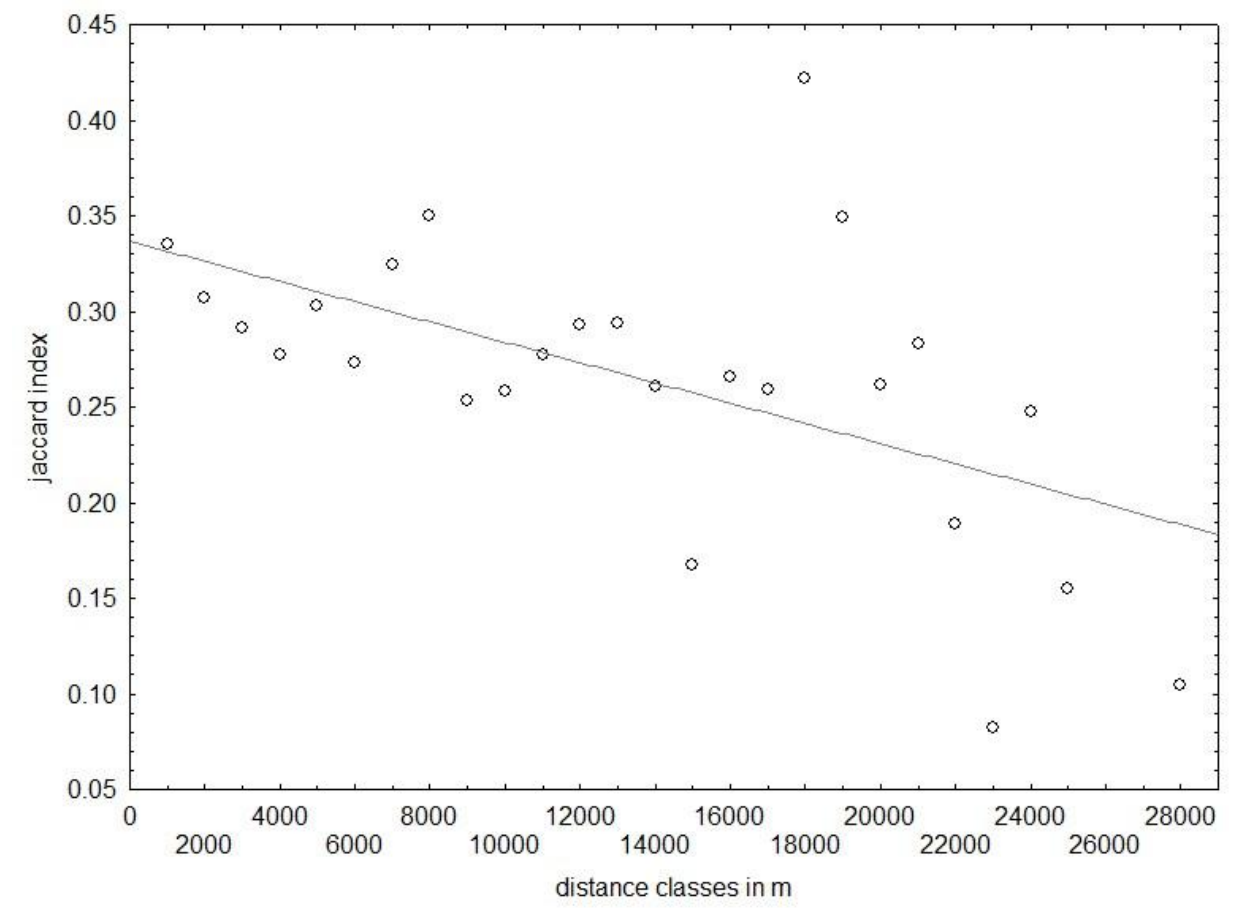

Figure 4 Jaccard index for fungal endophyte composition in leaves of cocoa plantations for all possible site pairs, grouped by distance: $y=0.34-5.30 \mathrm{E}-6^{*} \mathrm{x} ; \mathrm{r}$ $=-0.55 ; p=0.004 ; \mathrm{r} 2=0.30$ (for explanation of distance grouping calculations see text). 


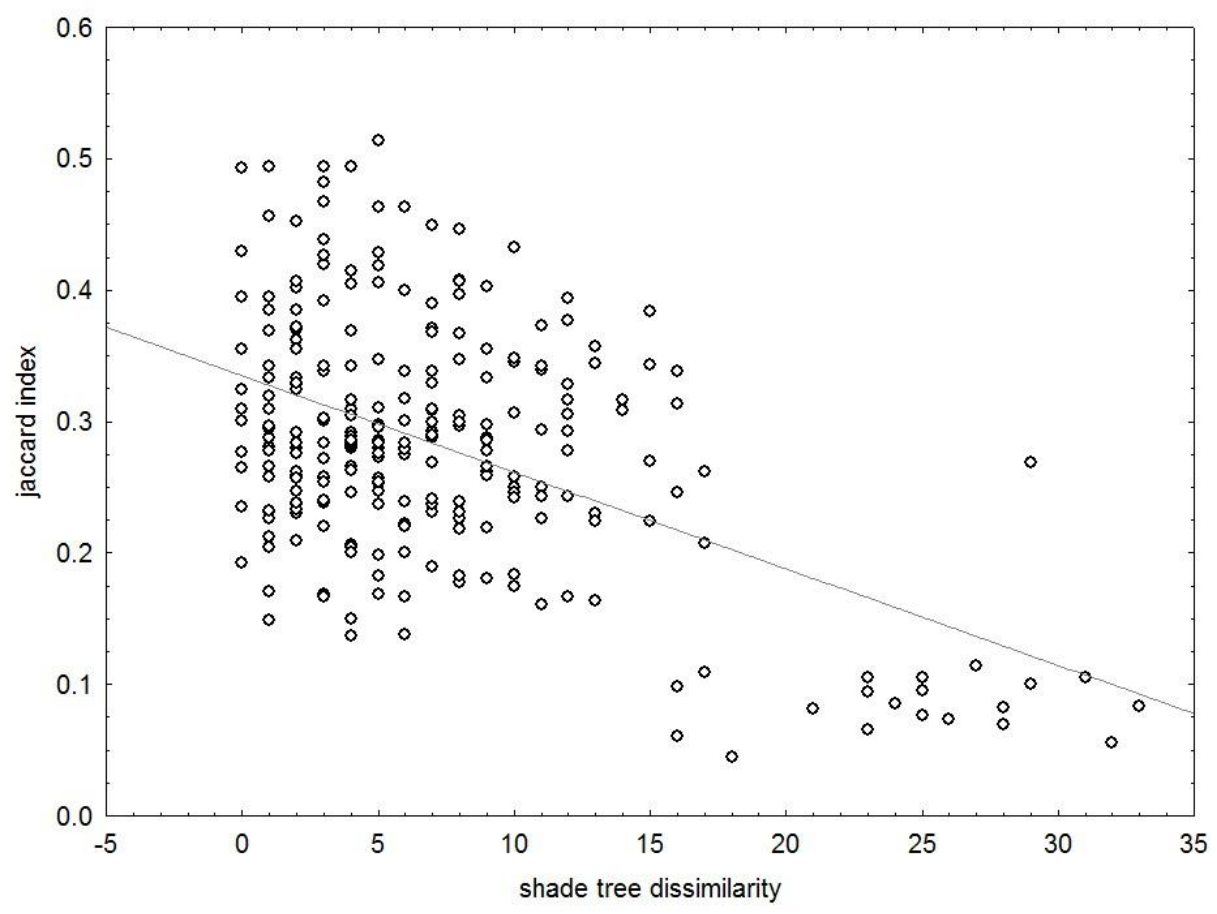

Figure 5 Correlation between similarity (Jaccard index) of foliar fungal endophyte composition and differences in species richness of shade trees for all possible site pairs. $y=0.34-0.01^{*} x ; r=0.52, p<0.000 ; r^{2}=0.27$.

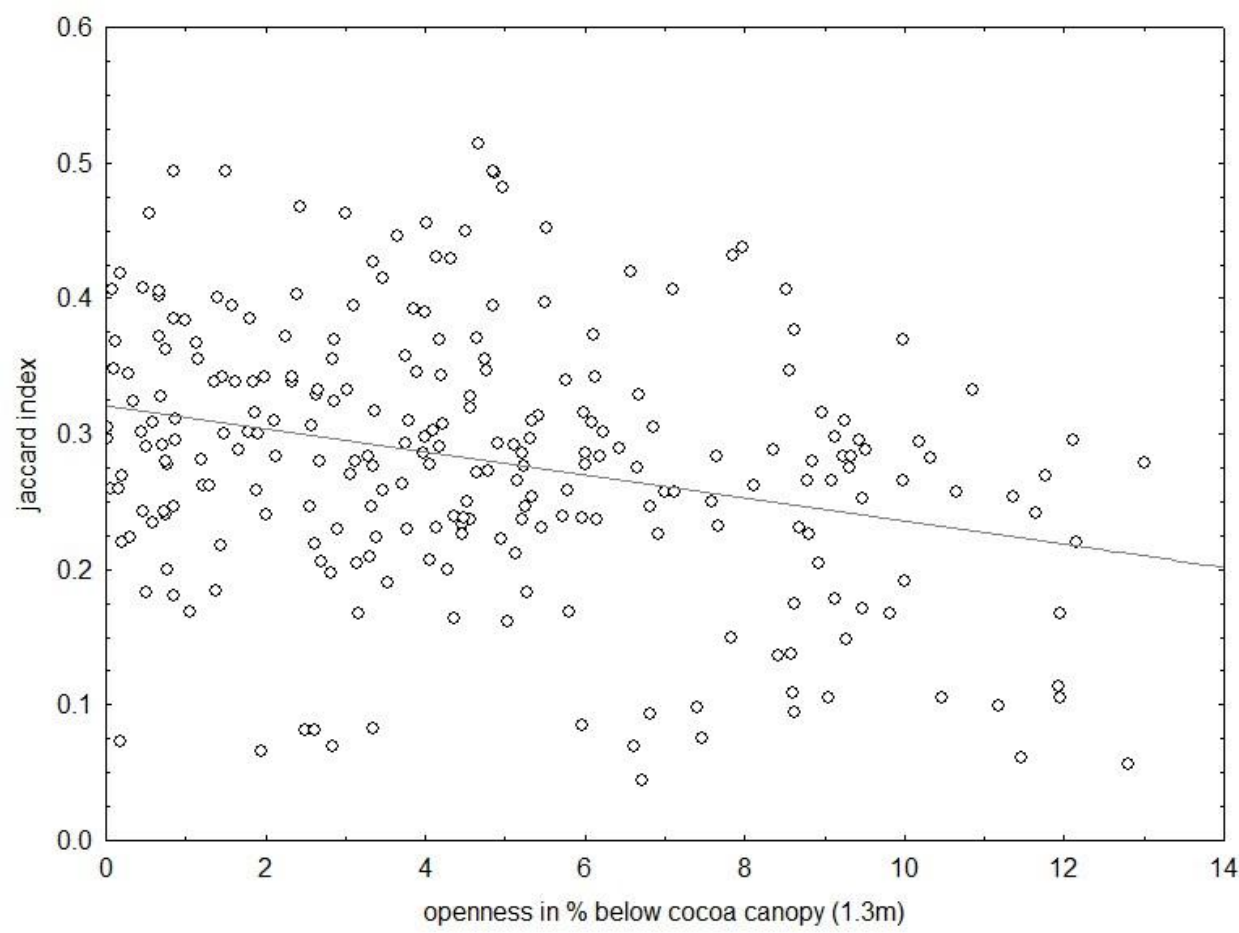

Figure 6 Correlation between similarity (Jaccard index) of foliar fungal endophyte composition and radiation (openness in $\%$ in $1.3 \mathrm{~m}$ height) differences for all possible site pairs. $y=0.32-0.01^{*} x ; r=-0.29 ; p<0.000 ; r^{2}=0.09$. 
The similarity between closely located plantations was higher compared to plantations separated by larger distance classes (Fig. 4). The regression between distance class and similarity $(\mathrm{JI})$ was highly significant and explained $30 \%$ of the variance $\left(y=0.34-5.23 \mathrm{E}-6^{*} \mathrm{x}\right.$; $r=-0.55, p<0.001 ; r 2=0.30)$. Species richness of shade trees also influenced fungal endophyte composition (Figure 5). Plantations with a similar amount of shade tree species shared significantly more fungal endophytes with $27 \%$ explained variance ( $\mathrm{Jl}, \mathrm{y}=0.33$ $\left.0.01^{*} x ; r=0.52, p<0.00 ; r^{2}=0.27\right)$. The diversity of weeds, as well as the distance to natural rain forests, did not show any significant effects on the endophyte composition (Tab. 3). For abiotic factors correlated with altitude, as annual mean and minimum temperature, a significant impact could not be proved. Canopy openness measured under the canopy of cacao correlated negatively with similarity (JI. in endophyte composition (Fig. 6; y=0.32$\left.0.01^{*} x ; r=-0.29 ; p<0.001 ; r^{2}=0.08\right)$.

\section{Discussion}

\section{Total diversity}

Host plant population characteristics, environmental conditions and whether a plant species is native to a given region will affect the diversity of interacting species, such as endophytes. Non-native plants are known to harbour a lower diversity of fungal endophytes than closely related native species in the same environment (Hoffman \& Arnold 2007). In this study 149 fungal morphospecies were found in 544 cacao leaves. The estimated morphospecies richness (Fig. 3) suggests the regional endophyte community was well-sampled. This number is relatively low, when compared to the endophyte communities reported by Arnold et al. (2003), where 344 morphospecies were isolated from 126 cacao leaves in Panama, Central America. Arnold et al. (2000 and 2001) calculated species accumulation curves for endophytes of the hosts Heisteria concinna Standl. and Ouratea lucens Engl. in Panama, that suggest increase of sample size would lead to extraordinary high number of endophytes. Between-country differences in fungal endophyte diversity are not restricted to T. Cacao L.. Vega et al. (2009) investigated several tissues of non-resident coffee (Coffea arabica L.), from Colombia, Hawai'i, Mexico and Puerto Rico. The number of obtained genotypes for all tissue types ranged from 113 genotypes representing a Fishers alpha of 75.3 in Colombia to 32 genotypes representing a Fishers alpha of 14.9 in Mexico. The same variation occurs in Musa accuminata Colla, where 32 morphospecies could be found in Hong Kong, while in three different places in Queensland (Australia. could be found 15, 18 and 25 morphospecies (Brown et al. 1998). In the case of cacao, we expected a lower diversity in South East Asia than in South America, given that 1). it is likely that only a fraction of the endophyte community was introduced to Sulawesi together with the crop and 2) given the short time for adaptation, few fungi have at present adapted to become endophytic fungi within cacao, 
being an introduced crop species. Unspecialised soil-borne fungal endophytes are challenged by different abiotic conditions within the new location and need to prevail against soil microorganism to re-infect leaves (Parker \& Gilbert 2004, Herre et al 2007). Furthermore, an important prerequisite for any differences in fungal species composition between Sulawesi and Central America is that specialised endophytic fungi make up a significant part of the hosts species richness in the area of origin (Hoffman \& Arnold 2008). The identity and specialisation of cacao endophytic fungi may help in understanding the mechanisms behind the low total diversity found in this study.

The dominant and subdominant genera found in this study have been frequently reported in previous studies. Nodulisporium species have been isolated as endophytes before (Petrini \& Fisher 1990, Rodrigues \& Samuels 1990, Fisher et al. 1992, Polishook et al. 1996, Polishook et al. 1999). Some Nodulisporium species act as pathogens (Stao et al. 1995), but some other isolates also showed anti-pathogenic potential in combinations with the fungal endophyte Cordana sp. against Anthracnose Disease in Banana (Nuangmek et al. 2008). Fusarium occurs nearly all over the world as a pathogen, endophyte or even antipathogen (Lodge et al. 1996, Evans et al. 2003, Kim et al. 2007, Vega et al. 2009). Unlike the genera named above, the widespread family of Xylariaceae is known to be species-rich and widely distributed in the American and Asian tropics. The genus Xylaria, especially, is a highly diverse taxon (Lodge et al. 1996, Bayman et al. 1998; Rogers 2000, Rubini et al. 2005, U'ren et al. 2009, Vega et al. 2009). These groups seems to contain fast growing competitive generalists, which have the capacity to colonize plants more successfully and thereby dominate the endophyte communities. A caveat may be that a bias through isolation technique favouring particular taxa cannot be entirely excluded (Hyde \& Soytong 2008).

Dissimilarities in plant defences or plant metabolites between closely relative species may divide fungal endophyte communities in groups the tree is susceptible or unsusceptible for (Schulz \& Boyle 2005). Arnold et al. (2003) found a significant amount of endophyte nonsingleton morphospecies occurring in only one of the tested host species ( $T$. cacao L., $H$. concinna Standl. and O. lucens Engl.). The authors therefore concluded that host specificity might be prevalent among tropical endophytes. Further support comes from a study by Vega et al. (2009), who obtained only four genotypes of foliar endophytes occurring in more than one country in his survey for coffee plants endophytes in four tropical countries in Latin America. Because coffee does not originate from these countries, he suggested these endophytes are either generalists, or have coevolved and were distributed together with the hosts. Based on the hypothesis of host affinity, the comparably low number of fungal endophytes of cacao plants in Sulawesi represents decreased endophyte diversity. Some foliar endophytes specialized in cacao might has been lost as the host plant was introduced. 
At the same time, other fungal endophytes may have established, forming new dominant groups in the host plant. Xylariaceae and Fusarium species for instance are frequently occurring in Theobroma spp. (Evans et al. 2003, Rubini et al. 2005, Crozier et al. 2006, Thomas et al. 2008, Mejia et al. 2008), while there have been no previous reports about Nodulisporium showing dominance in cacao endophyte communities. In our study, only a small amount of non-singletons were found in more than one site (Tab. 2). This may indicate host preference, by a small group of specialists, or the presence of a small pool of generalists with a broad environmental tolerance.

Because there are no studies available about endophyte diversity of African cacao trees, comparisons between Indonesia, Africa and South America are not yet possible. We expect the endophyte diversity in African cacao to be also dominated by generalists and reduced compared to South America, but possibly not as much as Asian cacao, given that a longer history of cacao cultivation may have provided enough evolutionary time for naïve fungal species to adapt to the new host (see Mitchell et al. 2010). The distribution of endophytes seems to be strongly affected by environmental factors like temperature, radiation and precipitation (Suryanarayanan et al. 2002, Hoffman \& Arnold 2007, Arnold 2008). Comparisons between regions are difficult due to a lack of replication at that scale. However, our data allowed us to correlate within-region patterns in composition to environmental variables and discern spatial autocorrelation.

\section{Diversity Gradient}

The community of fungal leaf endophytes was dominated by a small group of numerically dominant morphospecies associated with an assemblage of sporadically occurring species. As a result the mean similarity of leaf endophyte composition among sites was low (Fig. 2). Investigating leaf-litter fungi of two tree species (Guarea guidonia (L.) Sleumer and Manilkara bidentata (A.DC.) A. Chev.) in two sites separated by $200 \mathrm{~m}$ in Puerto Rico, Polishook et al. (1996) obtained comparable degrees of similarity $(\mathrm{JI}=0.34,0.38)$. Arnold et al. (2000) instead obtained a higher similarity value $(\mathrm{Jl}=0.48)$ for $H$. concinna associated leaf endophytes on sites $500 \mathrm{~m}$ apart. The leaf endophyte composition predictably changed along the valley of the study area in Sulawesi. The highest similarity (JI) was found between neighbouring plantations (Fig. 2), suggesting either similarity in management, environmental conditions or cacao type, or a dispersal-limitation of cacao leaf endophytes, resulting in spatial structure. At distances of more than $300 \mathrm{~m}$, similarity decreases with distance between two sites (Fig.4). A similar pattern was found in cacao in Panama by Arnold et al. (2003), where the similarity ( $\mathrm{JI})$ of endophyte composition in cacao was reduced from 0.458 to 0.023 within $325 \mathrm{~km}$, and for Cirsium arvense (L.) in England (Gange et al. 2007), where similarity between endophyte composition was declining significantly within $52 \mathrm{~km}$. On the other hand, 
Vega et al. (2009), who investigated the endophyte composition of coffee plants in four different countries found low similarities between sites, with a Jaccard index ranging from 0.226 to 0.092 , regardless of distance between plots. In the investigation area in Sulawesi similarity between individual distant plots pairs did occur, and was likely due to similarity in environmental conditions (Fig.4). Very high similarity occurred between two plantations at high altitude, which presented, due to a steep slope in south direction, the same annual minimal temperature as sites at altitudes $100 \mathrm{~m}$ below. This suggests that similarity of endophyte composition is not only a matter of endophyte dispersal, but as well affected by temperature, even though a general effect of temperature could not be verified in this study (Tab. 3). However, canopy openness slightly influenced endophyte composition. The similarity $(\mathrm{JI})$ in endophyte composition between plantations was positively, although only weakly, correlated with the similarity in openness (Fig. 6). Openness below the cacao canopy depends on the density of the shade tree canopy and the cacao canopy, which can both be managed by planting, felling or pruning shade trees, or pruning the cacao trees. The openness above the cacao trees, representing the shade tree layer, was not significant suggesting an important role of the cacao layer. Shade tree diversity was much more important for the fungal endophyte composition (Fig. 5). A similar number of shade tree species grown within cacao plantations resulted in similar endophyte composition in the cacao canopy. Closely neighboured trees even of different species are known to share more endophytes with each other, than with distant trees of the same species or their relatives (Arnold et al. 2000, Arnold et al. 2003, Hoffman \& Arnold 2008). Therefore it is likely, that most of the collected endophytes in this study are cosmopolitan generalists, or generalists reflecting a part of the regional/local occurring diversity. The amount of endophytes distributed with the host may be smaller than expected. Anyhow, the sample size with 16 leaves per plot may not have been sufficient to assess the complete gamma diversity of each plot (Fig. 3) which could lead to artificially higher dissimilarity, and a lack of power to detect further, but less important environmental gradients. An exhaustive sampling on the complete pool of plots may reveal further patterns, but was beyond the scope of this study.

\section{Conclusions}

Compared to South America, where the species originates, cacao (Theobroma cacao L.) trees grown in Indonesia harbour reduced diversity of foliar fungal endophytes. Endophyte diversity is spatially structured, following a gradient along the valley along which the sites were located. Endophyte composition was more similar grown with similar diversity of shade tree species and in similarly shaded environments. The results contribute to our understanding of the spatial patterns of leaf endophytes and environmental determinants. Manipulative studies and long-term surveys of endophyte community changes will be 
required to better understand spatio-temporal patterns in endophyte communities and their functional consequences.

\section{Acknowledgements}

We would like to thank Stefan Erasmi for satellite maps and openness data, Ramadhanil Pitopang for shade tree identification and Daniele Cicuzza for herb data. The study was financed by the DFG (Deutsche Forschungsgemeinschaft) within the framework of the SFB552 "Stability of Rainforest Margins in Indonesia" (STORMA).

\section{References}

Arnold AE, Maynard Z, Gilbert GS, Coley PS, Kursar TA (2000) Are tropical fungal endophytes hyperdiverse? Ecology Letters 3:267-272

Arnold AE, Maynard Z, Gilbert GS (2001) Fungal endophytes in dicotyledonous neotropical trees: patterns of abundance and diversity, Mycological Research 105:1502-1507

Arnold AE, Herre EA (2003) Canopy cover and leaf age affect colonization by tropical fungal endophytes: ecological pattern and process in Theobroma cacao (Malvaceae), Mycologia 95:388-398

Arnold AE, Mejía LC, Kyllo D, Rojas El, Maynard Z, Robbins N, Herre EA (2003) Fungal endophytes limit pathogen in a tropical tree, Proceedings of the National Acadamy of Science 100:15649-15654

Arnold AE (2007) Understanding the diversity of foliar endophytic fungi: progress, challanges, and frontiers, Fungal Biology Reviews 21: 51-66

Arnold AE (2008) Endophytic fungi: hidden components of tropical community ecology. In: Schnitzer S, Carson W, eds. Tropical forest community ecology, Malden, MA, USA: Blackwell Scientific, Inc., 254-271

Bayman P, Angulo-Sanoval, P, Báez-Ortiz Z (1998) Distribution and dispersal of Xylaria endophytes in two tree species in Puerto Rico, Mycol.Res. 102:944-948

Brown KB, Hyde KD, Guest DI (1998) Preliminary studies on endophytic fungal communities of Musa acuminate species complex in Hong Kong and Australia, Fungal Diversity 1:27-51

Cicuzza D, Kessler M, Clough Y, Pitopang R, Leitner D, Tjitrosoedirdjo SS (2010) Conservation value of cacao agroforests for terrestrial herbaceous plants in Central Sulawesi, Indonesia, Biotropica 43: 755-762 
Clough Y, Putra DD, Pitopang R, Tscharntke T (2009) Local and landscape factors determine functional bird diversity in Indonesian agroforestry, Biological Conservation 142:1032-1041

Crozier J, Thomas SE, Aime MC, Evans HC, Holmes KA (2006) Molecular characterization of fungal endophytic morphospecies isolated from stems and pods of Theobroma cacao, Plant Pathology 55:783-791

Colwell RK (2008) RangeModel: Tools for exploring and assessing geometric constraints on species richness (the mid-domain effect) along transects, Ecography 31:4-7.

Edwin J, Masters WA (2005) Genetic Improvement and Cocoa Yields in Ghana, Experimental Agriculture 41:491-503

Engelmann HD (1978) Zur Dominanzklassifizierung von Bodenarthropoden, Pedo biologica $18: 378-380$

Evans HC, Holmes KA, Thomas SE (2003) Endophytes and mycoparasites associated with an indigenous forest tree, Theobroma gileri, in Ecuador and preliminary assessment of their potential as biocontrol agents of cocoa diseases, Mycological Progress 2:149-160

Fisher PJ, Petrini O, Lappin Scott HM (1992) The distribution of fungal and bacterial endophytes in maize (Zea mays L.). New Phytol 122: 299-305

Gange AC, Dey S, Currie AF, Sutton BC (2007) Site-and species-specific differences in endophyte occurrence in two herbaceous plants, Journal of Ecology 95:614-622

Herre EA, Mejía LC, Damond AK, Rojas E, Maynard Z, Butler A, van Bael SA (2007) Ecological Implications of Anti-Pathogen Effects of tropical fungal Endophytes and Mycorhizae. Ecology, 88:550-558

Hoffman MT, Arnold AE (2008) Geographic locality an host identity shape fungal endophyte communities in cupressaceous trees, Mycological Research 112:331-344

Hurst WJ, Taraka SM jr., Powis TG, Valdesz F jr., Hester TR (2002) Cocoa usage by the earliest Maya cultivation, Nature 418:289-290

Hyde KD (2001) Where are the missing fungi? Mycolgical Research 105:1409-1412

Hyde KD, Soytong K (2008) The fungal endophyte dilemma, Fungal Diversity 33:163-173

Kim H-Y, Choi GJ, Lee HB, Lee S-W, Lim HK, Jang KS, Son SW, Lee SO, Cho KY, Sung ND, Kim J-C (2007) Some fungal endophytes from vegetable crops and their anti-oomycete activities against tomato late blight, Letters in Applied Microbiology 44:332-337 
Kogel KH, Franken P, Hückelhoven R (2006) Endophyte or parasite - what decides? Current Opinion in Plant Biology 9:358-363

Köhler M, Dierick D, Schwendenmann L, Hölscher D (2009) Water use characteristics of cacao and Gliricidia trees in an agroforest in Central Sulawesi, Indonesia, Ecohydrology 2:520-529

Laird SA, Awung G, Lysinge RJ (2007) Cocoa farms in the Mount Cameroon region: biological and cultural diversity in local livelihoods, Biodiversity and Conservation 16:24012427

Lass T (2004) Balancing cocoa production and consumption, In: Flood J, Murphy R (eds) Cocoa futures-a source book on some important issues facing the cocoa industry. CABIFEDERACAFE, USDA, Chinchina, Colombia, pp 8-15

Lodge DJ, Fisher PJ, Sutton BC (1996) Endophytic fungi of Manilkara bidentata leaves in Puerto Rico. Mycologica 88:733-738

Mejía LC, Rojas El, Maynard Z et al. (2008) Endophytic fungi as biocontrol agents of Theobroma cacao pathogens, Bio Control 46: 4-14

Mitchell CE, Blumenthal D, Jarošik V et al. (2010) Controls on pathogen species richness in plants' introduced and native ranges: roles of residence time, range size and host traits, Ecol Lett 13: 1525-1535

Motamayor JC, Risterucci AM, Lopez PA, Ortiz CF, Moreno A, Lanaud C (2002) Cacao domestication I: the origin of the cacao cultivated by the Mayas, Heredity 89:380-386

Müller CB, Kraus J (2005) Symbiosis between grasses and asexual fungal endophytes, Current Opinion in Plant Biology 8:450-456

Nuangmek W, McKenzie EHC, Lumyong S (2008) Endophytic Fungi from Wild Banana (Musa acuminata Colla) Works Against Anthracnose Disease Caused by Colletotrichum musae, Research Journal of Microbiology 3:368-374

Parker IM, Gilbert GS (2004) The evolutionary ecology of novel plant-pathogen interactions, Annu Rev Ecol Syst 35: 675-700

Petrini O, Fischer PJ (1990) Occurrence of fungal endophytes in twigs of Salix fragilis and Quercus robur, Mycol Res 94: 1077-1080

Polishook JD, Bills GF, Lodge DJ (1996) Microfungi from decaying leaves of two rain forest trees in Puerto Rico, Journal of Industrial Micobiology 17:284-294 
Polishook JD, Pelez F, Platas G, Ondeyka J, Dombrowski A, Teran S (1999) Biogeography and relatedness of Nodulisporium sp. Producing nodulisporic acid, Mycologica 93:1125-1137

Propastin P, Erasmi S (2010) A physically based approach to model LAI from MODIS $250 \mathrm{~m}$ data in a tropical region, International Journal of Applied Earth Observation and Geoinformation, 12:47-59

Rubini MR, Silva-Ribeiro RT, Pomella AWV, Maki CS, Araújo WL, dos Santos DR, Azevedo J L (2005) Diversity of endophytic fungal community of cacao (Theobroma cacao L.) and biological control of Crinipellis perniciosa, causal agent of Witches' Broom Disease, International Journal of Biological Sciencis 1:24-33

Rodrigues KF, Samuels GJ (1990) Preliminary study of endophytic fungi in a tropical palm, Mycol Res 94: 827-830

Rogers JD (2000) Thoughts and musing on tropical Xylariaceae, Mycological Research 104:1412-1420

Saikkonen K, Faeth SH, Helander M, Sullivan TJ (1998) Fungal Endophytes: A Continuum of Interactions with Host Plants, Annual Review of Ecology and Systematics, Syst. 29:319-43

Sato M, Watanabe T, Furuki L, Morite H (1995) Root rot of melon caused by Nodulisporioum melonis in Japan. Occurrence, symptoms, isolation and pathogenicity, Annals of Phytopathology Society of Japan 61: 325-329

Schroth G, Harvey CA (2007) Biodiversity conservation in cocoa production landscapes an overview, Biodiversity and Conservation 16:2237-2244

Sereno ML, Albuquerque P SB, Vencovsky R, Figueira A (2006) Genetic diversity and natural population structure of cacao (Theobroma cacao L.) from the Brazilian Amazon evaluated by microsatellite markers, Conservation Genetics 7:13-24

Schulz B, Boyle C (2005) The endophytic continuum. Mycolgical Research 109:661-686

Simpson EH. (1949). Measurement of Diversity, Nature 163:688

Sonwa DJ, Nkongmeneck BA, Weise SF, Tchatat M, Adesina AA, Janssens MJJ (2007) Diversity of plants in cocoa agroforests in the humid forest zone of Southern Cameroon, Biodiversity and Conservation 16:2385-2400

Suryanarayanan TS, Vijaykrishna D (2001) Fungal endophytes of aerial roots of Ficus benghalensis. Fungal diversity 8:155-161 
Suryanarayanan TS, Murali TS and Venkatesan G. (2002). Occurrence and distribution of fungal endophytes in tropical forests across a rainfall gradient, Canadian Journal of Botany 80:818-826

The Nature Conservancy. (2004) Lore Lindu National Park Management Plan p. 2004-2029

Thomas SE, Crozier J, Aime MC, Evans HC, Holmes KA (2008). Molecular characterization of fungal endophytic morphospecies associated with the indigenous forest tree, Theobroma gileri, in Ecuador, Mycological Research 112:852-860

U'ren JM, Dalling JW, Gallery RE, Maddison DR, Davis EC, Gibson CM, Arnold AE (2009) Diversity and evolutionary origins of fungi associated with seeds of a neotropical pioneer tree: a case study for analysing fungal environmental samples, Mycological Research 113:432-449

Vega FE, Simpkins A, Aime MC, Posada F, Peterson SW, Rehner SA, Infante F, Castillo A, Arnold AE. (2009). Fungal endophyte diversity in coffee plants from Colombia, Hawai'i, Mexico and Puerto Rico, Fungal Ecology 3:122-138

Zabalgogeazcoa I (2008) Fungal endophytes and their interactions with plant pathogens, Spanish Journal of Agricultural Research 6:138-146

Zhang D, Mischke S, Johnson ES, Phillips-Mora W, Meinhardt L (2009) Molecular characterization of an international cacao collection using microsatellite markers, Tree Genetics \& Genomes 5:1-10 


\section{Appendix}

Table 1 Mean number of fungal endophytes isolated per cocoa leave, species richness of endophytes, and explanatory variables used in general linear models to explain fungal endophyte diversity in cocoa plantations along the Kulawi valley in Central Sulawesi. The variables are: Distance of each plantation to natural the forest, altitude above sea level, radiation (measured by openness in \%) above $(5.8 \mathrm{~m})$ and below $(1.3 \mathrm{~m})$ cocoa canopy, mean temperature within plantations, the number of non-cocoa tree species, the number of weed species, and the number of tall shade trees $(h>15 \mathrm{~m})$.

\begin{tabular}{|c|c|c|c|c|c|c|c|c|c|c|}
\hline $\begin{array}{l}\text { Plantation } \\
\text { No. }\end{array}$ & $\begin{array}{l}\text { No./ } \\
\text { Leave }\end{array}$ & $\begin{array}{l}\text { Species } \\
\text { richness }\end{array}$ & $\begin{array}{l}\text { Distance } \\
\text { to forest } \\
\text { in } \mathrm{m}\end{array}$ & $\begin{array}{l}\text { Altitude } \\
\text { ASL in } \\
m\end{array}$ & $\begin{array}{l}\text { Openness } \\
\text { in \% at } \\
1.30 \mathrm{~m}\end{array}$ & $\begin{array}{l}\text { Openness } \\
\text { in \% at } \\
5.80 \mathrm{~m}\end{array}$ & $\begin{array}{l}\text { Mean } \\
\text { temperature } \\
\text { per plot }\end{array}$ & $\begin{array}{l}n \text { tree } \\
\text { species }\end{array}$ & $\begin{array}{l}n \text { weed } \\
\text { species }\end{array}$ & $\begin{array}{l}n \text { tall } \\
\text { trees }\end{array}$ \\
\hline 1 & 0.5 & 7 & 550 & 675 & 20.01 & 55.99 & 23.60 & 13 & 19 & 16 \\
\hline 2 & 3.56 & 38 & adjacent & 650 & 12.61 & 21.79 & 22.70 & 20 & 10 & 21 \\
\hline 3 & 6.13 & 51 & 650 & 600 & 13.20 & 64.21 & 24.15 & 13 & 13 & 12 \\
\hline 4 & 6.63 & 56 & 50 & 675 & 10.95 & 30.66 & 23.21 & 11 & 19 & 24 \\
\hline 5 & 4.19 & 44 & 500 & 725 & 11.41 & 35.96 & 22.63 & 19 & 19 & 20 \\
\hline 6 & 3.44 & 39 & adjacent & 750 & \begin{tabular}{|l|}
17.18 \\
\end{tabular} & 64.44 & 22.43 & 8 & 19 & 4 \\
\hline 7 & 6.38 & 57 & 300 & 675 & 14.05 & $\begin{array}{l}33.02 \\
\end{array}$ & 23.07 & 12 & 2 & 27 \\
\hline 8 & 3.94 & 42 & 700 & 650 & 8.08 & 34.81 & 22.90 & 9 & 6 & 9 \\
\hline 9 & 2.06 & 26 & 650 & 625 & 8.25 & 24.80 & 23.39 & 7 & 8 & 22 \\
\hline 10 & 6.63 & 56 & 350 & 575 & 9.54 & \begin{tabular}{|l|}
65.46 \\
\end{tabular} & 23.97 & 5 & 15 & 2 \\
\hline 11 & 4.56 & 50 & 650 & 550 & 7.20 & 20.26 & 23.31 & 4 & 10 & 32 \\
\hline 12 & 3.25 & 37 & 500 & 550 & 8.83 & 29.27 & 24.24 & 7 & 5 & 17 \\
\hline 13 & 4.44 & 45 & 2500 & 475 & 8.55 & 34.03 & 24.30 & 20 & 15 & 25 \\
\hline 14 & 7.00 & 58 & 700 & 500 & 18.06 & 36.42 & 23.85 & 13 & 22 & 25 \\
\hline 15 & 8.31 & 59 & 2000 & 425 & \begin{tabular}{|l|}
17.52 \\
\end{tabular} & \begin{tabular}{|l|}
76.65 \\
\end{tabular} & 24.61 & 8 & 14 & 11 \\
\hline 16 & 3.81 & 37 & 1600 & 400 & 20.20 & 60.40 & 24.72 & 10 & 12 & 14 \\
\hline 17 & 3.44 & 35 & \begin{tabular}{|l|} 
adjacent \\
\end{tabular} & 400 & 8.05 & \begin{tabular}{|l|}
51.21 \\
\end{tabular} & 24.28 & 13 & 14 & 12 \\
\hline
\end{tabular}




\begin{tabular}{|l|l|l|l|l|l|l|l|l|l|l|}
\hline 18 & 3.63 & 39 & 650 & 700 & 11.39 & 36.04 & 23.58 & 11 & 20 & 21 \\
\hline 19 & 7.13 & 64 & 400 & 775 & 12.54 & 27.15 & 22.41 & 11 & 12 & 29 \\
\hline 20 & 7.19 & 60 & 100 & 800 & 17.39 & 36.19 & 22.80 & 15 & 20 & 20 \\
\hline 21 & 6.63 & 54 & 300 & 800 & 13.39 & 53.95 & 22.67 & 8 & 11 & 5 \\
\hline 22 & 2.94 & 39 & adjacent & 925 & 13.29 & 33.34 & 22.33 & 18 & 13 & 15 \\
\hline 23 & 2.75 & 30 & 800 & 560 & 16.67 & 52.00 & 24.41 & 3 & $\mathrm{np}$ & $\mathrm{np}$ \\
\hline
\end{tabular}

Table 2 Taxa of fungal leaf endophytes extracted from Theobroma cacao $L$. identified to the genus level based on spore charactersitics after one month of UV-exposition. Non-sporulating isolates were grouped by mycelium characteristics.

\begin{tabular}{|c|c|}
\hline Taxon & No. \\
\hline Nodulisporium sp. & 303 \\
\hline Fusarium sp. & 280 \\
\hline Xylariaceae & 214 \\
\hline Isolate A & 165 \\
\hline Isolate B & 101 \\
\hline Isolate C & 47 \\
\hline Colletotrichum sp. & 46 \\
\hline Phomopsis sp. & 41 \\
\hline Isolate $\mathrm{E}$ & 39 \\
\hline Isolate $\mathrm{D}$ & 29 \\
\hline non-typed & 27 \\
\hline Lasiodiplodia theobromae (Pat.) & 26 \\
\hline Acremonium sp. & 24 \\
\hline sporulating form $\mathrm{x}$ & 21 \\
\hline Virgaria sp. & 20 \\
\hline Phoma sp. & 19 \\
\hline Pycnidial form & 13 \\
\hline Hyphomycetes $\mathrm{x}$ & 8 \\
\hline Cladosporium sp. & 6 \\
\hline Scopulariopsis sp. & 2 \\
\hline Trichoderma sp. & 2 \\
\hline Paecilomyces sp. & 2 \\
\hline Isolate F & 2 \\
\hline Isolate G & 2 \\
\hline Basidiomycota & 1 \\
\hline
\end{tabular}




\begin{tabular}{ll}
\hline Geotrichum $s p$. & 1 \\
Gliomastix $s p$. & 1 \\
Guignardia $s p$. & 1 \\
Pestalotia $s p$. & 1 \\
Verticillium $s p$. & 1 \\
Phialidic form & 1 \\
Phialophora $s p$. & 1 \\
Botryotrichum $s p$. & 1 \\
\hline
\end{tabular}

Table 3 Impact of assumed environmental parameters of diversity on similarity of endophyte composition calculated using the Jaccard Index between each possible pairs of plantations.

\begin{tabular}{lll} 
tested parameter & $\mathrm{r}^{2}$ & $\mathrm{p}$ \\
\hline distance to forest & 0.003 & 0.353 \\
distance between plots & 0.302 & $0.004^{* * *}$ \\
altitude & 0.011 & 0.121 \\
openness in 1.3m & 0.084 & $<0.001^{* * *}$ \\
openness in 5.8m & 0.003 & 0.389 \\
temperature mean & 0.003 & 0.382 \\
temperature minimum & 0.002 & 0.527 \\
tree species & 0.271 & $<0.001^{* * *}$ \\
weed species & 0.006 & 0.219 \\
$\mathrm{n}$ tall trees & 0.011 & 0.103
\end{tabular}




\title{
Chapter 2:
}

\section{Endophytes stressed out: Effect of a simulated ENSO-drought on fungal endophyte communities in cacao trees}

\author{
Carsten Schmidt ${ }^{1}$. Stefan Vidal ${ }^{1}$ \\ ${ }^{1}$ Plant Pathology. Agricultural Entomology. University of Goettingen. Grisebachstrasse 6. \\ 37077 Goettingen. Germany
}

\section{Summary}

The distribution and diversity of fungal endophytes are driven by environmental factors as well as by host plant conditions. Climate change may alter the interactions between fungal endophytes and their host plants. Here, we analysed the composition of the foliar fungal endophyte diversity in cacao trees before and after an experimentally-imposed drought in Central Sulawesi, Indonesia Cacao trees exposed to this drought treatment (a 13-month throughfall displacement) harboured significantly less endophyte diversity in their leaves than control trees. Additionally, fungal endophyte composition became more similar under the influence of drought. Fungal species known to have pathogenic potential against other endophytes outcompeted other taxa and became more abundant. The changes in the fungal endophyte composition induced by drought were related to seasonal changes, indicating that seasonal dry spells may also have contributed to these findings. This study highlights the close interaction between fungal endophytes and their host plants and suggests that the endophytes are potential indicators for climate change-induced impacts on the physiology of their host plants.

Keywords: cocoa. diversity, Theobroma cacao, seasonality, drought stress, climate change 


\section{Introduction}

According to climate models, predicted changes in the EI Niño Southern Oscillation (ENSO) (IPCC 2001) will cause droughts and other extreme weather events to become more frequent and severe in subtropical and tropical regions including Southeast Asia (Sheffield \& Wood 2008). Drought extremes will greatly affect rain-fed crop plants and food resources worldwide (Patz et al. 2005). Most of the common crop plants are highly susceptible to changes in precipitation rates (Le Houérou 1996, Malinowski \& Belesky 2000, Lloret et al 2004, Sivakumar et al. 2005), while trees in agroforestry plantations have deeper roots and are able to tolerate drought stress to some extend (Le Houérou 1996).

In many tropical countries including Indonesia, cacao (Theobroma cacao L.) agroforestry plantations are a mainstay of the economy and provide a sustainable livelihood for smallholder farmers (Smith et al. 1996, Duguma et al. 2001, Belsky \& Siebert 2003, ICCO 2009). Cacao plantations in Indonesia, however, have suffered from severe ENSO relateddroughts in recent decades (Quinn et al 1978, D'Arrigo et al 2006). Cacao production in the province of Central Sulawesi, Indonesia, is especially prone to drought, and cacao yields decreased up to $38 \%$ during an ENSO-related drought (Keil et al. 2008).

Plant tolerance to drought and drought-associated heat can be increased by certain fungi that live in the plant tissues without detriment to their host. Some of these endophytic fungi are able to stimulate genes related to drought stress (Sherameti et al 2008) and to regulate photosynthesis rates (Bacon 1993, Arnold \& Engelbrecht 2007, Arnold \& Herre 2003). Other fungal endophytes contribute to the recovery of host plants from drought effects by enhancing regrowth (Latch et al. 1985, Arechavaleta et al. 1989, Rahman \& Saiga 2005). Host plants of arid deserts (El-Zayat et al. 2008, Porras-Alfaro et al. 2008), temperate regions (Espinosa-Garcia \& Langenheim 1990, Unterseher et al. 2007), and tropical regions (Arnold et al. 2000, Arnold et al. 2001, Suryanarayanan et al. 2002, U'ren et al. 2007, Thomas et al. 2008) contain a species-rich community of fungal endophytes. The diversity and distribution of fungal endophytes are especially high in tropical plants (Arnold et al. 2000). Although these fungal endophytes are usually not strictly host specific (Cannon \& Simmons 2002), Hoffmann \& Arnold (2008) demonstrated that fungal endophyte diversity was less in non-native plants than in native plants in arid areas.

Cacao trees were introduced into Sulawesi from Latin America via the Philippines less than 25 years ago, and fungal endophyte diversity in cacao is lower in Sulawesi than in Latin America (Schmidt et al. unpublished). Because the fungal endophytes of cacao trees in Sulawesi are of tropical origin, the endophytes could be sensitive to drought, and drought could cause the endophytes to damage their hosts. Some fungal endophytes are able to 
switch from a mutualistic to a parasitic or saprophytic lifestyle, depending on the species and the physiological status of the host plant (Müller \& Kraus 2005, Schulz \& Boyle 2005, Kogel et al 2006, Arnold \& Engelbrecht 2007, Arnold 2007). These so-called latent pathogens may become actively pathogenic during drought stress.

In the current study, we experimentally induced a permanent drought event in a 7-year-old cocoa plantation in the upland region of Central Sulawesi, by establishing a roof below the canopy of the trees. Soil water content and sap flux of the host plants were measured continuously during the experiment, and foliar fungal endophyte composition was monitored before the experiment started and after 13 months of permanent drought stress. We tested the hypothesis that i) the species richness of fungal endophytes in the cacao trees would decrease within 1 year in response to the drought stress, and that ii) the abundance of latent pathogens would increase as cacao trees were subjected to drought.

\section{Results}

From 192 mature leaves of cacao trees, representing two treatments (roof and control) and two sampling periods (period 1 and 2), a total of 86 fungal morphospecies were recovered. Morphospecies richness per plot ranged from 13 to 32 before the drought treatment commenced (period 1). After 13 months of drought treatment (period 2), morphospecies richness ranged from 17 to 27 for the control and 11 to 16 for the roof plots (Tab. 1). Thus, the endophyte morphospecies richness in cacao leaves in period 2 was significantly less $(F=$ 7.9, $\mathrm{df}=5, \mathrm{P}=0.044$ ) in the roof plots than in the control plots (Fig. 1). In addition, the number of morphospecies in the control plots was slightly smaller in period 1 than in period 2 (Tab. 1). The number of fungal morphospecies did not significantly differ between control plots and roof plots for period $1(F=15.7, \mathrm{df}=5, \mathrm{P}=0.308)$ or between roof plots for period 1 and period $2(\mathrm{~F}=11.9, \mathrm{df}=5, \mathrm{P}=0.402)$.

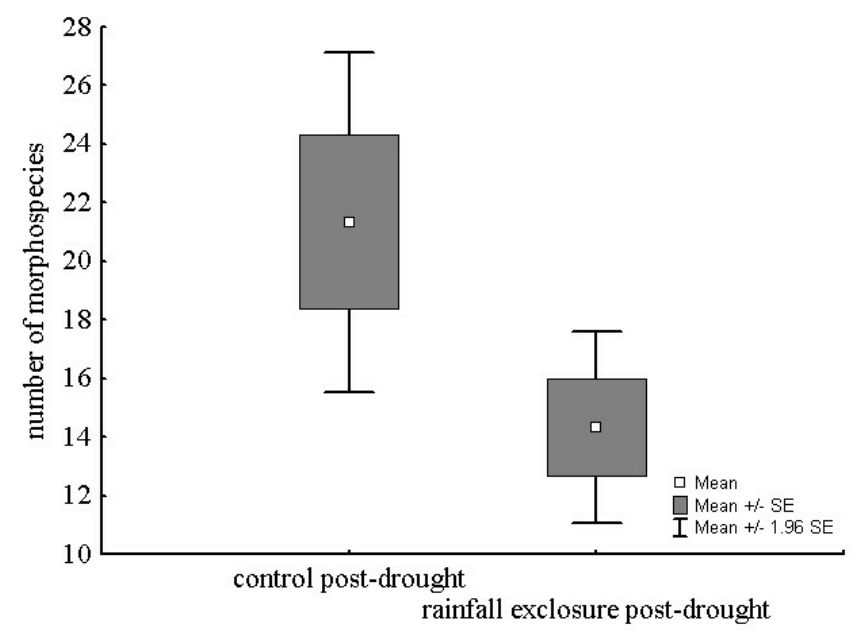

Figure 1 Difference between number of morphospecies in roof treatment and control in period 2. (generalized linear model based on Poisson distribution, intercept $<2 e-16, p=0.044$, dispersion parameter $=0.909)$. 
Table 1 Species richness (N) for control (Cont) and rainfall exclosure plots (RFE), mean species richness per leaf in each plot ( $N /$ leaf) and alpha diversity index (Fishers alpha; +SD).

\begin{tabular}{llllll|llllll}
\multicolumn{1}{c|}{ Period 1 } & & & & \multicolumn{3}{l}{ Period 2 } & & \\
\hline & & & & & & & & \\
& N/leaf & SD & $\alpha$ & SD & N & N/leaf & SD & $\alpha$ & SD \\
\hline I (Cont) & 30 & 2.75 & 2.57 & 25.93 & 7.87 & 27 & 3.75 & 1.98 & 29.82 & 2.8 \\
II (RFE) & 15 & 1.88 & 1.78 & 27.13 & 5.04 & 16 & 2.25 & 2.18 & 29.93 & 2.64 \\
III (RFE) & 30 & 3.38 & 2.78 & 28.32 & 4.13 & 11 & 1.56 & 1.21 & 30.02 & 2.51 \\
IV (Cont) & 32 & 4.5 & 2.83 & 29.01 & 3.61 & 17 & 2.19 & 2.01 & 30.04 & 2.4 \\
V (Cont) & 20 & 2.88 & 2.36 & 29.39 & 3.25 & 20 & 2.56 & 1.86 & 30.04 & 2.31 \\
VI (RFE) & 13 & 0.81 & 1.76 & 29.63 & 2.99 & 16 & 2.56 & 1.15 & 30.01 & 2.23 \\
\hline
\end{tabular}

We found a similar pattern when comparing fungal species composition pooled per treatment. A high similarity in species composition was found between control and roof treatments in period $2(\mathrm{JI}=0.45, \mathrm{MHI}=0.88)$, while the similarities for roof treatments in period 1 vs. period $2(\mathrm{JI}=0.30, \mathrm{MHI}=0.56)$ and for control treatments $(\mathrm{JI}=0.35, \mathrm{MHI}=$ 0.40 ) in period 1 vs. period 2 were very low (Tab. 2). Comparisons of all possible plot pairs (Morisita-Horn) revealed medium similarities for period 1 , but relatively high similarities for period 2 (Fig. 2).

Table 2 Similarity indices comparing species richness for treatments and periods.

\begin{tabular}{lc} 
& $\begin{array}{c}\text { Morisita-Horn } \\
\text { index }\end{array}$ \\
\hline pre- vs. post drought sampling & 0.510 \\
rainfall exclosure: pre- vs. post drought sampling & 0.563 \\
control: pre- vs. post drought sampling & 0.397 \\
pre-drought sampling: control vs. rainfall exclosure & 0.799 \\
post-drought sampling: control vs. rainfall exclosure & 0.877 \\
\hline
\end{tabular}



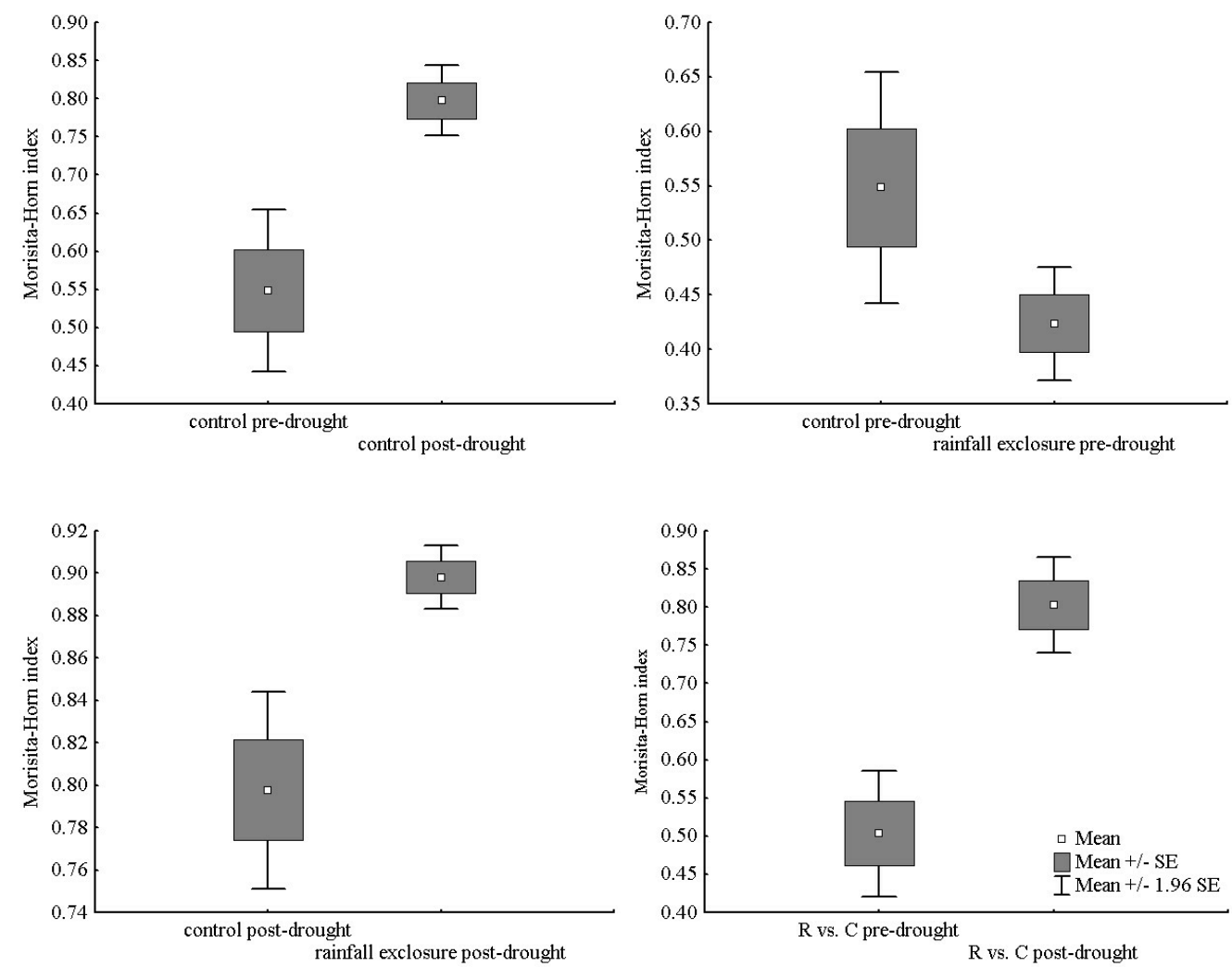

Figure 3 Comparing mean similarity (Morisita-Horn index) of a) controls of both periods $(p=0.014), b)$ controls and roof plots of period $1(p=0.108), c)$ controls and roof plots of period $2(p=0.016)$ and $d)$ all mixed pairs of roof and control comparing period 1 and $2(p>0.000)$ with general linear model based on Gaussian distribution.

The mean similarity between all roof pairs in period 1 was not significantly different from the mean similarity of all control pairs in period 1 (Fig. $3 b, F=4.2$, df $=4, P=0.108$ ). However, the mean similarity in period 2 was significantly higher in roof plots than in control plots (Fig. $3 c, F=9.6$, df $=4, P=0.016)$. Overall, the similarity of fungal endophyte morphospecies composition was significantly higher in period 2 than in period 1 within control plots (Fig. 3a, $\mathrm{F}=5.3, \mathrm{df}=4, \mathrm{P}=0.014$ ), within roof plots (not displayed, $\mathrm{P}<0.000$ ), and within all possible mixed pairs of roof and control plots (Fig. 1, Fig. 3d, $F=12.0$, df $=4 P<0.000$ ). There were no significant correlations between species composition and the mean sap flux during the sampling periods for each sampled cacao tree (data not shown). 


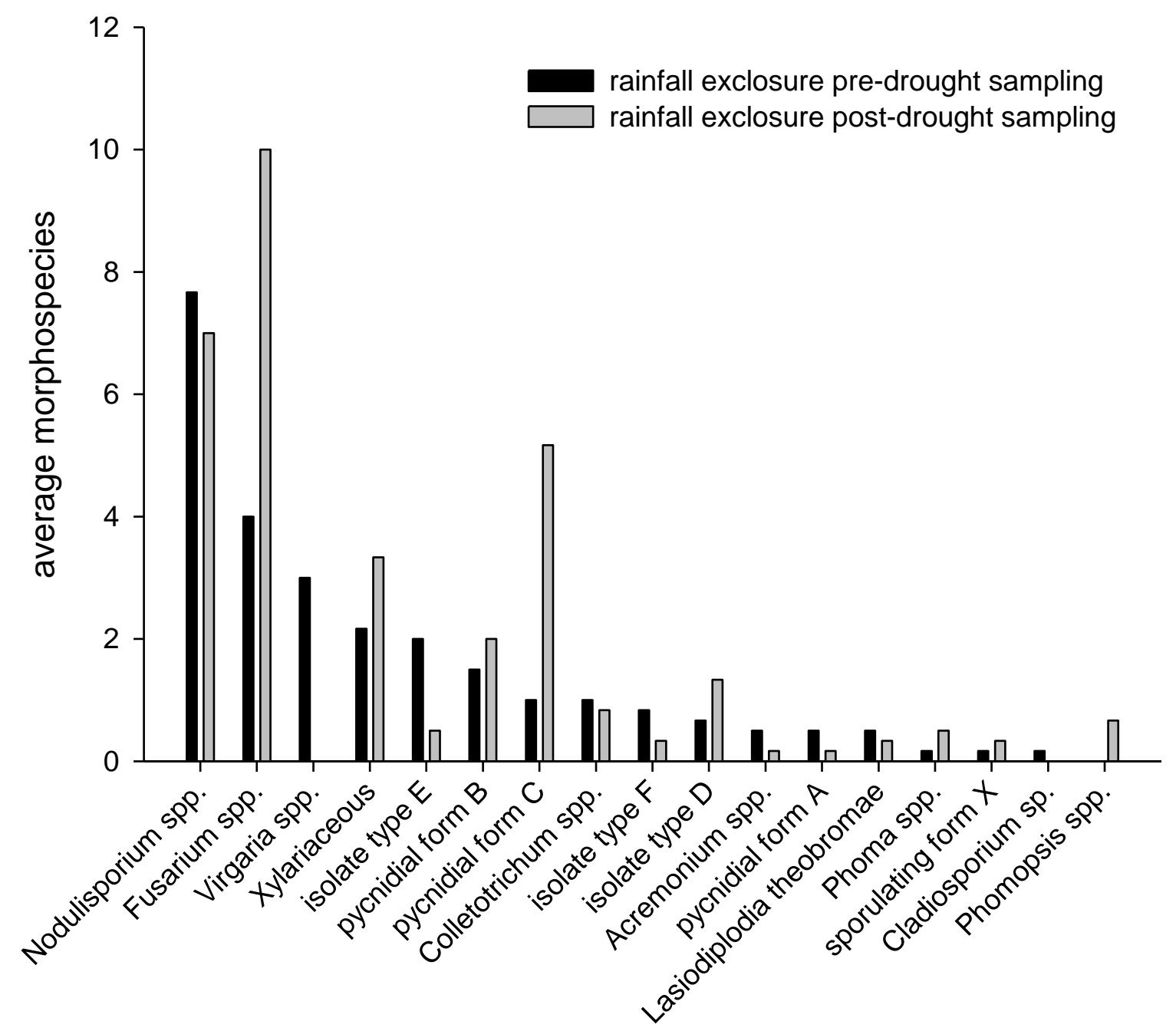

Figure 3 Abundances of all taxa identified based on spore or mycelium morphology of both periods. All subdominant taxa (categorized after Engelmann 1978) are labelled with value dominance.

Based on spore and mycelium characteristics, the 86 morphospecies were classified into 17 distinct taxa (Fig. 4). In period 1, Nodulisporium spp. ( $\mathrm{D}=30 \%$ ) were the most abundant in both treatments, followed by Fusarium spp. ( $D=16 \%)$, Virgaria spp. ( $D=12 \%)$, and Xylariacea spp. $(D=8 \%)$. In period 2, more species of the genus Fusarium $(D=31 \%)$ were found than species of the genus Nodulisporium ( $D=21 \%$ ) or of the genus Xylariaceae $(D=$ $10 \%$ ). Virgaria spp. were not found in period 2, while more pycnidium-forming species (type 3) were found $(D=16 \%)$ in period 2 than period 1. 


\section{Discussion}

\section{Species diversity}

In this study, we isolated 86 morphospecies from 192 leaves of cacao trees growing in control and roof plots. Based on the results of previous studies, in which 149 morphospecies were isolated from 544 cacao leaves of 22 different cacao plantations in Central Sulawesi (Schmidt et al. 2010), we expected to find at least 100 fungal morphospecies. Previous surveys of the fungal endophyte diversity in cacao leaves in Panama detected 344 morphospecies from 126 cacao leaves (Arnold et al. 2003). As irradiance diversity has been shown to be a major driver for fungal endophyte diversity (Schmidt et al. unpublished), the low diversity of shade trees, represented by Gliricidia and coconut palms in the experimental plots, may explain the lower number of morphospecies found in the control and roof plots in the Marena area. Moreover, the high management intensity of the Marena plantation, including annual fertilizer applications and herbicide use previous to the experiment, might have affected fungal soil and leaf litter communities (Sarathchandra et al 2001). Because foliar fungal endophytes are horizontally dispersing by spores (e.g., Arnold 2007), foliar fungal endophyte diversity is related to the fungal leaf litter communities (Herre et al. 2007, Suryanarayanan et al. 2009, U'ren et al 2010). This relationship between endophytes in the litter and leaves and the previous treatment of litter with fertilizers and herbicides may explain the overall low diversity but high variability between the plots, resulting in low similarities (JI) between all treatments and periods (Table 2). The total species richness was additionally reduced in roof and control plots during the experiment (Table 1), and this may have partially masked the impact of the roof installation. We conclude that a drought stress that simulates an ENSO event significantly reduces the species richness of fungal endophytes.

\section{Species composition}

During the 13 months of experimental drought, the roof installation linearly decreased soil water content in roof plots to a depth of $2.5 \mathrm{~m}$, diverting about $80 \%$ of the throughfall (Moser et al. 2010, Schwendenmann et al. 2010). Cacao trees responded to the reduced water availability with a monthly linearly decreasing sap flux density (Köhler et al. 2010), suggesting that the trees were indeed water stressed. Although water availability was continuously reduced in the roof plots during this period, cacao trees displayed no visible stress reactions, e.g., higher leaf fall as reported by Ling (1986) or Heuveldop et al. (1988). Compared to control plots, the increase in defoliation on trees within roof plots was only minor (8\%) (Schwendenmann et al. 2010). Apparently, cacao trees were able to mitigate the drought effects primarily by their shallow root system (Moser et al. 2010), which guaranteed 
access to the throughfall that occasionally penetrated the roofs and rewetted the topsoil (Köhler et al. 2010).

Although the cacao trees appeared to tolerate the imposed drought, the endophytic fungi inside the leaves were sensitive to the altered environmental conditions, resulting in decreased species richness (Fig. 2). Because the fungal endophytes are located within the leaves and therefore were continuously exposed to humid conditions above the roof, it seems likely that the fungal endophytes were sensitive to changes in tree physiology rather than to the direct effects of reduced rain and humidity. The loss of species richness in period 2 (Fig. 1) coincided with the significantly higher similarities (MHI) in the roof plots than in the control plots (Fig. 3d), suggesting that selective forces specifically limited the re-colonisation of new leaves on cacao trees on stressed trees, thus contributing to the lower endophyte diversity.

Based on measurements of trees sap flux and tree water use, stress values were calculated by Köhler et al. (2009) for the same tree species used in our survey. Sap flux density in cacao trees was quite variable and changed during daytime (Köhler et al. 2009), and thus correlations between sap flow and the fungal endophyte communities in the leaves, which change only slowly in time (Arnold \& Herre 2003), could not be expected. Thus, the reduced use of water by trees is not regarded as a driving force for decreasing fungal endophyte diversity. However, the endophytes may have responded to other changes in plant physiology. Saunders \& Kohn (2009) have shown that plant defence compounds influence fungal endophyte communities. Because aboveground biomass of the trees was not directly affected by reduced access to water (Moser et al. 2010), we hypothesize that plant cells might have accumulated metabolites that prevented or reduced drought-induced damage by functioning as osmolytes (e.g., sugars), antioxidants (e.g., peroxiredoxins), or scavengers (e.g., reactive oxygen species) as described by Bartels \& Sunkar (2005) and Seki et al (2007). It seems possible that an increase in concentrations of specific plant metabolites might have affected at least some fungal endophyte species, causing the observed change in endophyte composition (Schulz et al. 1999).

\section{Seasonal changes and fungal species shift}

The significant differences in the similarity of the fungal endophyte composition between plot pairs, observed within control plots in both sampling periods (Fig. 2, Fig. 3a) and observed when comparing plot pairs of both treatments from both periods (Fig. 3d) may be explained by i) a response to the naturally occurring dry spell from January to March 2008, which enhanced drought effects in roof and control plots (Schwendenmann et al. 2010) or by ii) a 
seasonal variation in endophyte occurrence as reported by Suryanarayanan \& Thennarasan (2004), Unterseher et al. (2007), and Porras-Alfaro et al. (2008). However, the endophyte communities of both periods were characterized by a group of commonly occurring and abundant endophytes (Fig. 4) known to be the most common endophytes in cocoa leaves in the Kulawi Valley (Schmidt et al. unpublished). Because most of the fungal endophytes recovered from the cacao leaves were found only infrequently as singletons or doubletons in the plots, the main changes in the similarity of the endophyte diversity during the two periods were due to a shift of dominances among the frequently occurring and often abundant endophyte species. For example, Nodulisporium spp. were the most abundant endophytes in period 1 but were second most abundant in period 2, whereas Fusarium spp. were the second most abundant in period 1 but the most abundant in period 2. Fusarium spp. produce a wide variety of mycotoxins (Guo et al. 2008) that could reduce the occurrence of other pathogenic fungi. The drought spell may have enhanced the mycotoxin production of the endophytic Fusarium spp., increasing its competitiveness with other fungal endophytes. By this mechanism, Fusarium spp. may have dispersed within the leaves, occupied many niches, and reduced the colonisation by other species, thereby increasing the similarity between the fungal endophyte communities. Fusarium spp. are causal agents of several plant diseases occurring near the plantation in the current study, and these include Fusarium wilt in Musa spp., Coffea spp., Gossypium spp., and Elais guineesis, and malformation of Magnifera indica fruits. These alternative hosts might have contributed to the higher colonisation rate by Fusarium spp. during period 2. Fusarium spp. are also the causal agent of cushion galls in cacao (Ploetz 2007), but no significant increase in plant pathogen incidence was observed on the trees (Schwendenmann et al. 2010). Contrary to other published reports (Suryanarayanan \& Thennarasan 2004, Porras-Alfaro et al. 2008), Xylariacea spp. were isolated more frequently following a period of low precipitation. This may indicate that the effects of roof-induced drought differ from those of naturally occurring drought as reported by Suryanarayanan \& Thennarasan (2004) and Porras-Alfaro et al (2008). In the current experiment, the leaves of the cacao trees in the roof plots were exposed to precipitation, whereas precipitation was drastically reduced and leaves were not exposed to precipitation in the other studies mentioned above. Temperature, radiation intensity, and humidity also differ between a roof-induced drought and a natural drought.

\section{Conclusion}

In terms of short-term biomass accumulation, the cacao trees showed no obvious response to the drought stress (Moser et al. 2010) and can therefore be regarded as resistant to ENSO-drought events, which typically last 12 months (Trenberth 1997). Cacao yields, however, decreased by $45 \%$ following the experimental drought (Schwendenmann et al. 
2010), indicating that cacao production may be substantially reduced by ENSO drought events. Following a 13-month throughfall displacement in the cacao 'roof' plots, the fungal endophyte composition in the leaves of cacao trees was significantly reduced relative to control plots. Because the roof in this experiment was built below the canopy of the cacao trees, adaptations of the fungal endophyte composition must have been driven indirectly via the colonised host plants. The reduced diversity of fungal endophytes and the high similarity in species composition in drought-exposed plots indicates that host-plant chemistry seems to control endophyte diversity. Fungal endophytes are evidently highly sensitive to host-plant conditions and may be better indicators of stress induced by climate change than host-plant growth or sap flux. Other effects associated with natural droughts (e.g., increased radiation, heat-damaged leaves, and reduced humidity) that have been shown to affect fungal endophyte composition (Suryanarayanan et al. 2002, Schmidt et al. unpublished) were not manipulated in this experiment and did not differ between roof and control plots (Moser et al. 2010). Understanding the complex interactions between endophytes and their host plants under climate change will require additional research on how plant metabolism changes in response to drought.

\section{Experimental Procedures}

\section{Study site}

The drought simulation experiment was conducted in a 7-year-old cocoa agroforestry plantation in the western margin of the Lore Lindu National Park in Central Sulawesi $\left(1.552^{\circ} \mathrm{S}, 120.020^{\circ} \mathrm{E}\right)$; this is in the centre of the cocoa production region in Indonesia. The plantation was located $560 \mathrm{~m}$ above sea level on a gentle slope $\left(8-12^{\circ}\right)$ where the ground water table was deeper than the tree rooting zone (Moser et al. 2010). The soil was a sandyloam Cambisol (Schwendenmann et al. 2010). The mean annual temperature at the nearby meteorological station was $25.5^{\circ}$, with an average annual precipitation of $2092 \mathrm{~mm}$ year ${ }^{-1}$ (Schwendenmann et al. 2010). The cacao trees were growing under an overstorey of Gliricidia spium trees interspersed with a few coconut palms (Cocos nucifera) in a plantation comprising $8400 \mathrm{~m}^{2}$. During the experiment, the cocoa trees were pruned in July and December 2007. No other agricultural measures than biweekly harvesting of the cocoa pods and manual removal of weeds were performed. Before the experiment started, the plantation had been fertilized annually.

\section{Artificial drought}

The plantation was divided into six plots of $40 \times 35 \mathrm{~m}$ each. Three plots were randomly designated as undisturbed control plots, and the other three plots were designated as treatment or "roof" plots. In the latter plots, a transparent roof was installed below the cocoa 
canopy. The roof diverted about $80 \%$ of the throughfall, while temperature, humidity, and incident radiation under the cover were unaffected by the roof (for further details, see Schwendenmann et al. 2010). Because the roof was located below the cacao canopy, cacao leaves were still exposed to precipitation, which is regarded as important for colonisation of foliage by fungal endophytes (Arnold \& Herre 2003). The experiment started in late January 2007, when the roofs were closed and ended with a rewetting phase in April 2008, when the roofs were reopened. During the experiment, soil water content was measured in soil-pits (Köhler et al. 2010). Sap flux of specific cacao trees, monitored for their fungal endophytes, was measured and tree water consumption was calculated in order to confirm water stress (Köhler et al. 2009, Köhler et al. 2010).

\section{Sample collection}

The endophytes were collected from four randomly selected Theobroma cacao trees in each plot. Edge effects were avoiding by excluding trees on the plot margins. Leaves were first sampled on 12 March 2007, in advance of the drought effects created by the installed roofs. This sampling of unaffected roof plots and control plots is referred to as period 1. Shortly before roofs were opened on 8 April 2008, when the drought was at its maximum (Köhler et al. 2010), leaves were sampled again from the same trees; this sampling is referred to as period 2. Leaves were sampled according to the methods of Schmidt et al. (unpublished). One leaf was collected from each of four branches from each cacao tree, giving a total of four leaves per tree. Two of the branches on each tree were located high in the canopy and two were located low in the canopy. Exclusive harvesting of matured leaves was assuring the assessment of a fully established endophyte community (Arnold et al. 2003). After sampling, the leaves were sealed in sterile polyethylene bags and transported to the laboratory at the Tadulako University (Palu, Central Sulawesi, Indonesia), where they were stored at $8^{\circ} \mathrm{C}$. The leaves were shipped to Germany by airmail for isolation of endophytic fungi.

\section{Fungal endophyte isolation}

Endophytic fungi were isolated following the protocol of Arnold et al. (2000). The collected leaves were surface sterilized in $3 \% \mathrm{NaOCl}$ for 3 minutes, placed in $70 \%$ ethanol for 3 minutes, and then rinsed in sterile-distilled water for 3 minutes. From each sterilized leaf, five discs were cut with a flame-sterilized circle-cutter size $6\left(78.54 \mathrm{~mm}^{2}\right)$. For each leaf, one disc was cut from the endophyte-rich midvein on the leaf tip (Cannon \& Simmons 2002), and four discs were cut along the midvein, with $3 \mathrm{~cm}$ between each disc. The five leave discs were placed on $2 \%$ MEA (malt extract agar, Roth $\mathrm{GmbH}$, Germany) containing streptomycin (600 $\mathrm{mg} / \mathrm{L}$ ) in one $9-\mathrm{cm}$ Petri dish, which was sealed with Parafilm. After 7 days at $25^{\circ} \mathrm{C}$, fungi growing out of the leaf discs were isolated and identified to morphospecies based on the 
following characteristics: colony surface texture, hyphal pigmentation, colour of exudate and growth rate (Brown et al. 1998, Arnold et al. 2000, Suryanarayanan \& Vijaykrishna 2001). We excluded isolates of Aspergillus, Penicillium, and Mucor species following the suggestions of Hyde \& Soytong (2008), because we assumed that they were contaminants. For sporulation, the isolated fungi were transferred to a thin layer of nutrient less MEA (Brown et al 1998) and stored in a UV-chamber at $20^{\circ} \mathrm{C}$ with a light regime of $12 \mathrm{~h}$ light:12 h darkness. Following 1 month of UV radiation, fungal morphospecies were identified based on their spores. Several of the fungal endophytes remained sterile under UV- and nutrient-stress conditions, and these were classified based on the characteristics of their mycelia.

\section{Statistical analysis}

We used leaf-level presence/absence data of the fungal endophyte morphospecies for the analyses. Because four leaves were collected from each tree, each tree had a maximal fungal endophyte abundance of four, while each site had a maximal fungal endophyte abundance of 16 . Besides species richness, Fishers $\alpha$ and dominances ( $D$, categorized in dominance classes, following Engelmann 1978) were calculated to assess the gamma diversity of the cacao plots. For testing the differences between treatments, a generalized linear model was calculated with adjustments in case of over-dispersion using the program $R$ (version 2.11.1) and after the suitability of the Poisson distribution for the sampled endophyte species richness data was tested (Onofri et al. 2010). Because of the time interval of 13 months between the sampling periods, leaves collected during period 2 were not present during period 1 , and we therefore regarded the samples as independent of each other. $A$ linear regression was calculated using Statistica (Version 2.0) to relate endophyte species richness to the mean monthly sap flux; sap flux data were obtained from Köhler et al. (2010). Similarity indices of endophyte composition were used to calculate differences between roof plots and control plots before and after the roof closure. Both the presence/absence-based Jaccard index ( $\mathrm{JI}$ ) and the abundance-based Morisita-Horn index (MHI) were computed because these indices use different weightings of community characteristics and therefore differ in sensitivity. Both species diversity and shared species analysis were calculated using Estimate $S$ version 8.2 with 1000 randomizations (Colwell 2008). Because species with high abundance in all plots are weighted higher, the $\mathrm{MHI}$ was regarded as more appropriate for measuring similarities and changes in fungal endophyte composition between the treatments. Values for $\mathrm{MHI}$ between all combinations of plot pairs were grouped for all combinations of treatments and periods. Differences between treatments and periods were tested with a generalized linear model based on a normal distribution and using the program R. 


\section{Acknowledgements}

This study was conducted within the framework of the joint Indonesian-German research project "Stability of Rainforest Margins (STORMA)" funded by the DFG (Deutsche Forschungs-Gemeinschaft). We would like to thank Trichur R. Suryanarayanan for advice and help in classification of fungal endophytes, Michael Köhler for the sap flux data, Gerald Moser for his cooperation and for providing cacao management data, and Thomas Klüter and his team for roof construction and maintenance. Further thanks go to Lana Dobrindt and Nayuf Valdez Aguirre for reviews and suggestions.

\section{References}

Arechavaleta M, Bacon CW, Hoveland CS, Radcliffe DE (1989) Effect of the tall fescue endophyte on plant response to environmental stress, Agronomy Journal 81: 83-90

Arnold AE (2007) Understanding the diversity of foliar endophytic fungi: progress, challenges, and frontiers, Fungal Biology Reviews 21: 51-66

Arnold AE, Maynard Z, Gilbert GS, Coley PS, Kursar TA (2000) Are tropical fungal endophytes hyperdiverse? Ecology Letters 3: 267-272

Arnold AE, Maynard Z, Gilbert GS (2001) Fungal endophytes in dicotyledonous neotropical trees: patterns of abundance and diversity, Mycological Research 105: 1502-1507

Arnold AE, Herre, EA (2003) Canopy cover and leaf age affect colonization by tropical fungal endophytes: ecological pattern and process in Theobroma cacao (Malvaceae), Mycologia 95: 388-398

Arnold AE, Mejía LC, Kyllo D, Rojas El, Maynard Z, Robbins N, et al. (2003) Fungal endophytes limit pathogen in a tropical tree, Proceedings of the Natural Academy of Science of the USA 100: 15649-15654

Arnold AE, Engelbrecht BMJ (2007) Fungal endophytes nearly double minimum leaf conductance in seedlings of a neotropical tree species, Journal of Tropical Ecology 23: 369372

Bacon CW (1993) Abiotic stress tolerances (moisture, nutrients) and photosynthesis in endophyte-infected tall fescue, Agriculture, Ecosystems and Envirnonment 44: 123-141

Bartels D, Sunkar R (2005) Drought and salt tolerance in plants, Critical Reviews in Plant Sciences 24: 23-58 
Belsky JM, Siebert, SF (2003) Cultivating cacao: Implications of sun-grown cacao on local food security and environmental sustainability, Agriculture and Human Values 20: 277-285

Brown KB, Hyde KD, Guest DI (1998) Preliminary studies on endophytic fungal communities of Musa acuminate species complex in Hong Kong and Australia, Fungal Diversity 1: 27-51

Cannon PF, Simmons CM (2002) Diversity and host preference of leaf endophytic fungi in the Iwokrama Forest Reserve, Guyana, Mycologia 94: 210-220

Colwell RK (2008) RangeModel: Tools for exploring and assessing geometric constraints on species richness (the mid-domain effect) along transects, Ecography 31: 4-7

D’Arrigo R, Wilson R, Palmer J, Krusic P, Curtis A, Sakulich J (2006) Monsoon drought over Java, Indonesia, during the past two centuries, Geophysical Research Letters 33: L04709

Duguma B, Gockowski J, Bakala J (2001) Smallholder cacao (Theobroma cacao Linn.) cultivation in agroforestry systems of West and Central Africa: challenges and opportunities, Agroforestry Systems 51: 177-188

El-Zayat SA, Nassar MSM, El-Hissy FT, Abdel-Motaal FF, Ito SI (2008) Mycoflora associated with Hyoscyamus muticus growing under extremely arid desert environment (Aswan region, Egypt), Journal of Basic Microbiology 48: 82-92

Espinosa-Garcia FJ, Langenheim JH (1990) The endophytic fungal community in leaves of a coastal redwood population - diversity and spatial patterns, New Phytologist 116: 89-97

Guo B, Wang Y, Tang K (2008) Bioactive natural products from endophytes: A review, Applied Biochemistry and Microbiology 44: 136-142

Herre EA, Mejía LC, Damond AK, Rojas E, Maynard Z, Butler A, van Bael SA (2007) Ecological implications of anti-pathogen effects of tropical fungal endophytes and mycorrhizae, Ecology 88: 550-558

Heuveldop J, Fassbender HW, Alpizar L, Enriquez G, Fölster H (1988) Modelling agroforestry systems of cacao (Theobroma cacao) with laurel (Cordia alliodora) and poro (Erythrina poeppigiana) in Costa Rica. II. Cacao and wood production, litter production and decomposition, Agroforestry Systems 6: 37-48

Hoffman MT, Arnold AE (2008) Geographic locality and host identity shape fungal endophyte communities in cupressaceous trees, Mycological Research 112: 331-344

Hyde KD, Soytong K (2008) The fungal endophyte dilemma, Fungal Diversity 33: 163-173

IDDO (2009) Quarterly Bulletin of Cocoa Statistics, Vol. XXXV, NO.2 
IPCC (200) Climate Change 2001: The Scientific Basis. Contribution of Working Group I to the Third Assessment Report of the Intergovernmental Panel on Climate Change [Houghton JT, Ding Y, Griggs DJ, Noguer M, van der Linden PJ, Dai X, et al. (eds.)]. Cambridge University Press, Cambridge, United Kingdom and New York, NY, USA, 881pp

Keil A, Zeller M, Wida A, Sanim B, Birner R (2008) What determines farmers' resilience towards ENSO-related drought? An empirical assessment in central Sulawesi, Indonesia, Climate Change 86: 291-307

Kogel K-H, Franken P, Hückelhoven R (2006) Endophyte or parasite- what decides? Current Opinion in Plant Biology 9: 358-363

Köhler M, Dierick D, Schwendenmann L, Hölscher D (2009) Water use characteristics of cacao and Gliricidia trees in an agroforest in Central Sulawesi, Indonesia, Ecohydrology 2: 520-529

Köhler M, Schwendenmann L, Hölscher D (2010) Throughfall reduction in a cacao agroforest: tree water use and soil water budgeting, Agricultural and Forest Meteorology 150: 1079-1089

Latch, G.C.M., and Hunt, W.F., Musgrave, D.R. (1985) Endophytic fungi affect growth of perennial ryegrass. New Zealand Journal of Agricultural Research 28: 165-168.

Le Houérou HN (1996) Climate change, drought and desertification, Journal of Arid Environments 34: 133-185

Ling AH (1986) Litter production and nutrient cycling in a mature cocoa plantation on inland soils of Peninsular, Malaysia. In: Proceedings of the International Conference on Cocoa and Coconuts, Kuala Lumpur (eds. Pushparajah, E., Chew, P.S.), pp. 451-465. Incorporated Society of Planters, Kuala Lumpur, Malaysia.

Lloret F, Peñuelas J, Estiarte M (2004) Experimental evidence of reduced diversity of seedlings due to climate modification in a Mediterranean-type community, Global Change Biology 10: 248-258

Malinowski DP, Belesky DP (2000) Adaptations of endophyte-infected cool-season grasses to environmental stresses: Mechanisms of drought and mineral stress tolerance, Crop Science 40: 923-940

Moser G, Leuschner C, Hertel D, Hölscher D, Köhler M, Leitner D, et al. (2010) The drought response of cocoa trees (Theobroma cocoa) to a 13-month desiccation period in Sulawesi, Indonesia, Agroforesty Sytems 79: 171-187 
Müller CB, Kraus J (2005) Symbiosis between grasses and asexual fungal endophytes, Current Opinion in Plant Biology 8: 450-456.

Onofri A, Carbonell EA, Piepho H-P, Mortimer AM, Cousens RD (2010) Current statistical issues in Weed Research, Weed Research 50: 5-24

Patz JA, Campbell-Lendrum D, Holloway T, Foley JA (2005) Impact of climate change on human health, Nature 438: 310-317

Ploetz RC (2007) Cacao diseases: Important threats to chocolate production worldwide, Phytopathology 97: 1634-1639

Porras-Alfaro A, Herrera J, Sinsabaugh RL, Odenbach KJ, Lowrey R, Natvig DO (2008) Novel root fungal consortium associated with a dominant desert grass, Applied and Environmental Microbiology 74: 2805-2813

Quinn WH, Zopf DO, Short KS, Yang R (1978) Historical trends and statistics of Southern Oscillation, EI Nino, and Indonesian droughts, Fishery Bulletin 76: 663-678

Rahman MH, Saiga S (2005) Endophytic fungi (Neotyphodium coenophialum) affect the growth and mineral uptake, transport and efficiency ratios in tall fescue (Festuca arundinacea), Plant and Soil 272: 163-171

Sarathchandra SU, Ghani A, Yeates GW, Burch G, Cox NR (2001) Effect of nitrogen and phosphyte fertilisers on microbial and nematode diversity in pasture soils, Soil Biology and Biochemistry 33: 953-964

Saunders M, Kohn LM (2009) Evidence for alteration of fungal endophyte community assembly by host defense compounds, New Phytologist 182: 229-238

Schmidt C, Clough Y, Vidal S, (unpublished) The lost endophytes: Endophyte diversity of a neotropical tree (Theobroma cacao) in Central Sulawesi, Indonesia, Open Mycology Journal, under review

Schulz B, Römmert A-K, Dammann U, Aust H-J, Strack D (1999) The endophyte-host interaction: a balanced antagonism? Mycological Research 103: 1275-1283

Schulz B, Boyle C (2005) The endophytic continuum, Mycological Research 109: 661-686

Schwendenmann L, Veldkamp E, Moser G, Hölscher D, Köhler M, Clough Y, et al. (2010) Effects of an experimental drought on the functioning of a cocoa agroforestry system, Sulawesi, Indonesia, Global Change Biology 16: 1515-1530 
Seki M, Umezawa T, Urano K, Shinozaki K (2007) Regulatory metabolic networks in drought stress responses, Current Opinion in Plant Biology 10: 296-302

Sheffield J, Wood EF (2008) Projected changes in drought occurrence under future global warming from multi-model, multi scenario, IPCC AR4 simulations, Climate Dynamics 31: 79105

Sherameti, I., Tripathi, S., Varma, A., and Oelmüller, R. (2008) The root-colonizing endophyte Pirifomospora indica confers drought tolerance in Arabidopsis by stimulating the expression of drought stress-related genes in leaves, Molecular Plant Microbe Interactions 21: 799-807

Sivakumar MVK, Das HP, Brunini O (2005) Impacts of present and future climate variability and change on agriculture and forestry in the arid and semi-arid tropics, Climate Change 70 : $31-72$

Smith NJH, Falesi IC, Alvim P de T, Serrão EAS (1996) Agroforestry trajectories among smallholders in the Brazilian Amazon: innovation and resiliency in pioneer and older settled areas, Ecological Economics 18: 15-27

Suryanarayanan TS, Vijaykrishna D (2001) Fungal endophytes of aerial roots of Ficus benghalensis, Fungal diversity 8: 155-161

Suryanarayanan TS, Murali TS, and Venkatesan G (2002) Occurrence and distribution of fungal endophytes in tropical forests across a rainfall gradient, Canadian Journal of Botany 80: 818-826

Suryanarayanan TS, Thennarasan S (2004) Temporal variation in endophyte assemblages of Plumberia rubra leaves, Fungal Diversity 15: 197-204

Suryanarayanan TS, Thirumalai E, Prakash CP, Rajulu, Govinda MB, Thirunavukkarasu N (2009) Fungi from two forests of southern India: a comparative study of endophytes, phellophytes, and leaf litter fungi, Canadian Journal of Microbiology 55: 419-426

Thomas SE, Crozier J, Aime MC, Evans HC, Holmes KA (2008) Molecular characterization of fungal endophytic morphospecies associated with the indigenous forest tree, Theobroma gileri, in Ecuador, Mycological Research 112: 852-860

Trenbert KE (1997) The definition of El Niño, American Meteorological Society 78: 27712777 
Unterseher M, Reiher A, Finstermeier K, Otto P, and Morawetz W (2007) Species richness and distribution patterns of leaf-inhabiting endophytic fungi in a temperate forest canopy, Mycological Progress 6: 201-212

U'ren JM, Dalling JW, Gallery RE, Maddison DR, Davis EC, Gibson CM et al. (2009) Diversity and evolutionary origins of fungi associated with seeds of a neotropical pioneer tree: a case study for analysing fungal environmental samples, Mycological Research 113: $432-449$

U'ren JM, Lutzoni F, Miadlikowska J, Arnold EA (2010) Community analysis reveales close affinities between endophytic and endolichenic fungi in mosses and lichens, Microbial Ecology 60: 340-353

Tamura K, Dudley J, Nei M \& Kumar S (2007) MEGA4: Molecular Evolutionary Genetics Analysis (MEGA) software version 4.0, Molecular Biology and Evolution 24:1596-1599

Vega FE, Simpkins A, Aime MC, Posada F, Peterson SW, Rehner SA, Infante F, Castillo A, Arnold AE (2009) Fungal endophyte diversity in coffee plants from Colombia, Hawai'i, Mexico and Puerto RicoFungal ecology, Fungal Ecology 3:122-138

Venables WN, Ripley BD (2002) Modern Applied Statistics with S, New York: Springer

Vilgalys R, Hester M (1990) Rapid Genetic Identification and Mapping of Enzymatically Amplified Ribosomal DNA from Several Cryptococcus Species, Journal of Bacteriology 172:4238-4246

Vujanovic V, Hamel C, Yergeau E, St-Arnaud M (2006) Biodiversity and Biogeography of Fusarium Species from Northeastern North American Asparagus Fields Based on Microbiological and Molecular Approaches, Microbial Ecology 51:242-255

Yli-Mattila T, Paavanen-Huhtala S, Parikka P, Konstantinova P, Gagkaeva TY (2004) Molecular and morphological diversity of Fusarium species in Finland and north-western Russia, European Journal of Plant Pathology 110:573-585 


\title{
Chapter 3:
}

\section{Distribution and Diversity of Fusarium spp. in Cacao Plantations of Central Sulawesi - Indonesia}

\author{
Carsten Schmidt ${ }^{1}$, Nayuf Valdez Aguirre ${ }^{2}$, Petr Karlovsky³, Stefan Vidal ${ }^{1}$ \\ ${ }^{1}$ Plant Pathology, Agricultural Entomology, Georg-August University of Goettingen, \\ Grisebachstrasse 6, 37077 Goettingen, Germany \\ 2Plant Pathology, General Plant Pathology and Crop Protection, Georg-August University of \\ Goettingen. Grisebachstrasse 6, 37077 Goettingen, Germany \\ ${ }^{3}$ Plant Pathology, Molecular Phytopathology and Mycotoxin Research, Georg-August \\ University of Goettingen, Grisebachstrasse 6, 37077 Goettingen, Germany
}

\begin{abstract}
The ecology and distribution of endophytic occurring Fusarium spp. in the tropics is largely unknown. In this investigation the phylogenetic relation among 172 Fusarium isolates, sampled in 23 cacao (Theobromae cacao) plantations along environmental gradients, was studied using partial sequences of the ribosomal large subunit (LSU) and transcription elongation factor 1 -alpha (TEF 1 $\alpha$ ). The observed diversity of endophytic Fusarium spp. was comparable to the Fusarium diversity that was found previously in cacao of South America. The composition of phylogenetically distinct Fusarium groups in the cacao plantations was dependent on local plant composition, and was reflecting Sulawesi's characteristic Fusarium diversity. The abundance of Fusarium phylogenetic groups was changing along local temperature gradients and seasonal patterns. Two shade tree species (Piper anduncum and Toona ciliata) within the cacao plantations could been discriminated based on their Fusarium ssp. composition. We hypothesize that the latter trees influence the Fusarium composition of a habitat by antifungal compounds. The neighbourhood of Mango trees (Mangiferae spp.) showed an enhanced Fusarium diversity compares to cacao trees. Neither yield losses nor symptoms of Fusarium induced diseases have been observed in the plantations investigated in this study, despite of the high diversity or abundance of Fusarium spp..
\end{abstract}




\section{Introduction}

Due to its high species diversity and its wide host range, Fusarium is one of the most widely distributed microbe associated to plants (Summerell et al. 2003, Leslie \& Summerell 2006). Many Fusarium spp. occurs as pathogens of various crops from temperate areas (e.g. YliMattila et al 2004, Logrieco et al. 2002, Punja et al. 2008, Nitschke et al. 2009) to the tropics (e.g. Ploetz 2006, Marasas et al. 2006, Dita et al. 2010). Fusarium pathogens cause worldwide considerable economic yield losses in field crops and agroforestry (see Leslie \& Summerell 2006). Furthermore, non-pathogen Fusarium spp. can also occur as endophytes without detriment to their host plants (Rubini et al. 2005, Evans et al. 2003, Vega et al. 2009, Pinaria et al. 2010). Some endophytes gained high popularity as biocontrol agents. Specifically non-pathogenic species and strains of the genus of Fusarium attracted high interest (e.g. Boyette \& Walker 1985, Freeman at al. 2002, Larkin \& Fravel 2002, Fravel et al 2002, Menjivar Barahona 2010). This suggests that investigations of Fusarium diversity in unexplored habitats might be a promosing approach to discover new potential biocontrol agents. Because endophytic fungal diversity is generally correlated to plant species diversity (Hyde 2001, Cannon \& Simmons 2002, Schmidt et al. unpublished), tropical rainforests can be regarded as a valuable source of yet unknown Fusarium spp., strains or varieties (Arnold et al. 2000, Arnold et al. 2001, Arnold \& Lutzoni 2007). In an investigation of leaf endophytes in 23 cacao (Theobroma cacao) plantations in Central Sulawesi (Indonesia) Fusarium was found to be the second most abundant taxa (Schmidt et al. unpublished). Because the fungal endophyte morphospecies richness correlated to the diversity of planted shade trees along the investigated plantations, it seems most likely that the cacao trees hosted more than one Fusarium spp. This assumption was supported by the results of a study, in which the changes in fungal endophyte composition of a cacao plantation were investigated under drought stress (Schmidt \& Vidal unpublished). After 13 month of artificial drought Fusarium spp. reacted to the induced changes in host plant conditions and became the dominant genus, pointing towards a possible increase in Fusarium diversity in cacao. Further support to the above mentioned hypothesis comes from Pinaria et al. (2010), who investigated Fusarium species associated with Vanillae planifolia, which is in Sulawesi commonly grown around stems of cacao plants, in seven locations in Indonesia. Half (six of twelve) of the Fusarium species which had been indentified in Pinaria et al. (2010), were previously known from North Sulawesi (Pinaria et al. 2010), suggesting a high diversity of Fusarium species in Central Sulawesi.

Some Fusarium spp. are known to have distinct climatic preferences for their distribution (Summerell et al. 2003). But besides regional climates, the drivers of Fusarium diversity are largely unknown. The aim of the present research was to screen Fusarium diversity based on the molecular identification of fungal isolates collected from 23 cacao plantations in two 
previous studies (Schmidt et al. unpublished, Schmidt \& Vidal unpublished). Another focus of the investigation was to survey for characteristics in Fusarium diversity along the Kulawi valley. In a previous investigation about endophyte diversity in cacao after drought simulation, several Fusarium spp. were isolated from sample leaves (Schmidt et al. unpublished). These results and isolates were used in the present study to determine whether Fusarium spp. populations varied following drought stress and whether this yielded to an increase in Fusarium spp. diversity.

\section{Material and Methods}

\section{Investigation area and sampling}

Fungi were isolated from cacao leaves of 23 cocoa plantations along the western margin of Lore Lindu National Park in Central Sulawesi, Indonesia. A total of 22 of the investigated cacao plantations were managed by small holders along the Kulawi valley (hereafter addressed). In an additional plantation close to the village Marena (hereinafter called Marena plantation), an artificial drought was established for a period of 13 month. The conditions and performance of the drought experiment was already described in Schmidt \& Vidal (unpublished). All samplings of fungal endophytes were conducted in March 2007. The Marena plantation was sampled again in April 2008, when the introduced drought reached its peak level (see. Schwendenmann et al. 2010). All investigated plantations succeeded the following environmental gradients: distance to natural rainforest, temperature, weed diversity, shadetree composition and degree of shading and solar exposition (see Schmidt et al. unpublished).

\section{Isolation of Fusarium species}

The sampled cacao leaves were immediately enclosed in sterile polyethene bags and transported to the laboratory of the University of Tadulako (Central Sulawesi), where they were stored at $8^{\circ} \mathrm{C}$ and processed within the following two days. The surface sterilization of the collected leaves was performed following the protocol suggested by Arnold et al. (2000). In 3 min steps, whole leaves were bleached in $3 \% \mathrm{NaOCl}$, washed in $70 \%$ ethanol and rinsed in distilled water. Five leave discs were cut out of each sterile leaf using a flame sterilized circle-cutter size $6\left(A=78.54 \mathrm{~mm}^{2}\right)$. One of the five leaf discs was cut from the leaf tip, which is known to contain most endophyte diversity (Cannon \& Simmons 2002). Four further leave discs were cut in the leave periphery aside the midvein to assure a leaf-representative endophyte extraction. The five leave discs of one leaf were transferred on antibiotic (streptomycin 600ppm) malt extract agar (Roth, Germany) in a $9 \mathrm{~cm}$ petri dish sealed with parafilm and incubated at $25^{\circ} \mathrm{C}$ for seven days. Fungi that grew out from the leaf discs were transferred into a new plate and purified through several isolations. Pure fungal culture were 
stimulated for sporulation using nutrient less malt extract agar and UV (light regiment UV darkness 12:12h). After one month of UV radiation, Fusarium spp. were characterized based on their spores morphology.

\section{Fungal DNA extraction}

For fungal DNA isolation, $4 \mathrm{ml}$ malt extract broth media (Roth) were inoculated with the fungus and shaken for growth at $25^{\circ} \mathrm{C}$ and $300 \mathrm{rpm}$ for five days. Hereinafter the hyphae were collected by vacuum-filtration and the mycelia were then freeze-dried for two days. Dried fungal material was used for DNA extraction according to the CTAB-protocol of Doyle

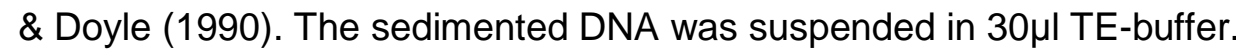

\section{Diversity study of selected Fusarium isolates}

Following comparable fungal diversity investigations, analysis by PCR amplification of the LSU followed by sequencing of the obtained PCR products was performed (Aime \& PhillipsMora 2005, Crozier et al. 2006). For this purpose the primers LROR (5'ACCCGCTGAACTTAAGC 3', Moncalvo et al. 1995, Maier et al. 2003) and LR6 (5'CGCCAGTTCTGCTTACC3', Vilgalys \& Hester 1990, Aime \& Phillips-Mora 2005) were used. The PCR reactions contained 25ng fungal DNA, 1x PCR-buffer (10x, Bioline), 1.5mM $\mathrm{MgCl} 2$ (Bioline), $0.4 \mu \mathrm{M}$ each of forward/reverse primer, $200 \mu \mathrm{M}$ of a dNTP-mix and 1 Unit of Taq-DNA-Polymerase (Bioline). After a first denaturation step of $5 \mathrm{~min}$ at $94^{\circ} \mathrm{C}$ a total of 35 cycles each of $94^{\circ} \mathrm{C}$ for $30 \mathrm{~s}, 50^{\circ} \mathrm{C}$ for $45 \mathrm{~s}$ and $72^{\circ} \mathrm{C}$ for $1 \mathrm{~min}$ were run followed by a final extension step at $72^{\circ} \mathrm{C}$ of $7 \mathrm{~min}$.

To achieve differentiation between species of the genus Fusarium, the translation elongation factor (TEF) 1 a gene was selected (O'Donnell et al. 1998, Nitschke et al. 2009). For PCR amplification the primers EF1 and EF2 (O'Donnell et al. 1998), have been modified by adding a restriction site on the 5 '-end of each primer, resulting in 5'TCAGTAGCGGCCGCATGGGTAAGGARGACAAGAC3'and

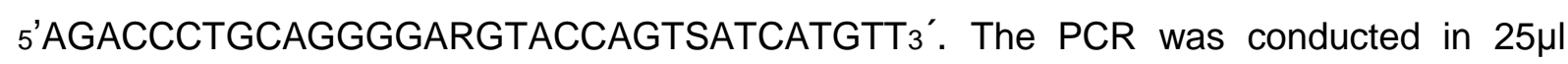
reactions containing $0.3 \mu \mathrm{M}$ primers ,1x PCR-buffer (10x, Bioline), 2mM MgCl2 (Bioline), $200 \mu \mathrm{M}$ dNTP-Mix, 1 Unit of Taq-DNA-Polymerase (Bioline) and 10ng fungal DNA and used in the following PCR-program: $94^{\circ} \mathrm{C}$ for $\mathrm{Xmin}, 30$ cycles of denaturing at $94^{\circ} \mathrm{C}$ for $20 \mathrm{~s}$, annealing at $54^{\circ} \mathrm{C}$ for $20 \mathrm{~s}$, and extension at $72^{\circ}$ for $35 \mathrm{~s}$ followed by an additional extension time for $2 \min$ at $72^{\circ} \mathrm{C}$.

\section{Sequence analysis}

LSU and TEF-1a PCR products were purified using SureClean (Bioline, Luckenwalde, Germany) following instructions of manufacturer. In order to proof quality and quantity of the PCR products these were separated on a $1.6 \%$ agarose-gel and then send for sequencing. 
All LSU PCR products were sequenced by Macrogen (Korea) and all TEF-1a PCR products were send for sequencing to MWG Biotech (Germany). The obtained sequences were aligned with known sequences in the databases NCBI and EMBL. Alignments and phylogenetic analysis were performed with MEGA4. Before conduction of phylogenetic analysis, the sequences were manually aligned on their 5 'site and hereafter the 3 '-ends were trimmed in order to obtain sequences of equal length. All LSU- and EF-1alpha sequences were aligned by ClustalW (Thompson et al., 1994). Maximum Likelihood of alignments was performed to analyze the phylogenetic relationship of the given samples. For the clustering were gaps treated as missing data. The estimation of nodal support was performed by 1000 bootstrap replications.

\section{Additional statistics}

Different statistical tests were used to correlate Fusarium diversity with environmental conditions based either on morphological or molecular data. The integration of Fusarium in the fungal endophyte community was calculated by a non-metric multidimensional model (NMDS) (Minchin 1987) based on the morphological data (Schmidt et al. unpublished). Thereafter to identify ecological drivers of diversity, the environmental data of the plantations were tested against the NMDS using the program $R$ (version 2.11.1). The impacts of: environmental factors, time discrimination and shade tree species on the distribution and diversity of Fusarium spp., represented by LSU sequences were tested. Therefore a generalized linear model analysis of the phylogenetic clusters from the LSU alignment based on poisson distribution was calculated (Venables \& Ripley 2002, Onofri et al. 2009). The model was performed and tested in R. Afterwards phylogenetic clusters of the LSU were correlated with environmental factors - the significance of the correlation was tested using a linear regression with the program Statistica (Version 2.0).

\section{Results}

\section{Cluster analysis of the LSU of 172 fungal isolates}

The phylogenetic analysis of 172 Fusarium isolates and seven species from the NCBI database reveales two main clusters with bootstrap values higher than $85 \%$ (Fishbein et al. 2001). The biggest cluster, with a bootstrap value of $92 \%$ comprises the sub-clusters $B, C$ and D (Fig. 1, A, B, C and D). Cluster A comprises three sub-clusters, in which most of the previously described Fusarium spp. arranges. In this cluster there is only one of the Fusarium isolates (160), clustering close to $F$. ambrosium. The next cluster (B) consists in a sub-cluster with three isolates (247,129 and 221), which are grouping with 243 . In cluster $C$ there are 14 isolates and no known species defining the origin of the isolates, while cluster D houses the rest of the isolates (153) and Fusarium oxysporum. This last cluster (D) can be 
divided into two groups ( 1 and 2 ), distinguished by a low bootstrap value of $61 \%$. Interestingly, both groups included two different sequences of Fusarium oxysporum, corroborating the solidity of cluster $D$ in terms of the distinction of one specific taxa, in this case, F. oxysporum. The Fusarium spp. clustered in geographical $(p=0.026)$ and seasonal groups ( $p<0.001$, Fig. 2). For example the whole cluster $C$ and group 1 of cluster D (LSU D1) mainly contained Fusarium spp. Isolated from the plantations along the Kulawi valley sampled in 2007. In the contrary isolates of cluster A and group 2 of cluster D (LSU D2) were mainly sampled in 2008 in the Marena plantation when the drought achieved its maximum level. There was no difference in Fusarium diversity or abundance between the 22 plantations in the Kulawi valley and in the Marena plantation before the drought experiment was conducted.

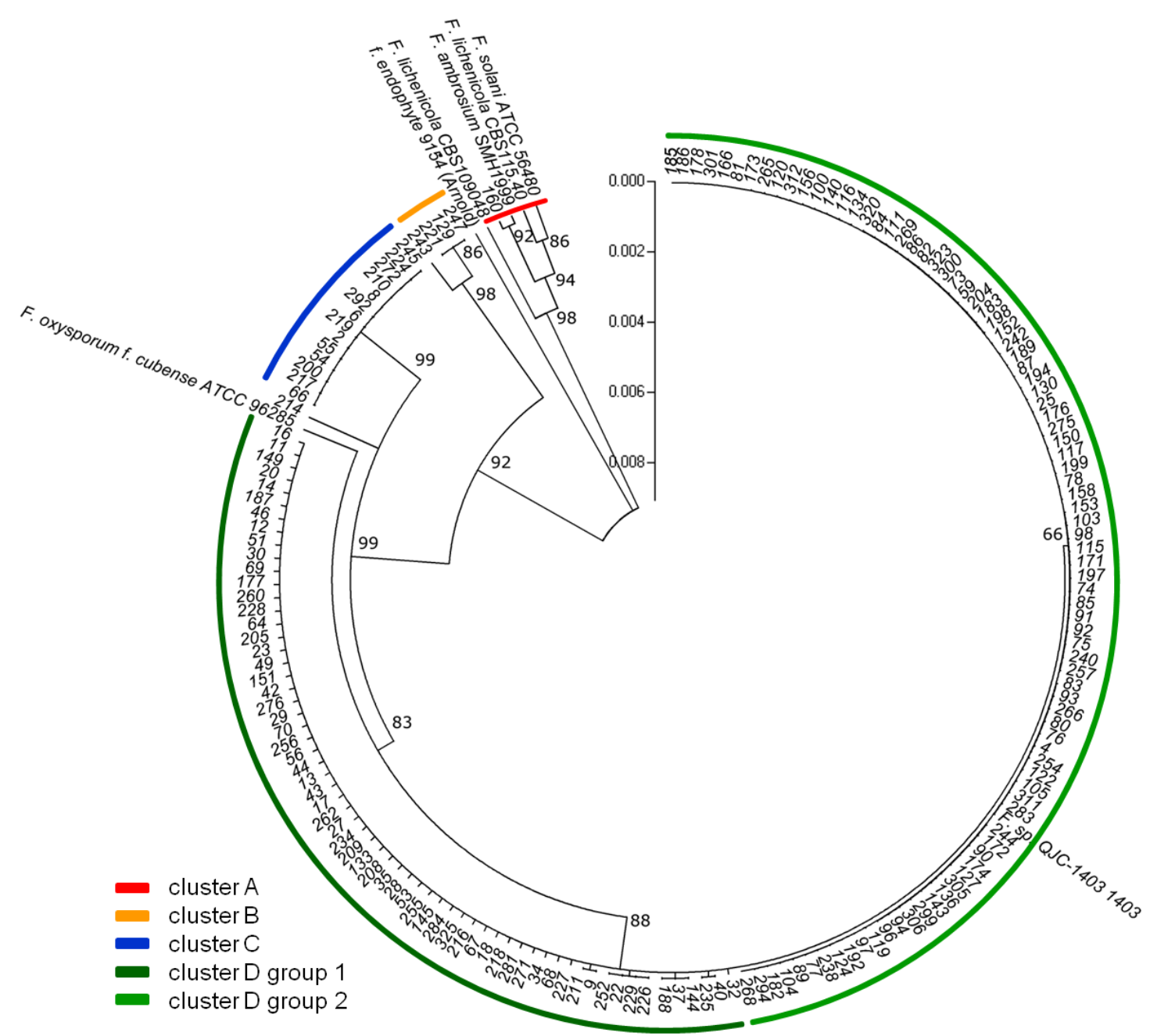

Figure 1 Phylogenetic analysis of 179 Fusarium spp. The evolutionary history was inferred using the Neighbor-Joining method. The optimal tree with the sum of branch length = 0.05362127 is shown. The tree is drawn to scale, with branch lengths in the same units as those of the evolutionary distances used to infer the phylogenetic tree. The evolutionary distances were computed using the Maximum Composite Likelihood method and are in the units of the number of base substitutions per site. All positions containing gaps and missing data were eliminated from the dataset. This analysis was conducted in MEGA4. 


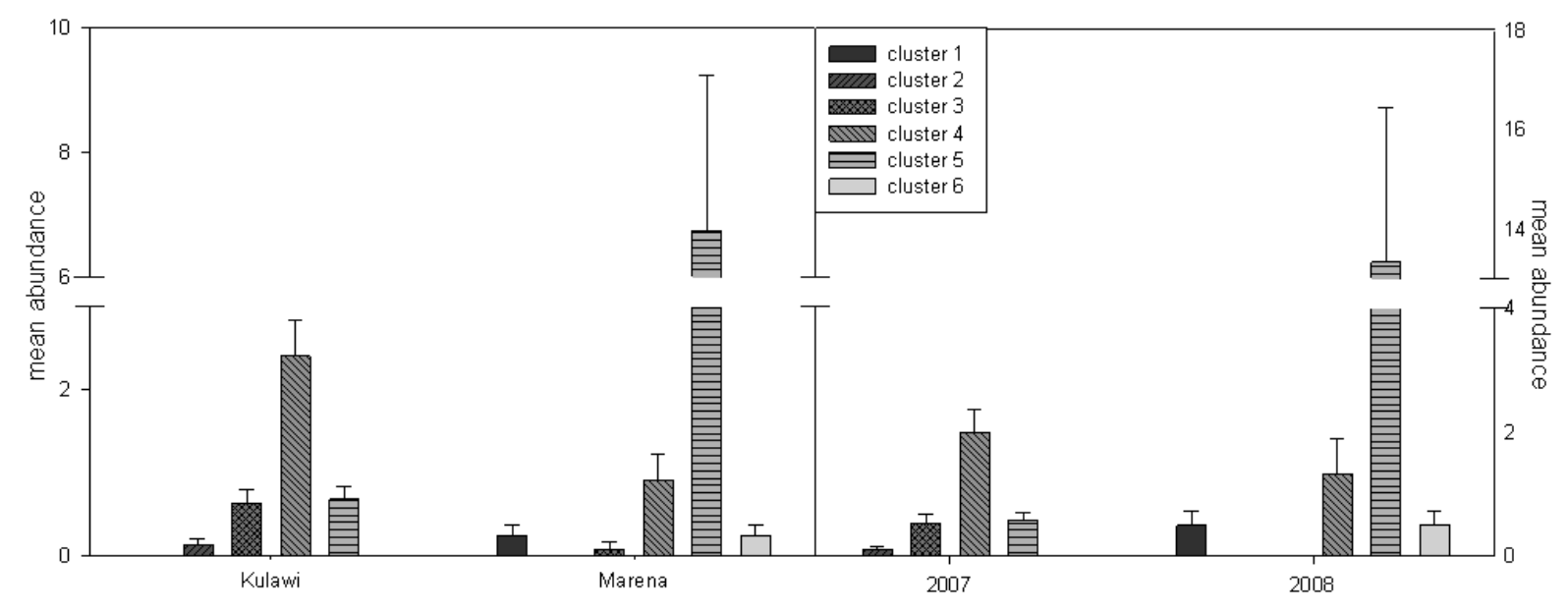

Figure 2 Mean isolate abundance (with standard error) based on LSU clusters and groups separated for two different locations and for two different sampling seasons. The distribution of Fusarium endophytes differed significantly by the influence of the locations $(p=0.026)$ and the sampling seasons $(p<0.001)$.

\section{Correlation analysis}

In the species composition of the Kulawi valley, Fusarium isolates were located centrally on the first axis of the NMDS model, reflecting the main gradient of distribution (Fig. 3). From the second axis it is however apparent that Fusarium isolates are affected by the opposed gradients of minimal annual temperature $\left(p=0.014, r^{2}=0,379\right)$ and altitude $(p=0.0052$, $r^{2}=0.449$ ). The distribution of Fusarium clusters showed similar pattern: the abundance of isolates per cluster correlated positive with the minimal annual temperature $(p=0.036$, $r^{2}=0.233$, Tab. 1), while the total species richness decreased with increasing altitude $\left(p=0.028, r^{2}=0.207\right)$. In a generalized linear model over all 6 LSU clusters the minimal annual temperature expressed a significant impact on the distribution of clusters over the area $(p=0.007)$, while altitude proved no relevance concerning the diversity of Fusarium spp.. In a linear regression the general abundance of all Fusarium clusters was decreasing with increasing altitude over sea level $\left(r^{2}=0.207, p=0.028\right.$, Tab. 1), suggesting that besides radiation, altitude might be the the main driver of temperature. Additional the minimal annual temperature correlated significantly with the mean Fusarium abundance per LSU cluster $\left(r^{2}=0.233, p=0.036\right)$ and with the annual cacao yield in total $\left(r^{2}=0.210, p=0.033, T a b .1\right)$. The cacao yield correlated positively with the diversity of LSU clusters $\left(r^{2}=0.425, p=0.003\right)$ and the Fusarium abundance $\left(r^{2}=0.249, p=0.029\right)$. There was also a strong correlation between the diversity of Fusarium clusters and the infection levels of the cacao pod borer $\left(r^{2}=0.491\right.$, $\mathrm{p}<0.001$, Tab. 1). 
Table 1 Significant correlations of a linear regression between factors along the cacao plantations in the Kulawi valley. The significance level is rated with * for $p<0.05$, ${ }^{*}$ for $p<0.01$ and ${ }^{* * *}$ for $p<0.001$. The direction of the correlation is shown by + for positive correlated and + for negative correlated factors.

\begin{tabular}{llllll} 
factor 1 & factor 2 & formula & $\mathrm{r}^{2}$ & $\mathrm{p}$ \\
\hline number of LSU clusters & annual yield & $\mathrm{y}=-31.3617+53.5482^{*} \mathrm{x}$ & 0.425 & $0.003+{ }^{* *}$ \\
number of LSU clusters & cacao pod borer & $\mathrm{y}=-0.189-0.2602^{*} \mathrm{x}$ & 0.491 & $>0.001+{ }^{* * *}$ \\
Fusarium abundance & annual yield & $\mathrm{y}=24.4181+13.669^{*} \mathrm{x}$ & 0.249 & $0.029+{ }^{*}$ \\
Fusarium abundance & altitude (asl) & $\mathrm{y}=9.5846-0.0082^{*} \mathrm{x}$ & 0.207 & 0.028 & - \\
mean abundance/cluster & min. temperatur & $\mathrm{y}=-5.881+0.3259^{*} \mathrm{x}$ & 0.233 & $0.036+{ }^{*}$ \\
annual yield & min. temperatur & $\mathrm{y}=-753.7016+41.6465^{*} \mathrm{x}$ & 0.210 & $0.033+{ }^{*}$
\end{tabular}

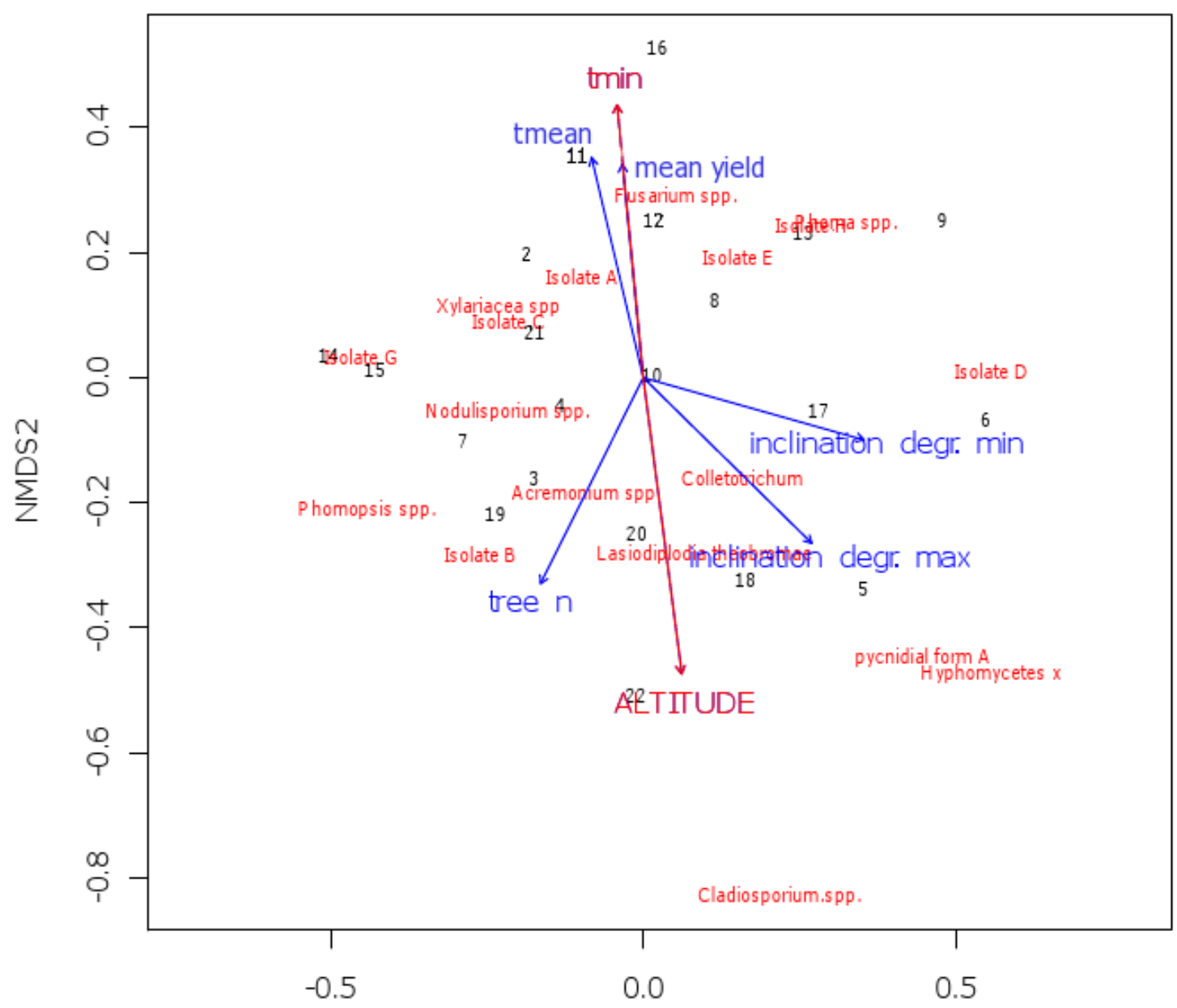

NMDS1

Figure 3 Calculated non-metric multidimensional model of the fungal endophyte diversity in cacao plantations along Kulawi valley, based on morphological data. Altitude $(P=0.005)$ and minimal annual temperature (tmin, $P=0.014$ ) displayed significant impact on the fungal distribution and diversity. The probability error of the impact by mean temperature (tmean), number of shadetrees (tree $n$ ), maximal and minimal degree of plantation inclination inclination degr. min \& max) and the mean annually yield lied between $10 \%$ and $5 \%$. 
Several shade tree species were found to have significant impact on the distribution of Fusarium spp. belonging to each LSU cluster respectively (Tab. 2). Some of the species that demonstrated an influence are planted intercrops like the Indonesian endemic mango (Mangifera mino) and its introduced relative (Mangifera indica), the endemic water apple (Syzygium aqueum) and an introduced coffee cultivar (Coffea robusta). Other forest trees like gliricidia (Gliricidia sepium) and toon (Toona ciliate) displayed also a significant correlation to the Fusarium cluster distribution.

Table 2 Positive tested tree species, which have an influence on the distribution of the different Fusarium groups of the LSU data. P-values smaller than significance level (0.05) were enlisted.

\begin{tabular}{|c|c|c|c|c|}
\hline & cluster & group & group & all \\
\hline tree species & LSU C & LSU D1 & LSU D2 & groups \\
\hline Mangifera indica & ns & 0.021 & 0.033 & 0.039 \\
\hline Mangifera minor & 0.05 & ns & 0.025 & ns \\
\hline Gliricidia sepium & ns & ns & 0.022 & ns \\
\hline Piper anduncum & ns & 0.017 & ns & ns \\
\hline Syzygium aqueum & ns & 0.003 & ns & ns \\
\hline Toona ciliata & ns & 0.013 & ns & ns \\
\hline Coffea robusta & ns & 0.049 & ns & ns \\
\hline
\end{tabular}

\section{Fusarium diversity based on TEF 1-alpha analysis}

In order to relate representative Fusarium isolates of the LSU clusters to known Fusarium species, 17 sequences of apparently suitable species were included in the TEF 1alphacluster analysis. Figure 4 shows the result of a neighbor joining tree based on maximum likelihood similarities of the alignment of the samples. The high bootstrap values allowed a differentiation of six clusters using G. zeae as an outgroup, however the focus of the present study stands in four clusters, namely clusters I, II, III and IV (Fig.4). Three of the isolates $(183,187$ and 98 ) arranged in a subcluster of $95 \%$ with Gibberella fujikuroi within the first cluster (I). Close related to these species are F. proliferatum and a subcluster $(100 \%)$ comprised by $F$. mangiferae and the isolate 243. Furthermore, cluster II shows a close relation between the isolate 66 and $F$. incarnatum, which appears as a subcluster that is moreover related to isolate 272 . The third cluster (III) indicates a high affinity of the isolates 16 and 214 to $F$. lateritium evidenced by a bootstrap of $94 \%$. Finally the fourth cluster (IV) demonstrates a relative close relation of $N$. haematococca to a subcluster constituted by the isolates 221 and 234, which show high affinity (bootstrap of 100\%) to N. rigidiuscula. 


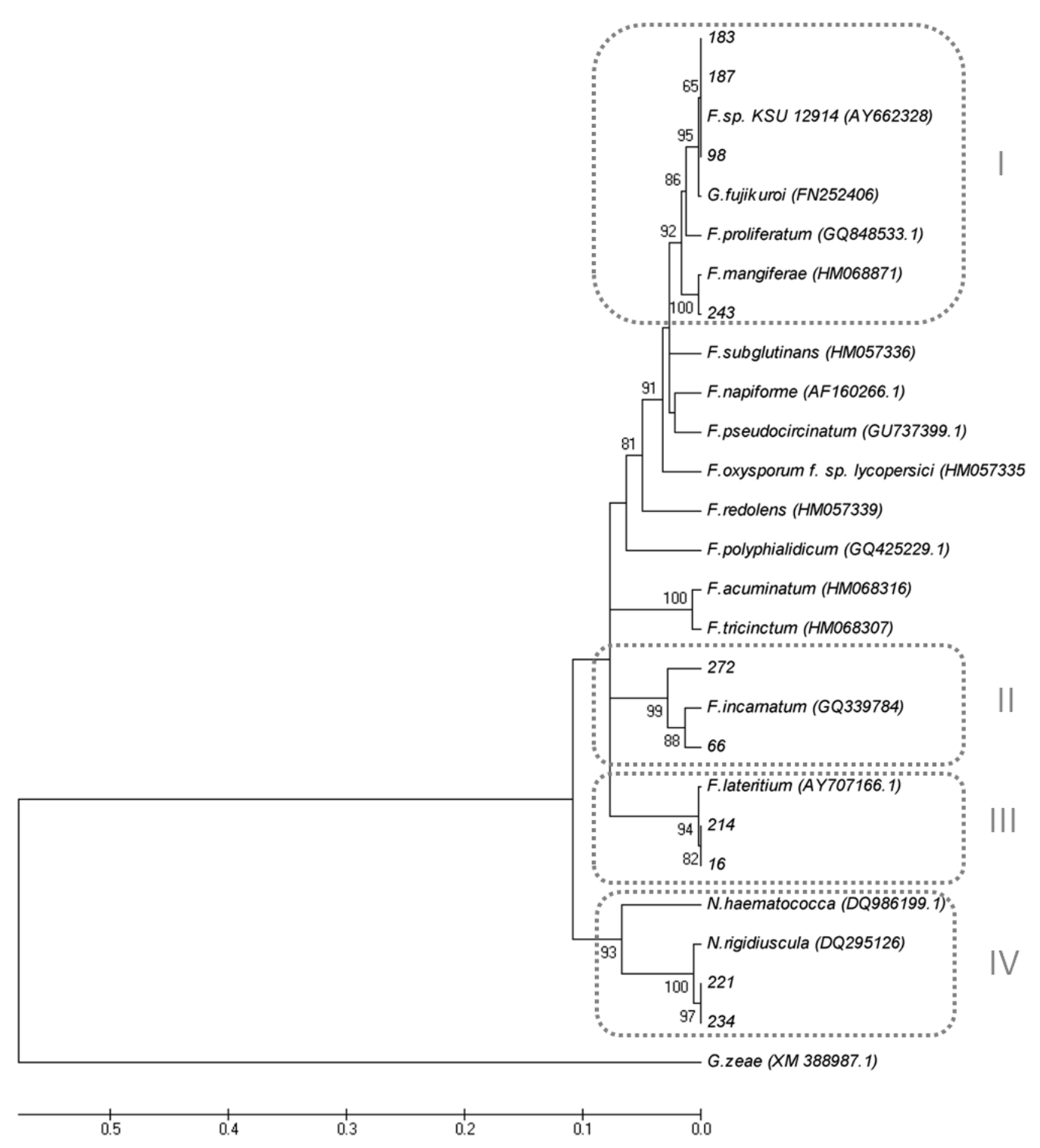

Figure 4 Phylogenetic analysis of 27 Fusarium spp.. The evolutionary history was inferred using the Neighbor-Joining method. The optimal tree with the sum of branch length = 1.91101542 is shown. The percentage of replicate trees in which the associated taxa clustered together in the bootstrap test (1000 replicates) is shown next to the branches. The phylogenetic tree was linearized assuming equal evolutionary rates in all lineages. The evolutionary distances were computed using the Maximum Composite Likelihood method and are in the units of the number of base substitutions per site. All positions containing gaps and missing data were eliminated from the dataset. This phylogenetic analysis was conducted in MEGA4. 


\section{Discussion}

\section{Phylogenetic identification}

The first phylogenetic analysis using the LSU sequences of 172 morphospecies confirmed the affiliation of the isolates to the genus Fusarium. In addition, it was possible to group the isolates in to four main clusters, indicating the presence of different species. Genetic variability in the LSU gene and the insufficient number of published sequences didn't allow sufficient discrimination among our isolates. Further resolution in the identification of the isolates was made possible using TEF-1alpha in the second cluster analysis. This more detailed analysis revealed a non negligible diversity of cacao associated Fusarium species in Sulawesi.

The first TEF-1alpha cluster (I) shows that three Fusarium isolates (98, 183 and 187) probably (bootstrap 65\%) belong to the same species, Gibberella fujikuroi (telomorph $F$. fujikuroi). All three isolates are found in cluster D of the LSU-phylogram, though in different groups. G. fujikuroi is a known phytopathogenic fungus that overloads its host with gibberellins causing bakanae, seedling rot and grain sterility especially on rice, barley, sugarcane, millet, but also some tropical trees. G. fujikuroi is known to be part of the endophytic community in cacao (Rubini et al., 2005). In the same cluster (I), the isolate 243 could be identified as $F$. mangiferae. This species is widely distributed and causes the mango malformation in the tropics (Marasas et al. 2006, Ploetz 2006). The isolate 243 was part of the cluster B in the LSU-phylogram, where it is clearly distinct from three other isolates (bootstrap of $98 \%$ ). In the same or at least close related to $F$. mangiferae cluster was suppose to be also isolate 221, since this Fusarium morphospecies was found in clulster $B$ in the LSU-phylogram as well. Instead, there seems to be a relation between this last isolate and $N$. rigidiuscula and the isolate 234 from cluster D-group 1 (cluster IV, Fig. 4). $N$. rigidiuscula (telomoroph $F$. decemcellulare) is known to be a pathogen of tropical trees (Lombard et al 2007) and was sampled in Indonesia before (Ali et al. 1998), but it never played a crucial role as a cacao pathogen (Ploetz 2007). Furthermore, high similarities in the TEF 1a cluster analysis were found between the isolate 214 , which was not within the main clusters in the LSU-phylogram, and the isolate 16 from cluster D (LSU). Both isolates could be identified as $F$. lateritium considering their position and bootstrap values in the TEF 1 alpha tree. To the best of our knowledge, this is the first report which describes $F$. lateritium in cacao (Theobroma cacao). This observation is nevertheless consistent with a previous report by Booth (1981) stating that strains of $F$. lateritium have a worldwide distribution and a wide host range. Recent changes in the classification $F$. lateritium group nevertheless complicate host range and distribution predictions (Kvas et al. 2009). Finally, it was possible to confine the identification of the isolates 66 and 272 by the analysis of the TEF-1alpha to the species $F$. incarnatum. The fungi of the species $F$. incarnatum (syn. F. pallidoroseum, $F$. 
semitecum) have a widespread host range (e.g. Srenivasa et al. 2006, Belisario et al. 2010). Strains of this species, known for their micotoxin production capacity, have been linked to several plant diseases (Knight et al. 1977, Jiménez et al. 1993, Ploetz 2005, Zaccardelli et al 2006) such as banana crown rot in tropical regions (Knight et al. 2008). Bananas (Musa $x$ paradisiaca) are commonly grown in home gardens and as shade trees within cacao plantation (Kehlenbeck \& Maass 2004). Therefore it seems plausible that both isolates 66 and 272 which are related to $F$. incarnatum infested cacao plants as endophytes. Some strains of the $F$. incarnatum group showed entomopathogenic potential against mosquitoes and could therefore be suitable as bio control agents (Mohanty et al. 2008). The pathogenicity of these cultivars was not tested, but the high diversity of bioactive endophytic Fusarium spp. isolated from cacao plants in this area increases the likelihood of the occurrence of potential bio control agents.

\section{Regional and temporal distribution}

Even though our study was limited in time and space, and thus did not cover Fusarium spp. occurrence exhaustively, it clearly revealed distribution patterns in Fusarium spp.. Fusarium distribution was significantly influenced by geographical and temporal differences (Fig. 2). According to the analysis, Isolates of the LSU D1 group formed a dominant cluster in all sites, except in the Marena plantation where the drought experiment was conducted. The Marena plantation has been managed more intensively in the past compared to the other plantations (Schmidt \& Vidal unpublished). Contrary to the other plantations the cacao plants in Marena have been fertilized annually. An additional nitrogen source could have influenced the competitiveness of single strains or species of Fusarium (Candau et al. 1992) and affect the diversity and abundances of the Fusarium spp.. Because the Fusarium diversity of the Kulawi valley was consistent with the Fusarium diversity sampled in 2007 Marena plantation before the drought was conducted, an influence due to plantations history can be excluded. Indeed there is a considerable difference between both sampling periods in the Marena plantation (Fig. 2), suggesting the geographical pattern might have been masked by temporal pattern. During the drought experiment in the Marena plantation the same shift in dominant species diversity observed in the treatment plots also occurred in the control plots (Schmidt \& Vidal unpublished). A dry spill, that occurred at once before the second sampling period in 2008 was held responsible for the shift in abundances of the dominant species on the one hand. On the other hand the induced drought stress of the host plants decreased the endophyte composition significantly (Schmidt \& Vidal unpublished). The drought might increase the evolutionary pressure on Fusarium spp., rebounding to the advantage of Fusarium spp. in the LSU D2 group, which might have benefited from the lack of precipitation (Suryanarayanan et al. 2002). Beside precipitation, other environmental factors were also affecting the distribution of LSU Fusarium clusters. 


\section{Environmental gradients}

The distribution of fungal endophytes in general (Arnold 2007, Arnold \& Herre 2003) and Fusarium spp. in particular (Blackhause \& Burgess 2002, Summerell et al. 2003, Vujanovic et al. 2006) are influenced by temperature. In this investigation Fusarium spp. were distributed along a local temperature gradient (Fig. 3). The minimal annual temperature correlated positively with the abundance per group, which was caused mainly by the lower abundance of the group LSU D1 in plantations with low temperatures (Tab. 1). Reasons for low abundances in this group might be: 1) some species or strains were sensitive to lower temperatures. 2) Some species or strains were limited in dispersal to host plants, which are only planted in lower altitudes and therefore higher temperatures (Tab. 1). 3) Or most likely, the main group of this cluster had (similar to its relative G. fujikurol) optimal growing conditions from 29 to $32^{\circ} \mathrm{C}$ (Borrow et al. 1964), which would result in a decrease of abundances in temperatures below $25^{\circ} \mathrm{C}$. Further evidence was given from the Marena drought experiment, where Fusarium spp. that where clustering mainly within group LSU D2 were most abundant after a drought spill. Though the air temperature in the shade was remaining constant (Köhler et al. 2009), it is likely that the temperature on the canopy surface might have increased. Further correlations between altitude over sea level and general Fusarium abundance were most likely caused by the link between altitude and temperature. Except cacao plantations with a slope, that may have higher mean temperatures as a result of increased solar exposition (Schmidt et al. unpublished).

\section{Fusarium, its influence on cacao yield and pathogenicity}

The results of this investigation showed that the Fusarium diversity is strong correlated to the cacao yield (Tab. 1), suggesting that some of the isolated Fusarium spp. could increase the yield. As discussed before, G. fujikuroi is known as causer of the Kabake disease in rice, but also as an industrial producer of gibberellins (Phinney 1983). Some gibberellins produced by bacteria have been shown to promote plant growth and increase the yield of many crop plants (Okon \& Labandera-González 1994, Bottini et al. 2004). In our study after the impact of drought, cacao plantations displayed an increased abundance of Fusarium group LSU D2, eventhough a decrease in yield was recorded. Because of the inhibition of gibberellins production in G. fujikuroi by nitrogen (Candau et al. 1992) and high nitrogen availability in the soil of the rainforest margins (Siebert 2002, Schwendenmann et al. 2010) it is very unlikely that gibberellins were produced and accounted for the increase yield. Yield increases by biocontrol activities of Fusarium spp. against insect pest, like expressed by some $F$. oxysporum strains (Barahona 2010), was excluded by the strong positively correlation of Fusarium diversity with the cacao pod borer (Conopomorpha cramerella, Tab. 1). An explanation for this correlation could be an increased Fusarium infestation of the cacao plant resulting from additional plant wounds by the cacao pod borer. Most reported wounds by the 
cacao pod borer are caused by the larvae tunneling cacao shells (Day 1989). The resting sites of the adults were found to be located at the undersides of branches (Day at al. 1994), suggesting occasional feeding on leaves, which could support the infestation of leaves by Fusarium spp.. But the most plausible hypothesis might be that the infestation rates of the cacao pod borer and Fusarium spp. follow the same temperature gradient as the cacao yield. Surprisingly, independently of the Fusarium infestation rates, no symptoms of Fusarium induced diseases had been observed in the cacao plantations during our investigation.

\section{Alternative host trees}

The number of observed fungal species in a habitat depends on the diversity of plant taxa (Hyde 2001, Cannon \& Simmons 2002). In this investigation, the neighbourhood of seven tree species were shown to have an influence on the distribution of endophytic Fusarium spp. in cacao plants (Tab. 2). The occurrence of the intercrops Coffea and Mangiferae in cacao plantations correlated with Fusarium diversity, explaining the isolation of typical associated Fusarium species. Both genera are known to host various Fusarium spp. (Ploetz 2006, Vega et al. 2009) and both genera have been commonly grown in cacao plantations in Sulawesi (Kehlenbeck \& Maass 2004). Additionally the most common planted shade tree $G$. sepium (Clough et al.) correlated positively with the abundance of group LSU D2. All cacao trees of plantations with numerous G.sepium stands showed high abundances of group LSU $\mathrm{D} 2$, except the cacao plantation with the highest G.sepium density, where Fusarium spp. of group LSU D2 were missing. The absence of one group might have been caused by the random selection of isolates for DNA identification, even though it is unlikely as it concerned only one group. Interestingly group LSU D1 correlated in the same plantation negatively with $P$. anduncum, which occurred rarely, except in this plantation where 23 indiviuals occurred. There is no literature evidence that P.anduncum might produce antifungal agents active against Fusarium (specifically of group LSU D2). In the contrary, T.ciliata, which was also negatively correlated with Fusarium group LSU D2, has previously been proven to contain antifungal metabolites (Govindachari et al. 2000, Chowdhury et al. 2003). Trees like T. ciliata with antifungal activities, might indeed reduce the endophyte composition in an area by three mechanisms 1) occupying the stand of an endophyte rich tree, or 2) by direct effects on the fungal diversity of a canopy located below the tree 3 ) or effects on the fungal community of the leaf litter below, as antifungal compounds remain temporary preserved in leaf litter (Chapuis-Lardy et al. 2002). Changes in the fungal leaf litter community due to different in susceptibility to antifungal compounds could change the ejected spore diversity and therefore affect the endophyte composition within cacao leaves (Herre et al. 2007, Suryanarayanan et al. 2009). 


\section{Conclusion}

In the present investigation we have shown how environmental gradients, such as temperature, drought or habitat plant composition, change the Fusarium composition within host plants and influence the distribution of phylogenetically distinct Fusarium groups. We conclude that the variety and the diverse combinations of distinct drivers makes tropical plant communities a hotspot for new endophytic, antagonistic or pathogenic Fusarium species and strains. The results of this investigation contribute to the knowledge about the development of Fusarium diversity and ecology.

\section{Acknowledgements}

We would like to thank Yann Clough for the cacao management data, Ramadhanil Pitopang for shade tree identification and Daniele Cicuzza for herb data. This study was conducted in the framework of the joint Indonesian-German research project "Stability of Rainforest Margins (STORMA)" founded by the DFG (Deutsche Forschungs Gemeinschaft).

\section{References}

Aime MC, Phillips-Mora W (2005) The causal agents of witches' broom and frosty pod rot of cacao (chocolate, Theobroma cacao) form a new lineage of Marasmiaceae, Mycologia 97:1012-1022

Ali N, Sardjono, Yamashita A (1998) Natural co-occurrence of aflatoxins and Fusarium mycotoxins (fumonisins, deoxynivalenole, nivalenol and zearalenone) in corn from Indonesia, Food Additives and Contaminants 15:377-384

Arnold AE, Maynard Z, Gilbert GS, Coley PS , Kursar TA (2000) Are tropical fungal endophytes hyperdiverse? Ecology Letters 3: 267-272

Arnold AE, Maynard Z, Gilbert GS (2001) Fungal endophytes in dicotyledonous neotropical trees: patterns of abundance and diversity, Mycological Research 105: 1502-1507

Arnold AE and Herre EA (2003) Canopy cover and leaf age affect colonization by tropical fungal endophytes: ecological pattern and process in Theobroma cacao (Malvaceae), Mycologia 95: 388-398.

Arnold AE, Luzoni F (2007) Diversity and host range of foliar fungal endophytes: are tropical leaves biodiversity hotspots? Ecology88:541-549

Arnold AE (2007) Understanding the diversity of foliar endophytic fungie: progress, challanges, and frontiers, Fungal Biology Reviews 21: 51-66 
Belisario A, Luongo L, Bitale S, Santori A (2010) First Report of Fusarium semitectum as the Agent of Twig Cankers on Persian (English) Walnut in Italy, Plant Diseases 6:791

Boyette CD and Walker HL (1985) Evaluation of Fusarium lateritium as a Biological Herbicide for Controlling Velvetleaf (Abutilon theophrasti) and Prickly Sida (Sidy spinosa), Weed Science 34:106-109

Menjivar Barahona RD (2010) The systemic activity of mutualistic endophytic fungi in Solanaceae and Cucurbitaceae plants on the behaviour of the phloem-feeding insects Trialeurodes vaporariorum, Aphis gossypii and Myzus persicae, University Bonn Germany

Blackhouse D, Burgess LW (2002) Climatic analysis of the distribution of Fusarium gramminearum, F. pseudogramminearum and $F$. culmorum on cereals in Australia, Australasian Journal of Plant Pathology 31:321-327

Borrow A, Brown S, Jefferys EG; Kessel RHJ, Lloyd EC, Lloyd PB, Rothwell A, Rothwell B, Swait JC (1964) The Effect of varied Temperature on the Kinetics of Metabolism of Gibberella fujikuroi in stirred Culture, Canadian Journal of Microbiology 10:445-466

Bottini R, Cassán F, Piccoli P (2004) Gibberellin production by bacteria and its involvement in plant growth promotion and yield increase, Applied Microbiology and Biotechnology 65:497-503

Candau R, Avalos J, Cerda-Olmedo E (1992) Regulation of Gibberellin Biosynthesis in Gibberella fujikuroi, Plant Physiology 100:1184-1188

Cannon PF, Simmons CM (2002) Diversity and host preference of leaf endophytic fungi in the Iwokrama Forest Reserve, Guyana, Mycologia 94:210-220

Chapuis-Lardy L, Contour-Ansel D, Bernhard-Reversat F (2002) High-performance liquid chromatography of water-souble phenolics in leaf litter of three Eucalyptus hybrids (Congo), Plant Science 163:217-222

Chowdhury R, Hasan CM, Rashid MA (2003) Antimicrobial activity of Toona ciliata and Amoora rohituka, Fitoterapia 74:155-158

Crozier J, Thomas SE, Aime MC, Evans HC, Holmes KA (2006) Molecular characterization of fungal endophytic morphospecies isolated from stems and pods of Theobroma cacao, Plant Pathology 55:783-791 
Dita MA, Waalwijk C, Buddenhagen IW, Souza jr. MT, Kema GHJ (2010) A molecular diagnostic for tropical race 4 of the banana fusarium wilt pathogen, Plant Pathology 59: 348357

Doyle JJ, Doyle JL (1990) Isolation of plant DNA from fresh tissue, Focus 12:13-15 Govindachari TR, Suresh G, Gopalakrishnan G, Masilamani S, Banumathi B (2000) Antifungal activity of some tetranortriterpenoids, Fitoterapia 71:317-320

Evans HC, Holmes KA, Thomas SE (2003) Endophytes and mycoparasites associated with an indigenous forest tree, Theobroma gileri, in Ecuador and preliminary assessment of their potential as biocontrol agents of cocoa diseases, Mycological Progress 2(2): 149-160

Fishbein M, Hibsch-Jetter C, Soltis DE, Hufford L (2001) Phylogeny of Saxifragales (Angiosperms, Eudicots): analysis of a rapid, ancient radiation, Syst. Biol. 50: 817-847.

Fravel D, Olivain C, Alabouvette C (2003) Fusarium oxysporum and its biocontrol, New Phytologist 157:493-502

Freeman S, Zveibil A, Vintal H, Maymon M (2002) Isolation of Nonpathogenic Mutants of Fusarium oxysporum f.sp. melonis for Biological Control of Fusarium Wilts in Cucurbits, Phytopathology 92:164-168

Herre EA, Mejía LC, Damond AK, Rojas E, Maynard Z, Butler A, van Bael SA (2007) Ecological Implications of Anti-Pathogen Effects of tropical fungal Endophytes and Mycorhizae, Ecology, 88(3): 550-558

Hyde KD (2001) Where are the missing fungi? Mycol. Res. 105: 1409-1412

Jiménez M, Lgrieco A, Bottalico A (1993) Occurence and Pathogenicity of Fusarium Species in Banana Fruits, Phytopathology 137:214-220

Kehlenbeck K, Maass BL (2004) Crop diversity and classification of homegardens in Central Sulawesi, Indonesia, Agroforestry Systems 63:53-62

Knight C, Cutts DF, Colhourn J (1977) The Role of Fusarium semitectum in causing Crown Rot of Bananas, Phytopathology 89:170-176

Köhler M, Dierick D, Schwendenmann L, Hölscher D (2009) Water use characteristics of cacao and Gliricidia trees in an agroforest in Central Sulawesi, Indonesia, Ecohydrology, 2:520-529 
Kvas M, Marasas WFO, Wingfield BD, Wingfield BD, Steenkamp ET (2009) Diversity and evolution of Fusarium species in the Gibberella fujikuroi complex, Fungal Diversity 34:1-21

Larkin RP, Fravel DR (2002) Effects of Varying Environmental Conditions on Biological Control of Fusarium Wilt of Tomato by Nonpathogenic Fusarium spp., Phytopathology 92:1160-1166

Leslie JF, Summerell BA (2006) Fusarium laboratory manual (Blackwell Publishing: Ames, IA Logrieco A, Mule G, Moretti A, Bottalico A (2002) Toxigenic Fusarium species and mycotoxins associated with maize ear rot in Europe, European Journal of Plant Pathology 108:597-609

Maier W, Begerow D, Weiß M, Oberwinkler F (2003) Phylogeny of the rust fungi: an approach using nuclear large subunit ribosomal DNA sequences, Canadian Journal of Botany 81:12-23

Marasas WFO, Ploetz RC, Wingfield MJ, Wingfield BD, Steenkamp ET (2006) Mango Malformation Disease and the Associated Fusarium Species, Phytopathology 96:667-672

Menjivar Barahona RD (2010) The systemic activity of mutualistic endophytic fungi in Solanaceae and Cucurbitaceae plants on the behaviour of the phloem-feeding insects Trialeurodes vaporariorum, Aphis gossypii and Myzus persicae, [Dissertation] University Bonn, Germany

Moncalvo J-M, Hseu R-S (1995) Phylogenetic relationships in Ganoderma inferred from the internal transcribed spacers and 25S ribosomal DNA sequences, Mycologia 87:223-238

Nitschke E, Niohlgard M, Varrelmann M (2009)Differentiation of Eleven Fusarium spp. Isolated from Sugar Beet, Using Restriction Fragment Analysis of a Polymerase Chan Reaction-Amplified Translation Elongation Factor 1 a Gene Fragment, Phytopathology 99:921-929

O'Donnel K, Kistler HC, Cigelnik E, Ploetz RC (1998) Multiple evolutionary origins of the fungus causing Panama disease of banana: Concordant evidence from nuclear and mitochondrial gene genealogies, PNAS 95:2044-2049

O’Donnel K, Nirenberg HI, Aoki T, Cigelnik E (2000) A Multigene phylogeny of the Gibberella fujikuroi species complex: Detection of additional phylogenetically distinct species, Mycoscience 41:61-78 
Okon Y, Labandera-González C (1994) Agronomic applications of Azospirillum: an evaluation of 20 years worldwide field inoculation, Soil Biol Biochem 26:1591-1601

Phinney BO (1983) The history of gibberellins. In A Crozier, edt, The Biochemistry and Physiology of Gibberellins, Vol 1. Praeger, New York, pp 19-52

Pinaria AG, Liew ECY, Burgess LW (2010) Fusarium species associated with vanilla stem rot in Indonesia, Australasian Plant Pathology 39:176-183

Ploetz RC (2006)Fusarium-induced diseases of tropical, perennial crops, Phytopathology 96:648-652

Punja ZK, Wan A, Rahman M, Goswami RS, Barasubiye T, Seifert KA, Lévesque CA (2008) Growth, population dynamics, and diversity of Fusarium equiseti in ginseng fields, European Journal of Plant Pathology 121:173-184

Rubini MR, Silva-Ribeiro RT, Pomella AWV, Maki CS, Araújo WL, dos Santos DR, Azevedo J L (2005) Diversity of endophytic fungal community of cacao (Theobroma cacao L.) and biological control of Crinipellis perniciosa, causal agent of Witches' Broom Disease, International Journal of Biological Sciencis 1: 24-33

Saitou N, Nei M (1987) The neighbor-joining method: A new method for reconstructing phylogenetic trees, Molecular Biology and Evolution 4:406-425

Schmidt C, Clough Y, Vidal S (unpublished) The Lost Endophytes: Endophyte Diversity of a Neotropical Tree (Theobroma cacao) in Central Sulawesi, Indonesia; Open Mycology Journal, under review

Schmidt C, Vidal S (unpublished) Endophytes stressed out: Impact of an Enso-drought simulation on fungal endophyte community in cacao plants (Theobroma cacao), Biodiversity Conservation, under review

Schwendenmann L, Veldkamp E, Moser G, Hölscher D, Köhler M, Clough Y, Anas I, Djajakirana G, Erasmi S, Hertel D, Leitner D, Leuschner C, Michalzik B, Propastin P, Tjoa A, Tscharntke T, van Straaten O (2010) Effects of an experimental drought on the functioning of a cocoa agroforestry system, Sulawesi, Indonesia, Global Change Biology 16:1515-1530

Siebert SF (2002) From shade- to sun-grown perennial crops in Sulawesi, Indonesia: implications for biodiversity conservation and soil fertility, Biodiversity and Conservation 11:1889-1902

Summerell BA, Salleh B, Leslie JF (2003) A Utilitarian Approach to Fusarium Identification, Plant Disease 87:117-128 
Suryanarayanan TS, Murali TS and Venkatesan G (2002) Occurrence and distribution of fungal endophytes in tropical forests across a rainfall gradient, Candian Journal of Botany 80: 818-826

Suryanarayanan TS, Thirumalai E, Prakash CP, Rajulu, Govinda MB, Thirunavukkarasu N (2009) Fungi from two forests of southern India: a comperative study of endophytes, phellophytes and leaf litter fungi, Canadian Journal of Microbiology, 55:419-426

Tamura K, Dudley J, Nei M \& Kumar S (2007) MEGA4: Molecular Evolutionary Genetics Analysis (MEGA) software version 4.0, Molecular Biology and Evolution 24:1596-1599

Vega FE, Simpkins A, Aime MC, Posada F, Peterson SW, Rehner SA, Infante F, Castillo A, Arnold AE (2009) Fungal endophyte diversity in coffee plants from Colombia, Hawai'i, Mexico and Puerto RicoFungal ecology, Fungal Ecology 3:122-138

Venables WN, Ripley, BD (2002) Modern Applied Statistics with S. New York: Springer.

Vilgalys R, Hester M (1990) Rapid Genetic Identification and Mapping of Enzymatically Amplified Ribosomal DNA from Several Cryptococcus Species, Journal of Bacteriology $172: 4238-4246$

Vujanovic V, Hamel C, Yergeau E, St-Arnaud M (2006) Biodiversity and Biogeography of Fusarium Species from Northeastern North American Asparagus Fields Based on Microbiological and Molecular Approaches, Microbial Ecology 51:242-255

Yli-Mattila T, Paavanen-Huhtala S, Parikka P, Konstantinova P, Gagkaeva TY (2004) Molecular and morphological diversity of Fusarium species in Finland and north-western Russia, European Journal of Plant Pathology 110:573-585 


\section{General Discussion}

\section{Endophytes: existence in a tight spot}

Fungal endophytes are one part of giant fungal continuum, which contains: soil, leaf litter and water fungi, as well as fungal epiphytes, phellophytes, mycorrhiza or fungi associated with plants, lichnens, and animals (Hawksworth 1991). Endophytes are neither a phyllogenetic group nor consistent in their definition. Fungi or bacteria are termed endophytes based on their lifecycle characteristic. For the definition it is sufficient if the organism occurs in living tissues of plants in some of his developmental stages without causing negative affects (Wilson 1995). Besides there are pathogens that occur endophytic in other host plants and endophytes that are regarded as latent pathogens, with the capability to change their life cycles (Müller \& Kraus 2005, Schulz \& Boyle 2005, Kogel et al. 2006, Arnold \& Engelbrecht 2007, Arnold 2007). Hence, the term endophyte is independent of the phylogenetic relationships among fungi and the kind of detriment free interactions that might occur between fungi and the host plants. Based on several studies that have shown the important role of the ubiquitous fungal endophytes in influencing the diversity, structure and dynamics of plant communities, fungal endophytes can be used as models investigating plant communities and their ecology (Cubit 1974). The close association to their host frees fungal endophytes of nearly all artificial selection pressure. This qualifies them as ideal model subjects for population biology analyses (Petrini 1998). Not least fungal endophytes can be cultivated on common malt extract or potato dextrose media, with the exception of most of the biotrophic endophytes, this makes them easily accessible for scientific investigations. In this study the foliar fungal endophyte community was investigated, because the foliage comprises the biggest surface of the tree and therefore reflects the diversity of fungal spores that have been ejected into the air surrounding the trees. Consequently the diversity obtained guaranties conclusions about the fungal diversity plant community present.

\section{Variations in diversity}

The amount of fungal endophytes species of a tree reported by previous studies differs from low diversities of 50 and less isolated species (e.g. Brown et al 1998, Suryanarayanan et al. 2002, Rubini et al. 2005) up to a high diversity of 200 and more species (e.g. Arnold et al. 2000, Vega et al. 2009b). Thereby, the total number of species depends on the sample size, the tree species, the tree's environment and the endophyte classification method. Comparing rare faction analysis, which normalize sampling size and estimates the total number of species, the number of endophyte species for a tree in temperate zones is limited to about 30 species (Unterseher et al. 2007, Hoffmann \& Arnold 2008). Interestingly, the estimated 
fungal endophyte diversity of algae is also below 30 species with the exception of brown algae which are expected to host more than 50 species. Host trees of tropical areas were proven to host more than several hundred of fungal endophytes (e.g. Arnold et al. 2000, Arnold et al. 2001, Vega et al. 2009b). According to the species estimation of Arnold et al. (2009) this high fungal endophyte diversity of tropical trees is comparable to the high fungal endophyte diversity of tropical lichens, suggesting that fungal endophyte diversity follows climatic conditions (Suryanarayanan et al. 2002, Hoffman \& Arnold 2007). Thus the same plant species in comparable climatic zones with a comparably diverse plant community should host a comparable amount of fungal endophytes. The results of the present study showed a decreased in diversity of endophytic fungi inhabiting cacao plants in Indonesia compared to Latin America. On one hand this suggests the high diversity of fungal endophytes Arnold et al. (2001) isolated from cacao that cacao plants are highly susceptible to fungal endophytes. On the other hand several studies showed some evidence for host preferences of endophytes to other host plants (Arnold et al 2000). This argument could explain the reduced diversity in Indonesia by the insusceptibility of cacao for the Indonesian fungal community, combined with the loss of cacao adapted fungal endophytes during the introduction of cacao in Indonesia 25 years ago. Conversely found Cannon \& Simmons (2002) no clear evidence for host preferences in Guyana, which leads to the suggestion that the fungal endophyte diversity in Indonsia might be decreased altogether. The molecular identification of the second most abundant taxa (Fusarium spp.) in the fungal endophyte community sampled in Indonesia revealed that the real diversity of species and strains might be much higher. Since the fungal taxa as well as the molecular differenced groups follows several environmental gradients, this provides various opportunities for speciation by isolation and evolutionary pressure (Wuenscher 1969, Dynesius \& Jansson 2000).

\section{Environmental drivers of diversity and host preferences}

The endophyte communities within the same host plant species are not the same, if they are located in different sites (Arnold 2000). For example, Arnold (2003) showed a continuously decreasing similarity of fungal endophyte communities in cacao plants with increasing distance between the locations of the communities compared. Other studies found differences in plant associated fungi of different areas respective to climatic differences (Blackhause \& Burgess 2002). Suryanarayanan et al. (2002) compared endophytes of a tropical dry thorn, a dry deciduous, a moist deciduous and a semi-evergreen forest resulting in a fungal diversity gradient correlating with precipitation rates. Contrary to that was the fungal endophyte composition of cacao plants shown in the present study which changed gradually under the impact several opposed gradients (Schmidt et al. unpublished). For example was the similarity of fungal endophyte composition influenced by the minimal 
temperature, which was dependent on the altitude (Schmidt et al. unpublished). This was reflected by the abundance of morphological distinguished Fusarium groups, which was more abundant in lower altitudes and therefore warmer cacao plantations. Additionally the degree of shade, or rather the intensity of exposure of solar radiation of the cacao canopy showed an impact on the fungal diversity (Schmidt et al. unpublished). Besides temperature and intensity of solar radiation, the fungal endophyte community was heavily influenced by the surrounding plant community. Similarities in the plant community of a cacao plantation resulted in very similar cacao inhabiting fungal endophyte compositions. Further correlations between molecular distinguished Fusarium groups and single shade tree species planted in between cacao plants outline the interactions of fungal communities in a habitat (Schmidt et al. unpublished). These correlations between fungal endophytes and tree species, give clear evidence for host preferences within the fungal endophyte community (Arnold et al 2000). Further support comes from drought experiment, where the fungal endophyte diversity was decreased, while the host plant was exposed to an artificial drought (Schmidt \& Vidal unpublished). Because the cacao canopy was exposed during the experiment to the same precipitation and humidity as the control, it was suggested that the fungal endophyte composition reacted to plants drought stress induced secondary metabolites (Bartels \& Sunkar 2005). If plants secondary metabolites can alter the fungal endophyte community (Saunders \& Kohn 2009), host preferences will be established. In this study, the influence of plant community on the fungal endophyte community showed that fungal endophyte assemblages of a host tree species can not be seen as being independent. The interactions between the fungal communities in the foliage and decaying leaf litter (Herre et al. 2007, Suryanarayanan et al. 2009) connects plant communities in dependency of the leaf fall range and spore distribution by wind. This characteristic of fungal endophytes communities qualifies them as ideal models in ecological research and as indicators of stable ecological systems.

\section{Climate Change}

One aspect of the climate change is the increased frequency and duration of El Niño Southern Oscillation (ENSO) events (IPCC 2001), tropical plant communities in Asia are affected by more frequent and more severe ENSO related drought events (Sheffield \& Wood 2008). As fungal distributions have been shown to be influenced by minimal temperature, climate change concerns fungal endophyte communities and therefore also all kinds of host plant endophyte relations. In this study an artificial drought was conducted independent of temperature, which allowed the investigation of fungal endophyte community in regards to the plants drought stress reactions. The decreased fungal endophyte diversity as well as higher similarity of fungal endophyte composition between cacao trees under the impact of 
drought compared to control, suggest a disturbance of interactions between host plant endophytes. While most of the fungal endophytes were affected by the changes within the host plant conditions, one endophyte taxa took benefit from the new situation. Molecular methods confined the characterization of this taxa to a group in close relation to Gibberella fujikuroi, the pathogen causes of kabake disease in rice. The increased of abundance in this group of $G$. fujikuroi could be seen as 1) competitive success of a latent pathogen, producing antifungal metabolites (Müller \& Kraus 2005. Schulz \& Boyle 2005), 2) benefit of a species resistant to secondary metabolites, as F. culmorum protects of reactive oxygen species conferring salt tolerance (Rodriguez et al. 2008), or 3 ) benefit of a species conferring resistance against drought e.g. by increasing the water use efficiency (Rodriguez et al. 2008). Anyhow, the decreased fungal endophyte diversity is alarming, because a reduced fungal community will support pathogens (see Arnold et al. 2003). Future ENSO related drought events might decrease the endophyte diversity of South-East Asia even more rapidly (Thomas et al. 2004). Further investigations of fungal endophyte diversity and pathogen interactions respectively climate change, could help creating fungal pathogen prediction models and agricultural management models. 


\section{References cited in general introduction and discussion}

Adu-Acheampong RK (2009) Pathogen diversity and host resistance in dieback disease of cocoa caused by Fusarium decemcellulare and Lasiodiploidia theobromae [phd study], Imperial collage London, Great Britain

Aime MC, Phillips-Mora W (2005) The causal agents of witches' broom and frosty pod rot of cacao (chocolate. Theobroma cacao) form a new lineage of Marasmiaceae, Mycologia 97:1012-1022

Arnold AE, Maynard Z. Gilbert GS, Coley PS, Kursar TA (2000) Are tropical fungal endophytes hyperdiverse? Ecology Letters 3: 267-272

Arnold AE, Maynard Z. Gilbert GS (2001) Fungal endophytes in dicotyledonous neotropical trees: patterns of abundance and diversity, Mycological Research 105: 1502-1507

Arnold AE, Mejía LC, Kyllo D, Rojas El, Maynard Z, Robbins N, Herre EA (2003) Fungal endophytes limit pathogen in a tropical tree, Proc Nat Acad Sci. 100:15649-15654

Arnold AE, Engelbrecht BMJ (2007) Fungal endophytes nearly double minimum leaf conductance in seedlings of a neotropical tree species, Journal of Tropical Ecology 23:369372

Arnold AE (2007) Understanding the diversity of foliar endophytic fungie: progress, challanges, and frontiers, Fungal Biology Reviews 21:51-66

Arnold AD, Miadlikowska J, Higgins KL, Sarvate SD, Gugger P, Way A, Hofstetter V, Kauff F, Lutzoni F (2009) A Phylogentic Estimation of Trophic Transition Networks for Ascomycetous Fungi: Are Lichens Cradles of Symbiotrophic Fungal Diversification? Systematic Biology 58:283-297

Appiah AA, Opoku IY, Akrofi AY (2004a) Natural occurrence and distribution of stem cankers caused by Phytophtera megakarya and Phytophtera palmivora on cocoa, European Journal of Plant Pathology 110:983-990

Appiah AA, Flood J, Archer SA, Bridge PD (2004b) Molecular analysis of the major Phytophtora species on cocoa, Plant Pathology 53:209-219

Bailey BA, Bae H. Strem MD, Crozier J, Thomas SE, Samuels GJ, Vinyard BT, Holmes KA (2008) Antibiosis, mycoparasitism, and colonization success for endophytic Trichoderma isolates with biological control potential in Theobroma cacao, Biological Control 46:24-35

Bartels D, Sunkar R (2005) Drought and Salt Tolerance in Plants, Critical Reviews in Plant Sciences 24:23-58 
Bisseleua DHB (2007) Ecological. social and economic determinants in cocoa production systems in southern Cameroon, [phd study] University Goettingen, Germany

Blackhouse D, Burgess LW (2002) Climatic analysis of the distribution of Fusarium gramminearum. F. pseudogramminearum and F. culmorum on cereals in Australia, Australasian Journal of Plant Pathology 31:321-327

Brown KB, Hyde KD, Guest DI (1998) Preliminary studies on endophytic fungal communities of Musa acuminate species complex in Hong Kong and Australia, Fungal Diversity 1:27-51

Cannon PF, Simmons CM (2002) Diversity and host preference of leaf endophytic fungi in the Iwokrama Forest Reserve, Guyana, Mycologia 94:210-220

Clay K, Holah J (1999) Fungal Endophyte Symbiosis and Plant Diversity in Successional Fields, Science 285:1742-1744

Clough Y, Faust H, Tscharntke T (2009) Cacao boom and bust: sustainability of agroforests and opportunities for biodiversity conservation, Conservation Letters 2:197-205

Clough Y, Barkmann J, Juhrbrand J, Kessler M, Wagner TC, Ansharv A, Buchori D, Cicuzza D, Daras K, Putra DD, Erasmi S, Pitopang R, Schmidt C, Schulze CH, Seidel D, SteffanDewenter I, Stenchly K, Vidal S, Weist M, Wielgoss AC, Tscharntke T (2011) Combining high biodiversity with high yields in tropical agroforests, PNAS

Crozier J, Thomas SE, Aime MC, Evans HC, Holmes KA (2006) Molecular characterization of fungal endophytic morphospecies isolated from stems an pods of Theobroma cacao, Plant Pathology 55: 783-791

Cubit JD (1974) Interactions of seasonally changing physical factors and grazing affecting high intertidal communities on al rocky shore, PhD thesis, University of Oregon, Eugene

Dynesius M, Jansson R (2000) Evolutionary consequences of changes in species' geographical distributions driven by Milankovitch climate oscillations, PNAS 97:9115-912

El-Zayat SA, Nassar MSM, El-Hissy FT, Abdel-Motaal FF, Ito SI (2008) Mycoflora associated with Hyoscyamus muticus growing under extremely arid desert environment (Aswan region. Egypt), Journal of Basic Microbiology 48:82-92

Gamboa MA, Laureano S, Bayman P (2002) Measuring diversity of endophytic fungi in leaf fragments: does size matter? Mycopathologica 156:41-45

Griffith GW (2004) Witches's brooms and frosty pods: threats to world cacao production, Biologist 51:71-75

Guest D (2007) Black Pod: Diverse Pathogens with a Global Impact on Cocoa Yield, Phytopathology 97:1650-1653 
Guest D, Keane P (2007) Vascular-Streak Dieback: A new encounter disease of cacao in Papua New Guinea and Southeast Asia caused by the obligate basidomycete Oncobasidium theobromae, Phytopathology 97:1654-1657

Hawksworth DL (1990) The fungal dimension of biodiversity: magnitude, significance, and conservation, Mycological Research 95:641-655

Hawksworth DL, Rossman AY (1997) Where are all the undescribed fungi? Phytopathology 87:888-891

Hawksworth DL (2001) The magnitude of fungal diversity: the 1.5 million species estimate revisited, Mycological Research 105:1422-1432

Herre EA, Mejía LC, Damond AK, Rojas E, Maynard Z, Butler A, van Bael SA (2007) Ecological Implications of Anti-Pathogen Effects of tropical fungal Endophytes and Mycorhizae, Ecology. 88(3): 550-558

Hoffman MT, Arnold AE (2008) Geographic locality and host identity shape fungal endophyte communities in cupressaceous trees, Mycological Research 112:331-344

Hyde KD (2001) Where are the missing fungi? Mycological Research 105: 1409-1412

Kogel K-H, Franken P, Hückelhoven R (2006) Endophyte or parasite- what decides? Current Opinion in Plant Biology 9:358-363

Krauss U, Soberanis W (2002) Effect of fertilization an biocontrol application frequency on cocoa pod diseases, Biological Control 24:82-89

Lass T (2004) Balancing cocoa production and consumption. In: Flood J. Murphy R (eds) Cocoa futures-a source book on some important issues facing the cocoa industry, CABIFEDERACAFE, USDA, Chinchina, Colombia, pp 8-15

Lodge DJ, Fisher PJ, Sutton BC (1996) Endophytic fungi of Manilkara bidentata leaves in Puerto Rico, Mycologica 88.733-738

Müller CB, Kraus J (2005) Symbiosis between grasses ans asexual fungal endophytes, Current Opinion in Plant Biology 8:450-456

Ownley BH, Gwinn KD, Vega FE (2010) Endophytic fungal entomopathogens with activity against plant pathogens: ecology and evolution, Biological Control 55:113-128

Petrini O (1986) Taxonomy of endophytic fungi of aerial plant tissues, In: Fokkema NJ. Hueval JV (eds), Micobiology of the phyllosphere, Cambridge University Press, Cambridge, pp. $175-187$

Petrini $O$ (1998) What are endophytes anyway? Proceedings $7^{\text {th }}$ international Congress Plant Pathology vol. 1, pp2.9.1s 
Ploetz RC (2007) Cacao Diseases: Important Threats to Chocolate Production Worldwide, Phytopathology 971634-1639

Porras-Alfaro A, Herrera J, Sinsabaugh RL, Odenbach KJ, Lowrey R, Natvig DO (2008) Novel Root Fungal Consortium Associated with a Dominant Desert Grass, Applied and Environmental Microbiology 74:2805-2813

Posada F, Vega FE (2005) Establishment of the fungal entomopathogen Beauveria bassiana (Ascomycota: Hypocreales) as an endophyte in cocoa seedlings (Theobroma cacao), Mycologia 97:1195-1200

Photita W, Lumyong S, Lumyong P, McKenzie EHC, Hyde KD (2004) Are some endophytes of Musa acuminata latent pathogens? Fungal Diversity 16: 131-140

Rodriguez RJ, White JF, Arnold AE, Rodman RS (2008) Fungal endophytes: diversity and functional roles, New Phytologist 182:314-333

Rubini MR, Silva-Ribeiro RT, Pomella AWV, Maki CS, Araújo WL, dos Santos DR, Azevedo J L (2005) Diversity of endophytic fungal community of cacao (Theobroma cacao L.) and biological control of Crinipellis perniciosa, causal agent of Witches' Broom Disease, International Journal of Biological Sciencis 1: 24-33

Saikkonen K, Faeth SH, Helander M, Sullivan TJ (1998) Fungal Endophytes: A Continuum of Interactions with Host Plants, Annual Review of Ecology and Systematics 29:319-343

Saunders M, Kohn LM (2009) Evidence for alteration of fungal endophyte community assembly by host defense compounds, New Phytologist 182:229-238

Schroth G, Harvey CA (2007) Biodiversity conservation in cocoa production landscapes an overview, Biodiversity and Conservation 16:2237-2244

Schmidt C, Clough Y, Vidal S (unpublished) The Lost Endophytes: Endophyte Diversity of a Neotropical Tree (Theobroma cacao) in Central Sulawesi, Indonesia; Open Mycology Journal, under review

Schmidt C, Vidal S (unpublished) Endophytes stressed out: Impact of an Enso-drought simulation on fungal endophyte community in cacao plants (Theobroma cacao), Biodiversity Conservation, under review

Schmidt C, Valdez Aguirre N, Karlovsky P, Vidal S (in prep.) Distribution and Diversity of Fusarium spp. in cacao plantations of Central Sulawesi, Indonesia

Schroth G, Harvey CA (2007) Biodiversity conservation in cocoa production, Biodiversity Conservation 16:2237-2244 
Schulz B, Römmert A-K, Dammann U, Aust H-J, Strack D (1999) The endophyte-host interaction: a balanced antagonism? Mycological Research 103:1275-1283

Schulz B, Boyle C (2005) The endophytic continuum, Mycol Res. 109:661-686

Sheffield J, and Wood EF (2008) Projected changes in drought occurrence under future global warming from multi-model, multi scenario, IPCC AR4 simulations, Climate Dynamics 31:79-105

Suryanarayanan TS, Murali TS and Venkatesan G (2002) Occurrence and distribution of fungal endophytes in tropical forests across a rainfall gradient, Canadian Journal of Botany 80:818-826

Suryanarayanan TS, Thirumalai E, Prakash CP, Rajulu, Govinda MB, Thirunavukkarasu N (2009) Fungi from two forests of southern India: a comperative study of endophytes, phellophytes and leaf litter fungi, Canadian Journal of Microbiology, Volume 55:419-426

Suryanarayanan TS, Venkatachalam A, Thirunavukkarasu N, Ravihankar JP, Doble M, Geetha V (2010) Internal mycobiota of marine macroalgae from the Tamilnadu coast: distribution, diversity and biotechnological potential, Biotica Marina DOI: 10.1515/BOT.2010.045

Thomas CD, Cameron A, Green RE, Bakkenes M, Beaumont LJ, Collingham YC, Erasmus BFN, Ferreira de Siqueira M, Grainger A, Hannah L, Huges L, Huntley B, van Jaarsveld AS, Midgley GF, Miles L, Ortega-Huerta MA, Peterson AT, Phillips OL, Williams SE (2004) Extinction risc from climate change, Letters to Nature 427:145-148

Tondje PR, Roberts DP, Bon MC, Widmer T, Samuels GJ, Ismaiel A, Begoude AD, Tchana T, Nyemb-Tshomb E, Ndoumbe-Nkeng M, Bateman R, Fontem D, Hebbar KP (2007) Isolation and identification of mycoparasitic isolates of Trichoderma asperellum with potential for suppression of black pod disease of cacao in Cameroon, Biological Control 43: 202-212

Tong-Kwee L, Muhamad R, Fee CG, Lan CC (1989) Studies on Beauveria bassiana isolated from the cocoa mired, Helopeltis theobromae, Crop Protection 8:358-362

Unterseher M, Reiher A, Finstermeier K, Otto P, Morawetz W (2007) Species richness and distribution patterns of leaf-inhabiting endophytic fungi in a temperate forest canopy, Mycological Progress 6:201-212

Vega FE, Posada F, Aime MC, Pava-Ripoll M, Infante F, Rehner SA (2008) Entomopathogenic fungal endophytes, Biological Control 46:72-82

Vega FE, Goettel MS, Blackwell M, Chandler D, Jackson MA, Keller S, Koike M, Maniania NK, Monzón A, Ownley BH, Pell JK, Rangel DEN, Roy HE (2009a) Fungal entomopathogens: new insights on their ecology, Fungal ecology 2:149-159 
Vega FE, Simpkins A, Aime MC, Posada F, Peterson SW, Rehner SA, Infante F, Castillo A, Arnold AE (2009b) Fungal endophyte diversity in coffee plants from Colombia, Hawai'i, Mexico and Puerto Rico, Fungal Ecology 3:122-138

William G (1953) Field Observations on the Cacao Mirids, Sahlbergella singularis Hagl, and Distantiella theobroma (Dist.), in the Gold Coast, Bulletin of Entomological Research 44:101119

Willson D (1995) Endophyte- the evolution of a term, and clarification of its use and definition, Oikos 73:274-276

Wuenscher JE (1969) Niche Specification and Competition Modeling, J. Theoret. Biol 25:436-443

Zabalgogeazcoa I (2008) Review, Fungal endophytes and their interactions with plant pathogens, Spanish Journal of Agricultural Research 6: 138-146 


\section{Publications}

\section{Articles}

Schmidt C, Clough Y, Vidal S (unpublished) The Lost Endophytes: Endophyte Diversity of a Neotropical Tree (Theobroma cacao) in Central Sulawesi, Indonesia; Open Mycology Journal, under review

Schmidt C, Vidal S (unpublished) Endophytes stressed out: Impact of an Enso-drought simulation on fungal endophyte community in cacao plants (Theobroma cacao), Biodiversity Conservation, under review

Schmidt C, Valdez Aguirre N, Karlovsky P, Vidal S (in prep.) Distribution and Diversity of Fusarium spp. in cacao plantations of Central Sulawesi, Indonesia

\section{Poster}

Schmidt C, Clough Y, Vidal S, (2008) Diversity of endophytic fungi in Theobroma cacao leaves in Central Sulawesi, Tropical Rainforest and Agroforests under Global Change, Bali, Indonesia

Schmidt C, Vidal S (2009) Distribution pattern of foliar fungal endophytic fungi in Theobroma cacao in Central Sulawesi, German Society for General and Applied Entomology (DGAAE), Goettingen, Germany 


\section{Acknowledgements}

Firstly, I want to thank my supervisor Prof. Dr. Stefan Vidal for the interesting topic, the given space, general support and suggestions for manuscripts.

I would like to thank Prof. Dr. Teja Tscharntke for the opportunity of working in the international STORMA project, for being the second supervisor of this thesis and the general good collaboration.

I am gratefull with Prof. Dr. Petr Karlovsky for advises, guidance in molecular questions and the provision of his lab unit.

Deeply Thanks to Dr. Yann Clough for discussions, suggestions, the management of the cacao plantations and general good collaboration.

Thanks to Dr. Gerald Moser for the management of the drought experiment.

My special thanks to Dr. Nayuf Valdez Aguirre for the criticism, suggestions and support.

Further thanks to my field assistant Hasrul, my helpers Stephan Buchner and Kirsten ... and my colleagues of the group of Agricultural Entomology of the institute of Plant Pathology, University Goettingen.

I am especially grateful to my parents for their love and support during all times. 


\section{Curriculum vitae}

1997 Abitur (A-level)

1997-1998 German obligatory military service

1998 Study of biology at University Leipzig, Germany

2002-2003 student assistant at University Leipzig

2002 Scientific expedition to the Himalaya, Nepal: "Physiological and psychological stress under extreme conditions"

2004 Diploma in biology

diploma thesis: „Spacial and temporal distribution pattern of xylobiont Coleoptera in canopy of the floodplain forest in Leipzig."

2005 assistent for public relation in Phyllodrom e.V. - museum und institut for rainforest ecology

2006 PhD study in Institute of Plant Pathology, University Goettingen

2006-2008 Fieldwork in Indonesia

20102 month project for Biocare - Society for biological Plant Protection

$2010 \mathrm{PhD}$ thesis defence

PhD thesis: Diversity and distribution patterns of foliar fungal endophytes in Theobroma cacao in Central Sulawesi and interactions between endophytes and host plant 


\section{Eidesstattliche Erklärung}

Hiermit erkläre ich eidesstattlich, dass diese Dissertation selbständig und ohne unerlaubte Hilfe angefertigt wurde

Göttingen, den 30. September 2010 